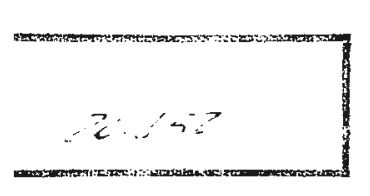

IITUTO DE QUIMICA ERSIDADE DE GÃO PAULO
INSTITUTO DE QUIMICA

Universtzade de Sāo Paulo C.2. 15

\section{Mauro Bertotti}

\title{
SENSORES ELETROQUÍMICOS: ESTUDOS FUNDAMENTAIS E APLICAÇÕES ANALÍTICAS
}

Texto Crítico apresentado ao Departamento de Química

Fundamental (Química Analítica) do Instituto de Química da USP para obtenção do título de Livre-Docência

\section{São Paulo}

2000 
One day an expert in time management was speaking to a group of business students and to drive home a point, used an illustration those students will never forget. As he stood in front of the group of high-powered overachievers he said, "Okay, time for a quiz", and he pulled out a one gallon wide mouth mason jar and set it on the table in front of him. He also produced about a dozen fist-sized rocks and carefully placed them, one at a time, into the jar. When the jar was filled to the top and no more rocks would fit inside, he asked, "Is this jar full?"

Everyone in the class yelled, "Yes." The time management expert replied, "Really?" He reached under the table and pulled out a bucket of gravel. He dumped some of the gravel in and shook the jar causing the pieces of gravel to work themselves down into the spaces between the big rocks. He then asked the class once more if the jar was full. By this time the class was on to him and said "Probably not".

"Good" he replied

He reached under the table and brought out a bucket of sand and started dumping it into the jar. The sand went into all of the spaces left between the rocks and the gravel. Once more he asked if the jar was full.

"NO!" the class shouted.

Once again he said "Good" and grabbed a pitcher of water and began to pour it into the jar until the jar was filled to the brim.

Then he looked around the room and asked,

"What is the point of this illustration?"

One eager beaver raised his hand and said, "The point is that no matter how full your schedule is, if you try really hard you can always fit some more in."

"NO", the speaker replied, "that's not the point. The truth is that this illustration teaches us that if you don't put the 'big rocks' in first, you'll never get them in at all. What are the 'big rocks' in your life? Time with our loved ones, your faith, your education, your dreams, a worthy cause, teaching or mentoring others. Remember to put these BIG ROCKS in first, or you'll never get them in at all. So, tonight, or in the morning, when you are reflecting on this short story, ask yourself this question:

What are the BIG ROCKS in my life?

Then, put those in your jar first." 
À Adriana e à pequena Daniela (que ainda está na barriga da mãe...). 


\section{Agradecimentos}

A meus pais e irmãos, pelo amor, carinho e alegria de convivio.

Ao Prof. Dr. Roberto Tokoro, pela orientação segura durante a pós-graduação e pelo contínuo incentivo e alegre convivência no laboratório.

Aos meus orientandos, sem os quais pouco deste trabalho poderia ser apresentado. Compartilhar com eles dúvidas e incertezas tem sido uma excelente maneira de aprender!!

Aos colegas docentes da Analítica, que num ambiente de colaboração e amizade souberam (e ainda sabem....) fazer a Área prosperar.

Ao Prof. Derek Pletcher, pelo apoio e acolhida durante minha estada em Southampton. Seus ensinamentos e postura cientifica certamente tiveram um impacto positivo no meu desenvolvimento profissional.

À Instituição, pela confiança depositada ao longo destes quase 10 anos e pela concessão de espaço físico, infra-estrutura e liberação para o pós-doutoramento.

Aos funcionários do Instituto e da Biblioteca pela colaboração sempre que necessário.

Ao $\mathrm{CNPq}$, à FAPESP e à Pró-Reitoria de Pós-Graduação pelo apoio financeiro na forma de auxílios financeiros e bolsas de pesquisa. 


\section{ÍNDICE}

1. ALGUMAS CONSIDERAÇÕES SOBRE ESTE TEXTO CRÍTICO

2. ELETRODOS QUIMICAMENTE MODIFICADOS 2

2.1 Introdução

2.2 Aspectos teóricos 3

$\begin{array}{lll}2.3 & \text { Tipos de filmes e métodos de preparação } & 7\end{array}$

$\begin{array}{ll}\text { 2.3.1 Filmes à base de monocamadas } & 7\end{array}$

2.3.2 Filmes à base de multicamadas 9

2.4 Técnicas empregadas na caracterização de eletrodos modificados 12

$\begin{array}{lll}2.5 & \text { Aplicações analíticas } & 14\end{array}$

3. MICROELETRODOS 17

$\begin{array}{lll}3.1 & \text { Introdução } & 17\end{array}$

$\begin{array}{lll}3.2 & \text { Aspectos teóricos } & 19\end{array}$

3.2.1 Difusão radial 19

3.2.2 Uso em experimentos eletroquimicos 22

3.3 Tipos de microeletrodos e métodos de fabricação 25

3.3.1 Microeletrodos de disco $\quad 25$

3.3.2 Microeletrodos de banda (ou linha) 30

$\begin{array}{lll}\text { 3.3.3 Microeletrodos cilindricos } & 31\end{array}$

3.3.4 Conjunto de microeletrodos ("arrays")

3.3.5 Outros tipos de microeletrodos 33

3.4 Aplicações analíticas 34 
$\begin{array}{lll}4.1 & \text { Introdução } & 37\end{array}$

4.2 Estudos sobre o uso de microeletrodos em sistemas hidrodinâmicos $\quad 38$

4.3 Utilização de técnicas eletroquímicas para a caracterização de processos eletródicos

4.3.1 Oxidação do iodeto em microeletrodos de platina

4.3.2 Determinação do coeficiente de difusão do NO

4.3.3 Utilização de microeletrodos na determinação de constantes cinéticas em processos cataliticos envolvendo espécies químicas em solução

4.3.4 Determinação de constantes de velocidades por cronoamperometria de duplo degrau de potencial

4.3.5 Investigações eletroquimicas sobre a formação de Cu(III) em meio complexante com eletrodo rotativo disco-anel

4.4 Estudos eletroquímicos relacionados a eletrodos modificados

4.4.1 Deposição de filmes de óxidos de molibdênio em eletrodos sólidos: estudos estruturais, dinâmicos e cinéticos

4.4.2 Estudos eletroquímicos envolvendo a oxidação do nitrito em eletrodos modificados com porfirinas metálicas

4.5 Desenvolvimento de metodologias analíticas associadas a sistemas de análise em fluxo

4.5.1 Processos envolvendo a oxidação de iodeto a triiodeto $e$ aproveitamento analitico

4.5.2 Uso de eletrodos modificados como sensores amperométricos

4.5.3 Procedimentos relacionados à geração química de espécies eletroativas 


\section{ALGUMAS CONSIDERAÇÕES SOBRE ESTE TEXTO CRÍTICO}

A idéia básica deste texto crítico é introduzir ao leitor, num primeira parte, os princípios teóricos relacionados ao desenvolvimento do conceito de eletrodos quimicamente modificados, os diversos procedimentos empregados para a imobilização de espécies químicas na superfície de eletrodos e as vantagens analíticas que se obtêm nestes casos. Um panorama do estado da arte neste campo também é apresentado tentando-se mostrar que progressos futuros certamente estarão associados a uma colaboração entre pesquisadores de áreas aparentemente distintas.

Num segundo tópico discorre-se sobre os recentes avanços na área relativa à construção de eletrodos de dimensões sub e até mesmo nanométricas. Estes eletrodos, cunhados há algumas décadas pelo termo "microeletrodos", possuem propriedades extremamente atraentes tanto do ponto de vista acadêmico como nas áraes mais aplicadas e neste sentido o texto pretende explicar do ponto de vista teórico os motivos que norteiam estes interesses. Exemplos do uso desta classe especial de eletrodos em pesquisas de caráter fundamental e no desenvolvimento de métodos analíticos são apresentados com o objetivo de demonstrar o largo espectro de aplicações.

Em face à crescente demanda por métodos analíticos que proporcionem informações sobre a composição de determinados materiais ou a concentração de uma substância numa matriz complexa, novos materiais e metodologias têm sido desenvolvidos levando em conta, sempre que possível, contextualizar os dados obtidos no ambiente em que os mesmos estão inseridos. Desta forma, na terceira seção apresentam-se resultados de pesquisas realizadas na área de eletroanalítica empregando-se métodos catalíticos (com espécies imobilizadas em eletrodos ou dissolvidas em solução) e microeletrodos. Pode-se observar que, na maioria dos casos, tenta-se desenvolver o método analítico com base em suporte teórico oriundo de informações coletadas na literatura ou advindas de experimentos de caráter fundamental, os quais foram realizados empregando-se técnicas eletroquímicas clássicas. No que tange aos métodos analíticos, cabe ressaltar o intenso uso da associação envolvendo detecção eletroquímica com análise por injeção em fluxo; os resultados obtidos corroboram esta feliz união e demonstram a potencialidade de extensão das aplicações, quer sejam estas realizadas com espírito mais fundamental (por exemplo, no caso de se desejar aumentar o coeficiente de transporte de massa visando à elucidação de mecanismos eletródicos) ou para o desenvolvimento de métodos analíticos. 


\section{ELETRODOS QUIMICAMENTE MODIFICADOS}

\subsection{Introdução}

Algumas décadas atrás, 3 atributos principais eram requeridos num eletrodo de trabalho utilizado em experimentos eletroquímicos: boa condutividade, estabilidade química perante processos redox em solução e larga faixa de potencial de trabalho. Desde então, essas premissas passaram a se tornar relativas uma vez que para determinados sistemas químicos percebeu-se a validade de se trabalhar com superficies seletivamente reativas, as quais proporcionavam resultados favoráveis em razão da atividade química. Neste contexto, estudos eletroquímicos envolvendo processos de adsorção em eletrodos sólidos ou líquidos (mercúrio) têm sido realizados tendo como motivação aspectos vantajosos tais como aceleração de processos eletródicos, promoção de mudanças morfológicas na superfície as quais facilitam processos de deposição e pré-concentração de analitos.

O uso de reagentes moleculares para manipular a superficie de eletrodos tem vasta aplicação em áreas como síntese eletroquímica, conversão de energia, "displays" eletrocrômicos e sensores. O primeiro exemplo de procedimento no qual objetivou-se a imobilização deliberada de composto específico em superfície sólida (manipulando a interface do eletrodo) remonta ao ano de 1973, quando Hubbard e Lane [1] demonstraram ser possível adsorver de forma irreversível certas oleifinas a um eletrodo de platina. Desde então o termo eletrodo quimicamente modificado vem sendo empregado e este deve ser explicitamente diferenciado por se tratar de alteração proposital da superficie do eletrodo com fins específicos, levando à preparação de um novo eletrodo cujas características químicas, eletroquímicas ou espectroscópicas se assemelham às do composto imobilizado. A modificação intencional da superfície de eletrodos é sustentada ao considerar-se que na voltametria ou na amperometria o potencial aplicado à célula eletroquímica governa o estado de oxidação do substrato na vizinhança do eletrodo de trabalho. $O$ processo de transferência de carga transforma então informações quantitativas em sinais de corrente mensuráveis em função da perturbação causada pelo potencial aplicado, conferindo ao eletrodo de trabalho posição de destaque nos experimentos eletroquímicos. Assim sendo, alternativas que viabilizem a melhoria da resposta eletroquímica de substratos de interesse revestem-se de adicional importância. 
Revisões bastante detalhadas sobre o assunto podem ser encontradas na literatura [2-8], incluindo definições e terminologias [9]. Na presente seção, pretende-se abordar diferentes aspectos referentes ao uso de eletrodos quimicamente modificados no campo da eletroanálise, considerando-se situações em que há passagem de corrente elétrica pela célula eletroquímica. Desta forma, uma definição adequada para o processo de modificação pode estar associada a procedimentos que conduzam a uma melhoria na capacidade de reconhecimento ou geração de sinais de corrente/potencial de materiais eletródicos para aplicações em situações nas quais a atuação estaria restrita.

\subsection{Aspectos teóricos}

Pesquisas relacionadas à modificação da superficie de eletrodos sólidos objetivam estabelecer condições nas quais a velocidade da transferência heterogênea de carga para certas espécies químicas seja aumentada. A idéia envolve a imobilização de mediadores apropriados na superficie do eletrodo de forma que o processo eletroquímico ocorra com menor sobretensão. Neste sentido, a interação química entre a espécie imobilizada e o substrato exerce papel preponderante no mecanismo catalítico.

Um eletrodo modificado é geralmente preparado para funcionar num processo dinâmico no qual camadas imobilizadas reduzem perdas de energia (no caso de conversores de energia), melhoram a seletividade e eventualmente a sensibilidade em sensores analíticos ou ainda atuam como inibidores de processos de corrosão. Há situações bem definidas em que o trabalho com monocamadas é desejável pois pode-se ter um controle mais preciso do grau de funcionalização da superficie [4]. Todavia, na maior parte dos casos trabalha-se com multicamadas as quais viabilizam um efeito catalítico em escala tridimensional devido à difusão do substrato pelo filme [10]. Além disso, existe a possibilidade de incorporação de diferentes grupos funcionais que permitem a ocorrência de eventos químicos controlados no tempo e no espaço. Investigações com filmes mais espessos dão ensejo a uma influência significativa da estrutura da camada imobilizada na dinâmica do processo global de eletrodo e interrelações entre estes dois parâmetros são bastante relevantes ao se lidar com eletrodos modificados.

$\mathrm{Na}$ avaliação da eficiência catalítica de um eletrodo modificado 4 aspectos devem ser levados em consideração [11-14]:

- difusão do substrato na solução 
- propagação da carga elétrica no filme

- penetração do substrato e sua difusão no filme

- velocidade da etapa de transferência eletrônica entre mediador e substrato

A figura abaixo representa esquematicamente um processo eletrocatalítico no qual um substrato S sofre redução mediada por catalisador imobilizado na superficie de um eletrodo.

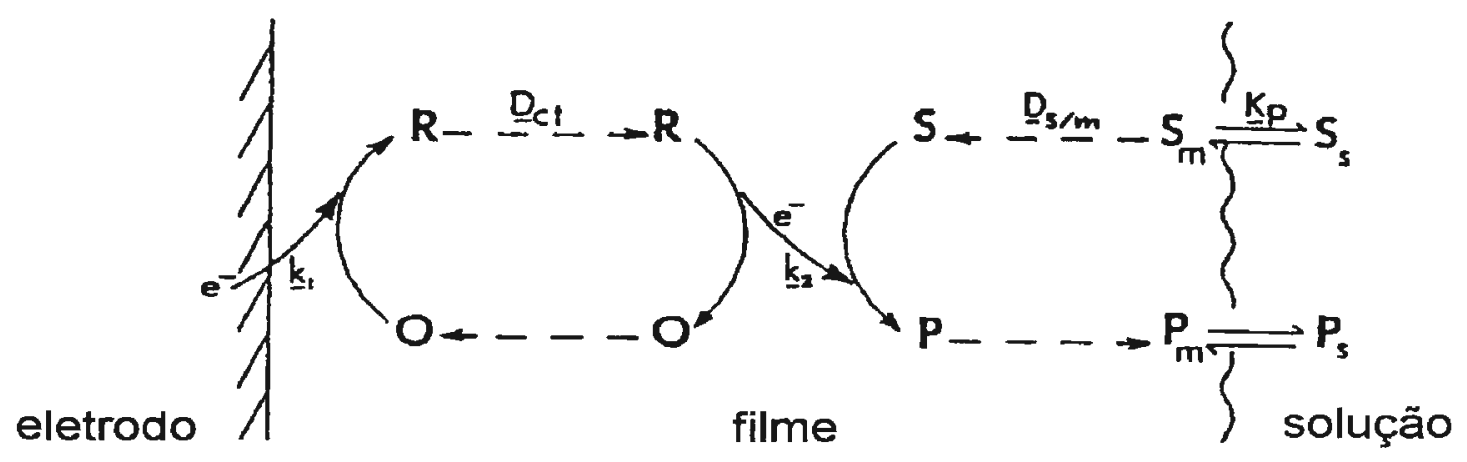

Figura 1. Esquema simplificado das várias etapas envolvendo a redução de um substrato (S) num eletrodo modificado.

Um dos parâmetros mais importantes do processo de mediação envolve a transferência de carga no filme e diferentes mecanismos têm sido estabelecidos na literatura. Um deles diz respeito à transferência de elétrons entre sítios catalíticos próximos, num processo definido como "selfexchange reaction" (ou "electron-hopping mechanism") $[15,16]$. Outra possibilidade envolve o transporte de elétrons via elétrons deslocalizados em estruturas poliméricas altamente conjugadas [17]. Em ambos os casos, a transferência de carga deve estar necessariamente associada a fenômenos paralelos como a difusão de contra-íons para manter a eletroneutralidade no filme e à eventual existência de gradientes de campo elétrico no filme resultantes da resistência à passagem da corrente. A conjunção destes fatores afeta em maior ou menor intensidade o coeficiente de transporte de carga $\left(\mathrm{D}_{\mathrm{\alpha}}\right)$ e por conseqüência a condutividade do filme.

O objetivo primordial da imobilização de uma espécie química numa matriz ancorada na superficie de um eletrodo diz respeito à intermediação da transferência de carga. A reação pode 
ser uma simples transferência eletrônica na qual o substrato recebe (ou doa) elétrons do mediador regenerando a forma inicialmente presente no filme em situação de não polarização. Estes processos são geralmente rápidos e como conseqüência acontecem em potenciais específicos do par redox imobilizado no eletrodo, sendo definidos como processos eletrocatalíticos de esfera externa ("redox catalysis"). Há entretanto casos em que a transferência de elétrons é precedida pela formação de intermediários transientes em reações de esfera interna. Nestes casos o potencial do processo eletrocatalítico pode ser deslocado em relação ao do par redox do mediador e o fenômeno catalítico é classificado como "chemical catalysis".

Outra consideração relevante a ser diagnosticada ao se discutir o mecanismo de funcionamento de um eletrodo modificado diz respeito à quantidade de sítios catalíticos presentes no interior do filme e principalmente à distribuição deste material (homogeneidade do filme). Levando-se em conta o aproveitamento ótimo do efeito eletrocatalítico é evidente que a melhor situação seria aquela em que o substrato pudesse penetrar no filme e interagir com o maior número possível de sítios catalíticos. Este tópico será abordado mais à frente mas fica claro que a localização da zona de reação e a permeabilidade do filme constituem-se em parâmetros de importância na operação do eletrodo modificado. Obviamente, a estabilidade do filme também deve ser avaliada principalmente quando o dispositivo é usado como sensor analítico. Neste sentido, aspectos a serem considerados envolvem a força da interação entre mediador e matriz imobilizadora e desta com a superficie do eletrodo, além da resistência química do filme a efeitos de degradação quando imerso no eletrólito suporte.

Conforme já citado anteriormente e em concordância com o esquema apresentado na Figura 1 , pode-se observar que a corrente global correspondente à transferência de elétrons para o substrato depende da contribuição individual de várias etapas, com valores de corrente definidos independentemente $[12,18-22]$ :

$\mathrm{I}_{\mathrm{s}}=\mathrm{FCA} / \delta=$ corrente devido à difusão do substrato em solução

$\mathrm{I}_{\mathrm{f}}=\mathrm{FC \kappa D}_{\mathrm{s}} / \Phi=$ corrente devido à difusão do substrato no filme

$\mathrm{I}_{\mathrm{e}}=\mathrm{FD}_{\mathrm{ct}} \mathrm{C}_{\mathrm{f}} \mathrm{D} / \Phi=$ corrente devido ao transporte de carga no filme

$\mathrm{I}_{\mathrm{k}}=\mathrm{FCk \textrm {k }} \Gamma=$ corrente devido ao processo catalítico 
A compreensão do mecanismo de funcionamento de um processo eletrocatalítico num eletrodo modificado depende numa primeira instância da avaliação independente dos vários parâmetros acima arrolados. Como resultado final espera-se também obter informações sobre a constante de velocidade da reação catalítica e para tanto uma abordagem geralmente empregada por simplificar os tratamentos matemáticos envolve a obtenção de informações sobre o sistema em condições nas quais os sinais medidos não variem com o tempo (estado estacionário). Neste sentido, dados obtidos em condições de convecção forçada com eletrodos rotativos satisfazem tal exigência a contento [23].

Saveant e colaboradores [12] fizeram extensivas contribuições neste campo avaliando de maneira qualitativa e quantitativa os perfis de concentração esperados para situações limite envolvendo as velocidades de difusão do substrato $(S)$, da transferência de carga $(E)$ e da constante cinética $(\mathrm{R})$. As diferentes combinações produzem subcasos definidos pela localização da zona de reação no filme, os quais podem ser caracterizadas com base nas informações obtidas em experimentos com eletrodos rotativos. Dentre as várias possibilidades, duas são facilmente distinguidas pois referem-se a eventos que ocorrem na região que delimita a interface filme/solução ou àqueles que acontecem diretamente na superficie do eletrodo.

1. O primeiro caso é previsto para sistemas em que tanto a transferência de carga no filme como a reação catalítica são rápidas mas a passagem do substrato pelo filme é lenta. Os sítios acumulados no interior do filme não participam do processo de eletrocatálise e constituem-se em barreira para a transferência de carga. Nestes casos a reação catalítica ocorre num único plano e perdem-se as vantagens da tridimensionalidade análoga à existente em catálise homogênea.

2. Uma situação diametralmente oposta é originada quando a difusão do substrato no filme é relativamente rápida em sistemas com elevados valores para a constante da reação catalítica. Se neste caso a difusão eletrônica no filme não é suficientemente efetiva, o processo de transferência de elétrons para o substrato ocorre virtualmente na superfície do eletrodo e novamente os sítios catalíticos não exercem papel de destaque no mecanismo eletródico global.

Em termos analíticos, onde se deseja maximizar o sinal de corrente e manter uma relação linear com a concentração do substrato, o sistema ideal seria aquele para o qual o mediador fosse 
empregado de maneira uniforme no filme [14]. Esta condição é obtida para sistemas químicos com cinéticas moderadas envolvendo mediador/substrato e difusão rápida de elétrons e do substrato, embora nestes casos deva-se levar em conta a incapacidade do dispositivo em lidar com elevadas taxas de material eletroativo proveniente da solução.

\subsection{Tipos de filmes e métodos de preparação}

O processo de modificação de um eletrodo deve resultar numa superficie estável e que desempenhe o papel requerido de maneira adequada. Há várias possibilidades para a fixação de espécies químicas de interesse na superfície de eletrodos mas todas baseiam-se em procedimentos relacionados à adsorção direta no eletrodo, ligação covalente do modificador a algum grupo funcional existente na superficie, imobilização fisica à base de polímeros ou com alguma matriz condutora à qual o modificador é convenientemente incorporado. Abaixo apresentam-se características e os métodos mais comuns de preparação de filmes levando-se em conta a espessura do material imobilizado:

\subsubsection{Filmes à base de monocamadas.}

Os primeiros procedimentos tiveram como inspiração as preocupações de pesquisadores ligados à área de cromatografia baseadas na necessidade de alterar as propriedades das colunas de sílica, tornando-as mais seletivas ao reconhecimento molecular e permitindo diferentes níveis de interações na interface sólido/solução. Procedimentos de modificação da superficie de eletrodos baseiam-se na formação de ligações covalentes entre os grupos carboxílicos, hidroxílicos e fenólicos do eletrodo com agentes modificadores apropriados. Neste contexto, eletrodos à base de óxidos metálicos $\left(\mathrm{RuO}_{2}, \mathrm{PtO}, \mathrm{TiO}_{2}\right.$ e alguns outros óxidos) e eletrodos de carbono vítreo são largamente empregados devido à presença das ramificações a partir das quais pode-se proceder à preparação do filme imobilizado [4]. Na Figura 2 representam-se algumas possibilidades relativas à introdução de grupos funcionais apropriados na superficie de eletrodos os quais apresentam inicialmente grupamentos $-\mathrm{OH}$ ou $-\mathrm{COOH}$, originados via etapa prévia de oxidação anódica ou outros tratamentos adequados (mecânicos, químicos, radiações, etc). Neste caso, cabe ressaltar outro aspecto vantajoso da modificação da superficie do eletrodo principalmente no que diz respeito a aplicações analíticas, o qual fundamenta-se na formação de uma superficie menos polar com o conseqüente decréscimo da capacitância elétrica da dupla camada [24]. 
Se como desvantagem dos procedimentos de formação de monocamadas emerge o fato de que o processo de eletrocatálise fica restrito a uma dimensão plana, vale lembrar que a preparação de filmes muito finos, com dimensões moleculares, viabiliza uma série de propriedades vantajosas. Após a modificação da superficie, o material imobilizado passa a conferir ao eletrodo propriedades via de regra específicas com relação à interação com substratos de interesse num ambiente onde interações entre os sítios catalíticos são menos efetivas do que no caso de filmes mais espessos. Adicionalmente, as dimensões moleculares destes filmes minimizam o acúmulo de espécies na superfície do eletrodo e permitem uma difusão rápida do substrato, o que não acontece no caso de filmes formados com base em multicamadas. Estudos de cunho fundamental também são viabilizados ao se trabalhar com monocamadas e entre eles podese citar a cinética de transferência eletrônica, processos de adsorção, efeitos de solvatação, formação de pares iônicos e efeitos de interações intermoleculares.

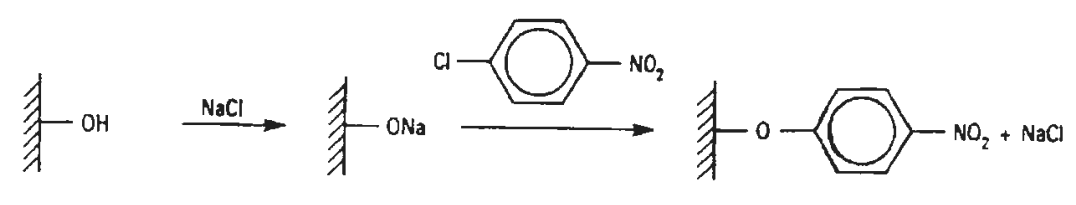

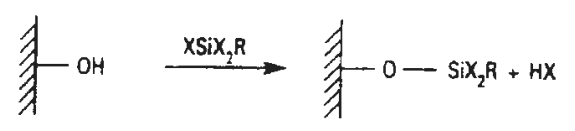
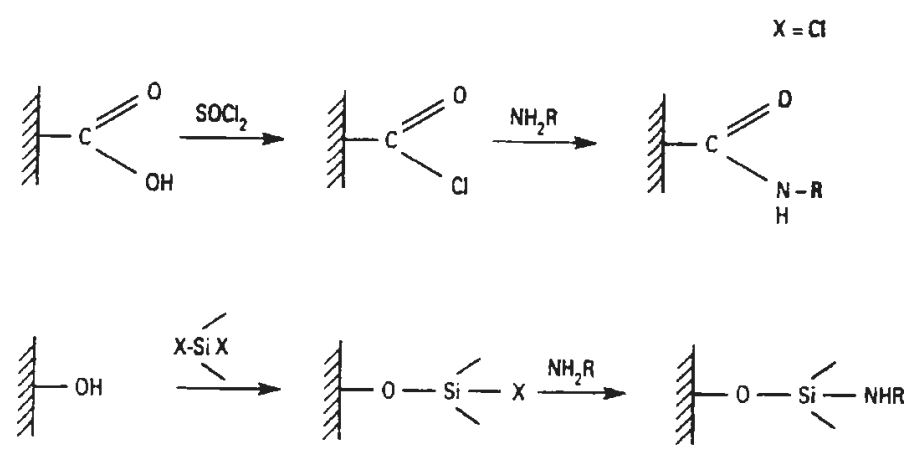

Figura 2. Alguns exemplos de compostos que podem ser imobilizados covalentemente a superficies sólidas, formando-se monocamadas. 
$\mathrm{Na}$ área de eletrodos modificados uma nomenclatura largamente difundida diz respeito ao termo "self-assembled monolayers" (SAM), especificamente usado ao se trabalhar com monocamadas [25]. Além dos trabalhos pioneiros relativos à derivatização da superfície de eletrodos via procedimentos de silanização, cabe destacar duas outras alternativas mais recentes e que são enquadradas no contexto de superfícies contendo monocamadas. Uma delas relaciona-se à formação de camadas de membranas lipídicas em superfícies metálicas, óxidos ou mercúrio e nestes casos a adsorção ocorre por meio de ligações intermoleculares fracas [26,27]. Interações mais efetivas podem ser encontradas na terceira classe de SAMs, na qual alcanos funcionalizados são irreversivelmente adsorvidos no eletrodo e exemplos típicos envolvem a modificação de superficies de ouro com tióis [28].

Em todos os casos onde ocorre formação de monocamadas é importante comentar que aspectos referentes à morfologia do eletrodo, interação superficie-adsorbato e forças intermoleculares definem a estrutura da monocamada, a qual invariavelmente possui "espaços vazios" ("pin-holes") não recobertos pelo agente modificador. Detalhes experimentais relacionados à etapa de imobilização da monocamada (agitação, tempo, aquecimento, etc) certamente influenciam a estrutura do material depositado e em muitas ocasiões é até desejável a existência de imperfeições controladas no filme, as quais podem conduzir à formação de conjuntos de microeletrodos.

\subsubsection{Filmes à base de multicamadas.}

Esta categoria de eletrodos modificados é certamente a mais extensa e tem como principal vantagem a melhoria da atividade catalítica do filme imobilizado em razão do maior número de sítios catalíticos confinados num espaço tridimensional. O material é via de regra mantido na superfície do eletrodo por alguma combinação envolvendo interação adsortiva ou ligação química a grupos funcionais existentes na superficie do eletrodo e filmes com espessuras da ordem de algumas monocamadas a $10^{5}$ monocamadas podem ser obtidos [4].

Não há dúvidas de que o emprego de substâncias químicas poliméricas (polímeros orgânicos ou organo-metálicos) consiste no método mais empregado para a preparação de filmes em eletrodos sólidos e as justificativas são várias: facilidade de preparação do filme utilizando rotas sintéticas pré-estabelecidas, a espessura do filme pode ser controlada adequadamente, a estabilidade do material é muito grande (inibindo perdas por degradação térmica, química ou 
fisica) e a introdução de grupos funcionais eletrocatalíticos à cadeia do polímero pode ser efetuada de maneira relativamente simples.

Há duas alternativas clássicas para a deposição de camadas poliméricas e estas envolvem a imobilização física do material no eletrodo a partir de polímeros pré-formados ou preparação do polímero diretamente na superfície do eletrodo. No primeiro caso, há necessidade do polímero ser solúvel num solvente apropriado com características químicas distintas do solvente no qual o eletrodo modificado vai ser usado (evitando-se assim a posterior dissolução do filme). Basicamente adiciona-se uma determinada quantidade da solução contendo o polímero na superficie do eletrodo e por evaporação ou secagem natural forma-se uma camada contendo o material desejado. A espessura dos filmes assim preparados não pode ser controlada, mas para a formação de filmes morfologicamente mais regulares dispõe-se de procedimentos envolvendo a rotação do eletrodo durante a deposição ("spin-coating").

$\mathrm{O}$ preparo de filmes à base de monômeros constitui-se no procedimento mais comumente empregado para a modificação de eletrodos e entre as várias possibilidades (polimerização química ou pela exposição de vapores de monômeros a certas radiações) destaca-se a eletropolimerização. O processo envolve a oxidação (fenóis, anilinas, pirróis, etc) ou redução (oleifinas) dos monômeros e tanto superficies condutoras ou isolantes podem ser preparadas. Neste último caso a permeabilidade do filme recém-formado deve ser considerada pois em caso contrário a formação de superficie passivadora impede o crescimento de camadas sucessivas do polímero. Estes filmes são aparentemente inúteis do ponto de vista eletroquímico devido à dificuldade no transporte de elétrons, porém vantagens analíticas podem ser vislumbradas controlando-se adequadamente a porosidade do material depositado o qual pode servir como membrana restritiva à passagem de interferentes relativamente volumosos.

Filmes poliméricos podem ser classificados em 3 grandes grupos [4]:

1. Polímeros redox, nos quais a propagação de carga ocorre por meio de sítios localizados no meio das cadeias poliméricas (ou em posições adjacentes) via mecanismo de transferência seqüencial de elétrons ("electron self-exchange" ou "electron hopping") e exemplos são encontrados no caso da o-quinona, porfírinas e ferrocenos. Nestes casos, o centro redox faz parte do esqueleto do polímero.

2. Polímeros condutores, para os quais a condução eletrônica ocorre via mecanismo envolvendo elétrons deslocalizados em cadeias altamente conjugadas. Devido ao elevado grau de 
conjugação, estes polímeros apresentam propriedades metálicas e são portanto melhores condutores do que os polímeros redox. Exemplos clássicos são os polipirróis, polianilinas e polifenóis.

3. Polímeros trocadores de íons apresentam eletroatividade em razão da incorporação de espécies eletroativas que funcionam como contra-íons. Neste grupo o composto mais empregado é o Nafion, ionômero perfluorssulfonado largamente empregado por causa de sua permeabilidade à passagem de cátions e restrição à difusão de espécies negativamente carregadas.

A Figura 3 apresenta alguns polímeros que têm sido usados na modificação de eletrodos de acordo com a classificação acima estabelecida.
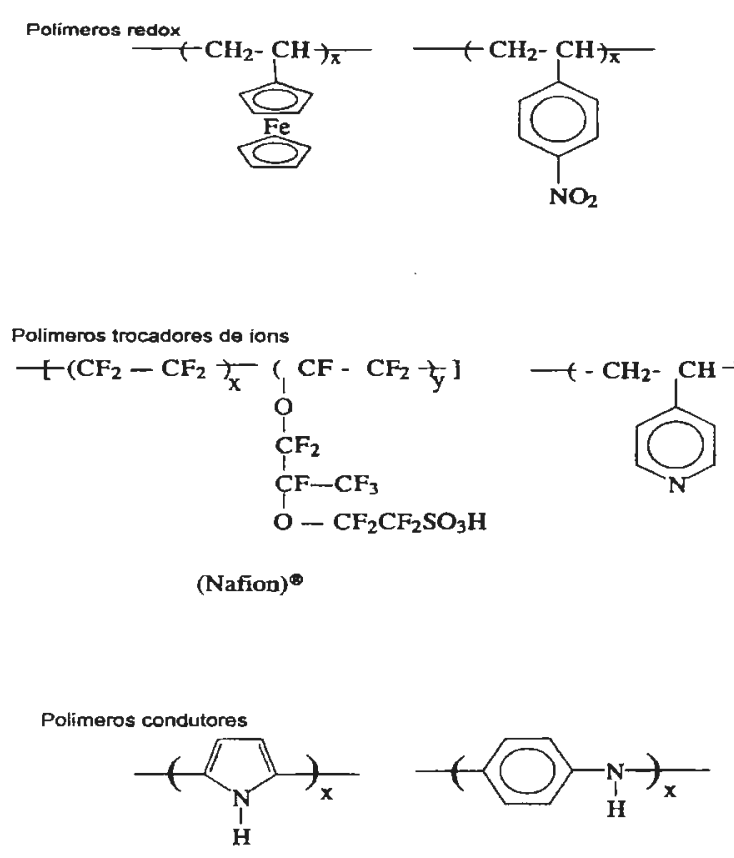

Figura 3. Algumas moléculas representativas dos 3 principais grupos de polímeros empregados na preparação de eletrodos modificados.

Outros compostos modificadores da superfície de eletrodos também são empregados e não se pretende enumerá-los na presente revisão. Cabe entretanto destacar o uso de zeólitas [29] e outros materiais estruturados de modo microcristalino. Estes compostos são trocadores de íons mas diferentemente de polímeros que apresentam esta característica, as zeólitas são mais resistentes 
tanto termicamente como no que tange a reações de oxidação em solução, o que as torna bastante vantajosas em termos de durabilidade do filme modificador. Devido à facilidade de preparação vale também ressaltar o intenso uso de eletrodos preparados com pasta de carbono [30], a qual apresenta boa condutividade e possibilita a fácil incorporação do agente modificador na matriz imobilizada. Vantagens associadas à modificação com pasta de carbono incluem a facilidade de preparação e regeneração da superfície, larga faixa de potencial de trabalho e pequeno risco de deterioração irreversível da superfície. De outro lado, aspectos relativos à difículdade de uso em solventes orgânicos, lenta cinética de transferência eletrônica e necessidade do uso de procedimentos manuais para renovação da superficie (que pode gerar irreprodutibilidade nas medições) são aspectos desfavoráveis do uso da pasta de carbono.

Novos engenhosos procedimentos continuam a ser desenvolvidos neste campo e um dos aspectos abordados relaciona-se à busca de sistemas para os quais se obtenha simultaneamente alta seletividade associada a completa reversibilidade, de forma que estes sensores químicos possam ser usados em medições contínuas [31]. Considerando-se que um dos parâmetros vinculados ao conceito de seletividade diz respeito ao reconhecimento molecular [32] em função de interações químicas específicas e relativamente fortes, prevê-se nestes casos situações menos reversíveis. Devido a este suposto "paradoxo", investigações na área de modificação de superfícies com fins de reconhecimento de substâncias em nível molecular podem ser direcionadas não mais no sentido de criar ambientes em que o substrato seja confinado por afinidade química mas sim devido à adequação de seu tamanho e forma em relação à matriz receptora.

\subsection{Técnicas empregadas na caracterização de eletrodos modificados}

Métodos eletroquímicos são os mais utilizados ao se caracterizar um eletrodo modificado e dois questionamentos são normalmente importantes: a quantidade de material imobilizado no eletrodo e a velocidade do transporte de carga no filme. Esta última questão é particularmente relevante no campo da eletrocatálise, quando várias etapas contribuem para o processo global de transferência de elétrons do/para o substrato.

No caso de monocamadas, a determinação da quantidade de material eletroativo $(\Gamma=$ $\mathrm{Q} / \mathrm{nFA}$, mol cm${ }^{-2}$ ) pode ser avaliada medindo-se a carga envolvida no processo de oxidação ou redução em experimentos voltamétricos [33]. Já no caso de filmes mais espessos, a determinação 
deve ser feita com mais critério pois dependendo da velocidade de varredura e da velocidade de transporte dos elétrons no filme (ou dos contra-íons que difundem para equilibrar a carga elétrica), nem todos os centros eletroativos podem ter participado do processo global de eletrodo, levando a resultados errôneos e subestimados. Nestes casos os procedimentos recomendados sugerem a obtenção de voltamogramas em janelas de tempo suficientemente longas (baixas velocidades de varredura) ou realização de experimentos coulométricos [34,35].

Qualquer que seja o mecanismo de transporte de elétrons no interior do filme, a velocidade desta etapa influência de maneira significativa o perfil voltamétrico obtido [36]. No caso de monocamadas ou para filmes em que a condutividade é muito elevada, voltamogramas em que os componentes anódico e catódico apresentam-se de maneira simétrica são obtidos em virtude do rápido equilíbrio termodinâmico entre as formas oxidado e reduzida e a superfície polarizada. Todavia, na maior parte dos casos o processo de transferência de carga não é suficientemente rápido a ponto de permitir o instantâneo ajuste das concentrações superficiais com o potencial aplicado, resultando em perfis de concentração que se estendem ao longo da extensão do filme em direção à interface filme/solução. Observa-se como conseqüência o decaimento da corrente (após o máximo valor) em concordância com as premissas da equação de Cottrell e que os potenciais de pico anódico e catódico passam a ter valores distintos (embora para este fato também pode haver contribuição da queda ôhmica devido à resistência do filme).

A velocidade da etapa de transporte de carga no filme pode ser quantificada com base em dados cronoamperométricos e cronocoulométricos obtidos em escalas de tempo muito curtas, nas quais prevalecem as características da difusão linear semi-infinita. $O$ parâmetro medido $\left(D_{\mathfrak{c}}\right)$ depende do tipo de filme e desta forma pode estar relacionado à difusão das espécies eletroativas presentes no interior do filme ou ao transporte de elétrons pelo mecanismo de "electron-hopping" quando se tratar de polímeros redox $[37,38]$. Cabe relembrar que o parâmetro $D_{a}$ engloba uma série de outros fenômenos que ocorrem no filme simultaneamente ao transporte de elétrons, como difusão dos contra-ions e do solvente.

Métodos espectroscópicos (UV/VIS, infra-vermelho) fornecem informações sobre a estrutura do filme em nível molecular [39]. Quando o eletrodo é relativamente transparente (como no caso dos eletrodos à base de óxidos de índio e estanho, ITOs), interações químicas dependentes do potencial aplicado ao eletrodo podem ser investigadas com o composto imobilizado registrando-se espectros UV/VIS. Informações sobre a identidade dos grupos 
funcionais e das espécies imobilizadas e sua orientação em relação à superficie do eletrodo podem ser obtidas em experimentos com espectroscopia Raman [40] e dados sobre a espessura do filme são fornecidos empregando-se elipsometria.

Técnicas mais sofisticadas permitem a obtenção de informações sobre a composição e a estrutura do material preso ao eletrodo [41]. Estas técnicas podem ser classificadas em 2 grandes grupos e o parâmetro empregado relaciona-se à presença do solvente durante as medições. Assim sendo, investigações in-situ envolvem a obtenção de dados com AFM ("atomic force microscopy"), STM ("scanning tunneling microscopy"), difração de raios-X e EXAFS ("extended $X$-ray absorption fine structure"). Ao empregar-se métodos em que se faz necessário o trabalho em ambientes de ultra-vácuo (XPS ("X-ray photoelectron spectroscopy") e RBS ("Rutherford back-scattering spectroscopy"), informações sobre composição elementar, quantidades proporcionais, o estado de oxidação das espécies químicas e espessura do filme podem ser obtidas. Entretanto, deve-se ressaltar que estes dados não condizem com o ambiente real em que se utiliza o eletrodo modificado e a perda do solvente certamente pode influenciar a dinâmica das interações entre as moléculas que compõem o filme.

Medições da variação de massa do material imobilizado em função do potencial aplicado ao filme podem ser úteis na caracterização da entrada e saída de espécies químicas no filme durante processos de polarização do eletrodo de trabalho [42]. O uso de cristais de quartzo adaptados para estes fins tem se apresentado como ferramenta valorosa a partir da qual a natureza de vários processos eletródicos pode ser deduzida.

\subsection{Aplicações analíticas}

A modificação da superfície de eletrodos com propósitos analíticos apresenta uma série de vantagens e entre elas podem ser destacadas: a) estabilidade química e mecânica do filme, características básicas para garantir a durabilidade do sensor e reprodutibilidade das medições, b) emprego de matrizes que permitam a imobilização de uma ou mais espécies catalíticas, c) larga faixa dinâmica de trabalho, com resposta linear em função da concentração do substrato/analito, d) correntes relativamente baixas e estáveis na ausência do substrato em faixa larga de potencial, e) compatibilidade com meios orgânicos e aquosos, f) facilidade de preparação de maneira reprodutível, g) sensibilidade (devido à melhoria na eficiência na etapa de transferência de elétrons) e seletividade de resposta no que se refere ao substrato investigado, h) viabilidade de 
acoplamento a técnicas complementares (espectroscópicas ou de separação), i) uso em sistemas biológicos para medições "on-line".

Consideradas as vantagens acima arroladas, o uso de eletrodos modificados em Química Analítica tem sido largamente difundido objetivando-se 3 distintos propósitos. Um deles fundamenta-se na melhoria do sinal de corrente devido ao efeito eletrocatalítico envolvendo o substrato (muitas vezes eletroinativo) e os sítios imobilizados no filme. Em alguns casos ganha-se inclusive em seletividade pois dependendo da natureza da interação entre substrato/mediador pode-se antecipar o processo redox referente ao substrato de interesse, minimizando os efeitos de eventuais espécies interferentes. Nesta área de pesquisa, em que o eletrodo modificado funciona essencialmente como um sensor amperométrico, diversas possibilidades têm sido apresentadas e entre elas pode-se citar o uso como detector amperométrico em sistemas cromatográficos [43] ou em FIA [44], na confecção de eletrodos descartáveis empregados comercialmente [45] e no monitoramento de espécies químicas de maneira contínua e em tempo real, como por exemplo na medição dos níveis de glicose no sangue [46].

Outra grande área de estudos envolvendo eletrodos modificados está vinculada à préconcentração de espécies químicas para posterior medição do sinal devido ao material acumulado. Nestes casos a possibilidade de se realizar medições para analitos em concentrações muito baixas constitui-se no foco das atenções, embora dependendo do sistema químico haja a possibilidade de se conferir seletividade ao método analítico desde que seja feita uma escolha apropriada do grupo funcional ou substância imobilizada no eletrodo. É o caso da análise de íons oxalato com eletrodos de pasta de carbono aos quais se imobiliza $\mathrm{Pb}$ (II) [47].

Em consonância com investigações relativas à pré-concentração de analitos na superficie do eletrodo, encaixa-se o terceiro foco de estudos envolvendo eletrodos modificados. Trata-se de pesquisas nas quais busca-se melhorar a seletividade das determinações com base em procedimentos que permitam o acúmulo seletivo do substrato (via complexação ou com trocadores de ions) ou viabilizem a exclusão de espécies interferentes presentes em matrizes complexas. Neste último caso, além da seletividade há vantagens associadas à minimização de problemas de envenenamento da superficie do eletrodo. Membranas apropriadas podem restringir o acesso de espécies químicas com base no (a) tamanho ou (b) na carga elétrica:

a) Acetato de celulose [48] é o caso típico de membrana empregada quando se pretende excluir substâncias químicas devido a suas dimensões uma vez que a porosidade do filme pode ser 
controlada adequadamente alterando-se o $\mathrm{pH}$ da solução e o tempo de hidrólise. Desta forma, somente espécies relativamente pequenas têm acesso à superficie do eletrodo (ou aos sítios catalíticos).

b) $\mathrm{O}$ controle da passagem de espécies carregadas pode ser feito imobilizando-se na superfície do eletrodo polímeros que possuem sítios aniônicos ou catiônicos dispostos de maneira estruturada no filme. O polímero mais usado nestes casos é o Nafion [49], que devido aos grupos sulfonatos restringe severamente a passagem de ânions mas é permeável a cátions e espécies eletricamente neutras.

Cabe lembrar que o grau de seletividade em qualquer dos 2 procedimentos depende da espessura do filme. Filmes mais espessos são mais eficientes em termos de seletividade, todavia deve-se ter em conta que a difusão do analito também torna-se restringida em maior ou menor extensão, ocasionando diminuição do sinal analítico. Portanto, a escolha da espessura ótima é função de um compromisso entre seletividade e sensibilidade e invariavelmente depende de uma análise do sistema químico.

O futuro de pesquisas sobre eletrodos modificados certamente vai envolver o conceito de interdisciplinaridade. A preparação de novos polímeros e matrizes hospedeiras aos quais se alojam catalisadores eficientes consiste em área onde químicos de diferentes especialidades podem atuar e neste sentido são relevantes não só pesquisas aplicadas mas também aquelas de cunho fundamental. A imobilização do material em eletrodos de dimensões nano ou micrométricas (ủtil para pesquisas em ambientes celulares) necessita de contínuos estudos na área de novos materiais e nanotecnologia. Investigações e novos desenvolvimentos relacionados ao uso do sensor eletroquímico no monitoramento de metabólitos de reações enzimáticas ou substâncias de interesse bioquímico podem ser de valia tanto para profissionais ligados à área de Química como também para aqueles ligados às áreas biológicas. Neste contexto, vale a pena ressaltar os excepcionais avanços na área de biossensores, onde enzimas são imobilizadas na superficie do eletrodo e respondem satisfatoriamente a substratos de contexto biológico [50,51]. Num futuro não muito distante é bem possível que a linha de pesquisa envolvendo eletrodos modificados tenha suplantado as fronteiras da academia e passe a ser de interesse tecnológico e comercial. 


\section{MICROELETRODOS}

\subsection{Introdução}

Estudos envolvendo o uso de microeletrodos em experimentos eletroquímicos remontam à década de 40 quando a necessidade de monitorar a concentração de oxigênio em organismos vivos originou a idéia da introdução de eletrodos de platina de dimensões reduzidas em tecidos e músculos [52]. Polarizando-se os eletrodos em potenciais suficientemente negativos, sinais proporcionais à concentração de oxigênio foram obtidos com a vantagem de que as pequenas correntes oriundas do processo faradaico não causavam danos às células.

O termo "microeletrodos" está associado à obtenção de situações de estado estacionário. Cabe relembrar que o termo "steady state voltammetry" foi introduzido algumas décadas atrás por Laitinen e Kolthoff [53], que trabalhando com discos de platina de dimensões convencionais (raio milimétrico) mediram a corrente em função do potencial aplicado somente quando esta atingia um valor constante. Os dados obtidos "ponto a ponto" permitiram a construção de curvas sigmoidais, como resultado da minimização dos efeitos da difusão planar. Todavia, nestes casos as irreprodutibilidades nas medições de corrente em função dos efeitos da convecção são inevitáveis.

Uma vez que o conceito de estado estacionário está intimamente ligado às propriedades dos microeletrodos, uma pequena discussão sobre este conceito se faz necessária [54]. Em eletroquímica, estado estacionário refere-se a uma condição experimental em que uma das variáveis em questão (corrente ou potencial) assume valores independentes do tempo. Assim, em experimentos cronoamperométricos (onde o potencial é constante) ou voltamétricos (em que varia-se o potencial em função do tempo) a corrente é constante em diferentes tempos ao longo do experimento ou qualquer que seja a velocidade de varredura e seu sentido (dentro de certos limites). No caso de experimentos cronopotenciométricos, situações de estado estacionário são verificadas pela independência do potencial em determinados valores de corrente aplicada à célula eletroquímica.

Há várias maneiras de se obter condições de estado estacionário como por exemplo garantindo a contínua chegada de material eletroativo à superficie do eletrodo por convecção forçada e controlada (eletrodo rotativo ou com células do tipo "wall-jet") ou pela utilização de um segundo eletrodo de trabalho (localizado nas proximidades do eletrodo principal) cuja função 
é minimizar as perdas oriundas da difusão planar gerando-se continuamente a espécie eletroativa. Outra possibilidade envolve o uso de eletrodos com geometria suficientemente apropriada para garantir um fluxo convergente do material eletroativo de forma a manter um contínuo fluxo em direção ao eletrodo de trabalho. Para tanto, eletrodos que possuem escala micrométrica em pelo menos uma de suas dimensões são bastante eficientes pois o tempo necessário para o atingimento do estado estacionário (como conseqüência da difusão convergente) é tanto menor quanto menor for esta dimensão. Desta forma, o trabalho com microeletrodos reveste-se de importância na medida em que minimizam-se os efeitos da convecção natural, sempre presente alguns segundos após o início dos experimentos.

Conforme já citadc anteriormente, estudos eletroquímicos onde se empregam eletrodos de dimensões micrométricas são relatados na literatura há várias décadas. Todavia, o contínuo desenvolvimento da eletrônica e da indústria de precisão tem possibilitado a construção de eletrodos com área eletroquimicamente ativa cada vez menor, impulsionando pesquisas envolvendo tais microelectrodos (ou ultramicroeletrodos) na área de estudos eletroquímicos fundamentais ou na aplicação dos mesmos com finalidades analíticas. Neste sentido, cabe também destacar os desenvolvimentos na área de instrumentação os quais permitiram a construção de equipamentos com tecnologia suficientemente precisa para o monitoramento de correntes baixíssimas, muitas vezes na ordem de picoamperes ou até mesmo femtoamperes. Em estudos envolvendo a determinação de traços de substâncias químicas com eletrodos de dimensões micrométricas, correntes desta ordem de grandeza são teoricamente esperadas e atualmente, mensuráveis. As peculiares propriedades desta classe de eletrodos alargou de maneira significativa as fronteiras da eletroquímica e eletroanalítica uma vez que estudos cuja realização era impossivel com eletrodos de tamanho convencional passaram a ser executados sem dificuldade empregando-se os microeletrodos de dimensões microscópicas [55-58].

Portanto, em face às diversas vantagens relativas ao uso destes microeletrodos, não é surpreendente a explosão do número de trabalhos envolvendo o uso de microeletrodos a partir da década de 80 . O gráfico a seguir mostra a evolução dos trabalhos publicados em algumas revistas de prestígio internacional onde microeletrodos são utilizados quer seja em pesquisas fundamentais ou em estudos mais aplicados. 


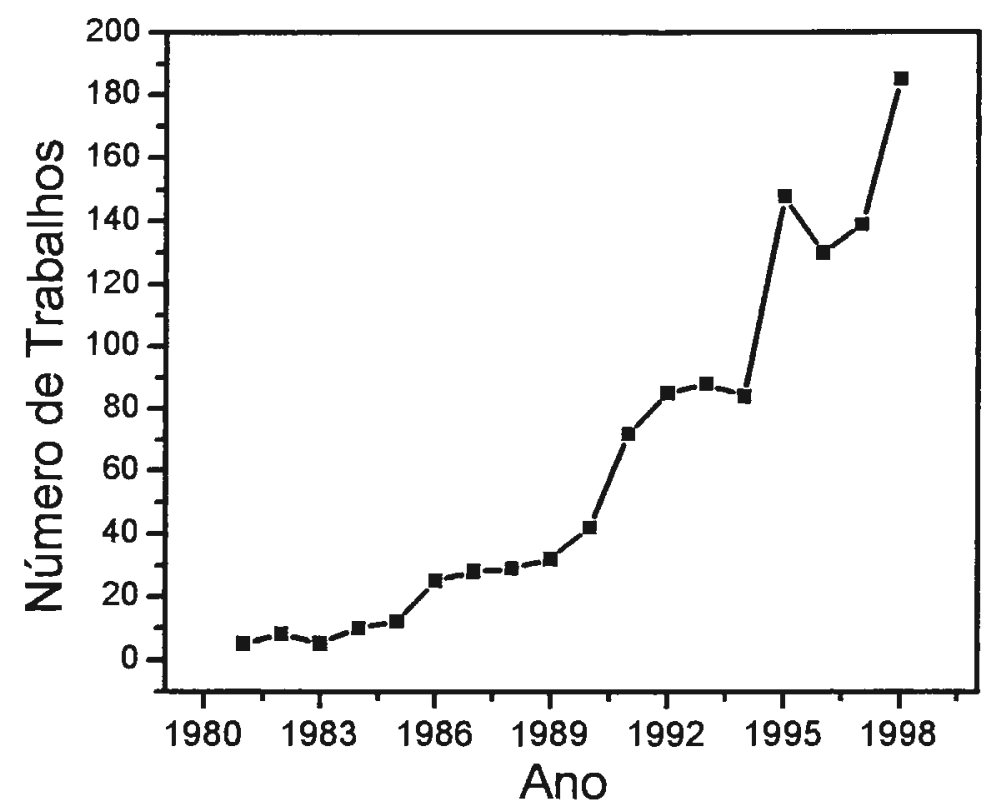

Figura 4. Evolução do número de trabalhos envolvendo o uso de microeletrodos com base em consulta a revistas especializadas.

Nas seções seguintes pretende-se apresentar um panorama dos principais aspectos referentes aos tipos e propriedades dos microeletrodos, alternativas para fabricação e prétratamento, além das aplicações analíticas como sensores eletroquímicos e como detectores em sistemas hidrodinâmicos.

\subsection{Aspectos teóricos}

\subsubsection{Difusão radial}

As vantagens associadas à utilização de microeletrodos devem-se basicamente à maneira como o material eletroativo difunde do seio da solução para a superfície onde ocorre a transferência de elétrons, o mesmo ocorrendo no processo de difusão do material formado no eletrodo. Para eletrodos com dimensões microscópicas, durante processos faradaicos a camada de difusão assume condições de difusão linear semi-infinita por tempo extremamente curto (e proporcional ao raio), valendo neste intervalo de tempo os princípios da equação de Cottrell [23]. Entretanto, como a camada de difusão tem suas dimensões aumentadas com o passar do tempo e atinge proporções semelhantes às do raio do microeletrodo, o processo de difusão linear deixa de 
ser preponderante prevalecendo então o transporte de material por difusão não-linear. Este processo por sua vez cria um campo de difusão convergente compensando o efeito de "diluição" da espécie eletroativa na superfície do eletrodo. Como resultado, a corrente passa a ser independente do tempo, atingindo-se desta forma o chamado estado estacionário [54].

A exemplo do conceito de reversibilidade em eletroquímica (um processo pode ser reversível ou não dependendo da "janela de tempo" considerada), uma definição exata e única para o termo "microeletrodos" (às vezes também denominados de ultramicroeletrodos) não existe pois a obtenção do estado estacionário depende do tempo considerado assim como da dimensão do eletrodo. Como conseqüência, um microdisco de platina de raio $25 \mu \mathrm{m}$ pode ser considerado como microeletrodo quando voltamogramas são registrados com velocidades de varredura relativamente baixas (até $100 \mathrm{mV} / \mathrm{s}$ ) ou em experimentos cronoamperométricos após algumas centenas de milissegundos após a aplicação do pulso de potencial. Nestes casos, voltamogramas, de estado estacionário (ou patamares de corrente, nos cronoamperogramas) são obtidos porque há tempo suficiente para que a difusão convergente predomine em relação à difusão planar. Levando em consideração esta "dualidade de comportamento", pode-se dizer que um microeletrodo é um eletrodo com no mínimo uma dimensão suficientemente pequena para que suas propriedades (por exemplo, o regime de transporte de massa ou o campo de difusão criado ao seu redor) seja função exclusiva de seu tamanho.

Devido à uniformidade de acesso da espécie eletroativa à superfície do eletrodo, microesferas são invariavelmente empregadas nos modelos relacionados à variação da corrente em função de parâmetros experimentais. De acordo com as premissas da segunda lei de Fick e considerando uma situação de contorno em que a concentração (C) da espécie eletroativa (coeficiente de difusão $=\mathrm{D}$ ) seja zero na superfície do eletrodo (processo totalmente controlado pelo transporte de massa), pode-se expressar a corrente (I) que flui numa microesfera (raio r, área A) de acordo com a equação abaixo [58]:

$$
\mathrm{I}_{\mathrm{t}}=\mathrm{nFDCA}\left[1 /(\pi \mathrm{Dt})^{1 / 2}+1 / \mathrm{r}\right]
$$

Observam-se 2 termos distintos na equação acima: o primeiro deles diz respeito ao decaimento da corrente em função do tempo (equação de Cottrell) e vale para situações onde prevalece a difusão planar (tempos curtos). O segundo termo é independente do tempo e 
representa a corrente que flui no circuito em condições nas quais a difusão radial passa a exercer influência determinante sobre a corrente total. Em situações intermediárias a corrente é função dos 2 termos e nenhum deles tem predominância marcante na magnitude da corrente global.

A análise da equação 1 , permite ratificar conclusões anteriores sobre a influência da dimensão do eletrodo na obtenção de situações de estado estacionário. Percebe-se que quanto menor o raio do microeletrodo mais rapidamente vai se atingir uma condição de corrente invariável com o tempo devido à predominância do termo relativo à difusão radial. A obtenção de situações de estado estacionário em tempos extremamente curtos constitui-se em ferramenta valorosa em estudos eletroquímicos e eletroanalíticos. Processos eletródicos em que reações químicas paralelas têm influência no sinal eletroquímico podem ser estudados variando-se o fluxo de material, o qual é função do raio do microeletrodo. $O$ intenso fluxo de material eletroativo em direção à superficie do eletrodo também explica o crescente uso dos microeletrodos em eletroanálise, uma vez que o sinal analítico é essencialmente dependente da difusão das espécies em solução. Além da melhoria no sinal faradaico deve-se destacar a diminuição no sinal capacitivo em função da diminuta área do eletrodo, ocorrendo aumento da razão sinal / ruído e diminuição dos limites de detecção. Ainda no que concerne à difusão nãolinear cabe salientar que, além de situações de estado estacionário serem atingidas muito mais rapidamente, o valor do coeficiente de transporte de massa $\left(k_{m}=D / r\right)$ assume valores altíssimos e inversamente proporcionais ao raio do microeletrodo. Comparando-se o fluxo de material num microeletrodo e num eletrodo de disco rotativo, observa-se pela análise dos dados da Tabela 1 que velocidades de rotação absolutamente inacessíveis deveriam ser utilizadas para atingir-se a mesma situação hidrodinâmica que se obtém ao trabalhar-se com microeletrodo de raio igual a alguns micrometros. 
Tabela 1. Comparação dos valores de coeficiente de transporte de massa $\left(k_{m}\right)$ referentes ao trabalho com microeletrodos de disco de diferentes raios e com eletrodos rotativos em várias velocidades de rotação.

\begin{tabular}{|c|c|c|}
\hline $\mathrm{r} / \mu \mathrm{m}$ & $\mathrm{k}_{\mathrm{m}}$ (estado estacionário) $/ \mathrm{cm} \mathrm{s}^{-1}$ & $60 \omega / 2 \pi / \mathrm{pm}$ \\
\hline 62,5 & 0,0016 & 63 \\
\hline 25,0 & 0,0040 & 396 \\
\hline 12,5 & 0,0080 & 1584 \\
\hline 5,0 & 0,0200 & 9901 \\
\hline 2,5 & 0,0400 & 39604 \\
\hline 1,0 & 0,1000 & 247527 \\
\hline 0,3 & 0,3333 & 2750303 \\
\hline
\end{tabular}

Trabalhando-se em condições experimentais apropriadas, nas quais prevalece o processo de difusão convergente, voltamogramas cíclicos obtidos para um sistema eletroquimicamente reversível devem consistir em curvas sigmoidais com pequena histerese (a resposta deve ser praticamente a mesma qualquer que seja o sentido da varredura de potencial). Sendo o sistema reversível, dados de potencial e corrente devem corresponder às premissas da equação derivada da equação de Nernst:

$$
\mathrm{E}=\mathrm{E}_{1 / 2}+(0.059 / \mathrm{n}) \log \left(\mathrm{I} /\left(\mathrm{I}_{\mathrm{L}}-\mathrm{I}\right)\right)
$$

em que $\mathrm{I}_{\mathrm{L}}$ é a corrente limite, proporcional ao raio do eletrodo. $\mathrm{O}$ registro dos voltamogramas com velocidades de varredura suficientemente altas (situação na qual os efeitos da difusão radial ainda não predominam) conduzem a voltamogramas semelhantes àqueles obtidos com eletrodos de dimensões convencionais, em que a corrente de pico é proporcional à raiz quadrada da velocidade de varredura (no caso de processos governados por difusão).

\subsubsection{Uso em experimentos eletroquimicos}

Uma das decorrências do uso de microeletrodos refere-se à baixa queda ôhmica originada quando se trabalha com eletrodos de pequena área uma vez que tal grandeza é função do produto da 
resistência da solução e da corrente elétrica, esta geralmente da ordem de alguns nA ou pA. Em razão disso, algumas vantagens podem ser esperadas [59]:

1. Pode-se trabalhar com soluções de baixa condutividade e sem adição deliberada de eletrólito suporte $[60,61]$. Neste caso, alarga-se o espectro de aplicações de técnicas eletroquímicas para o estudo em solventes orgânicos não polares, líquidos congelados, sistemas em fase gasosa e para aplicações analíticas in situ, sem manipulação das amostras $[62,63]$. Cabe entretanto notar que se existem aspectos desfavoráveis associados à adição de eletrólito suporte às soluções de trabalho (e entre eles pode-se citar a introdução de impurezas em estudos analíticos ou a necessária consideração das interações entre eletrólito suporte e espécie eletroativa em estudos relativos à determinação de parâmetros físico-químicos), estes são certamente sobrepujados por algumas vantagens tais como o aumento na condutividade das soluções, a maior compactação da dupla camada elétrica, a eliminação do fenômeno de migração elétrica e a minimização da conveç̧ão natural em razão da maior população iônica.

2. Estudos envolvendo a formação de intermediários lábeis podem ser realizados com velocidades de varredura suficientemente altas, as quais não provocam distorções apreciáveis nos voltamogramas $[64,65]$. Para tanto contribui o fato da constante de tempo da célula (produto entre a capacitância da dupla camada elétrica e a resistência da solução) ser proporcional ao raio do microeletrodo, minimizando assim problemas relacionados à corrente capacitiva. Desta maneira, informações faradaicas são menos distorcidas e disponíveis em tempos muito mais curtos.

3. Uma última vantagem associada às baixas correntes obtidas com microeletrodos refere-se à possibilidade de utilização de sistemas mais simples para obtenção das informações eletroquímicas. Para a grande maioria dos casos, a simples configuração contendo eletrodos de trabalho e referência é suficiente, dispensando-se o uso de potenciostatos.

Conforme será apresentado adiante, microeletrodos podem ser construídos com dimensões suficientemente pequenas empregando-se procedimentos relativamente simples. Além de outras propriedades vantajosas, a viabilidade de fabricar tais sensores eletroquímicos em escala reduzida constitui-se em fator motivador para o desenvolvimento da área de pesquisa em que medições químicas em ambientes diminutos (por exemplo, no interior de uma célula) devem ser efetuadas [66,67]. Comentário adicional no que tange às vantagens da utilização de eletrodos com área micrométrica relaciona-se à possibilidade de realizar medições com quantidades muito pequenas de amostra (nano e até picolitros) ou mesmo com amostras em fluxo contínuo, uma vez que, pelo menos teoricamente, 
processos de convecção são irrelevantes quando comparados ao transporte de material por difusão nãolinear em microeletrodos de raio inferior a alguns micrometros.

Estudos eletroquímicos envolvendo processos de eletrodo com cinéticas extremamente rápidas requerem técnicas que viabilizem a obtenção de dados em escalas de tempo adequadas às do evento e neste sentido os fenômenos capacitivos podem interferir nas medições em certos sistemas químicos. Uma vez que a capacitância da dupla camada elétrica é proporcional às dimensões do eletrodo, correntes capacitivas menos expressivas são obtidas ao se trabalhar com eletrodos de área micrométrica, possibilitando estudos voltamétricos com velocidades de varredura da ordem de milhares de volts por segundo [64]. Nestes casos, cinéticas de transferência eletrônica [68-71] e de processos químicos acoplados ao processo eletródico [72-79] podem ser acompanhadas e informações relativamente imunes a efeitos capacitivos podem ser obtidas. Um exemplo de caráter bastante fundamental relaciona-se à determinação do valor de $\mathrm{E}^{\circ}$ para sistemas redox em que uma das espécies não é termodinamicamente estável em solução, ocorrendo o deslocamento do potencial característico em virtude da reação química subseqüente ao processo eletródico [80]. Para janelas de tempo relativamente curtas, os efeitos da reação química são atenuados e a determinação desejada pode ser feita a contento.

O uso de microeletrodos em estudos eletroquímicos permite inclusive o controle da ordem de reação para determinado processo químico com base na variação do fluxo de reagente transportado para a superficie do eletrodo (alterando-se o raio do microeletrodo) e desta forma as dimensões da camada de difusão podem ser adequadamente reguladas [81]. Processos químicos catalíticos com cinética de segunda ordem podem ser tratados como se fossem reações de pseudo-primeira ordem pela diminuição do raio do eletrodo, de forma a diminuir a concentração da espécie eletroquimicamente gerada na camada de reação. Métodos ainda mais eficientes para melhorar o transporte de massa têm sido apresentados na literatura e estes envolvem o uso de microeletrodos em sistemas convectivos especialmente adaptados de forma que a espécie eletroativa atinja a superfície do eletrodo (na forma de disco $[82,83]$ ou anel [84]) em condições de elevado fluxo hidrodinâmico. Esta associação permite

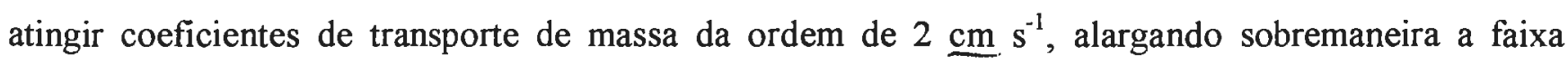
dinâmica de trabalho em estudos cinéticos devido à possibilidade de se medir constantes de velocidades com valores da ordem de $10^{8} \mathrm{~s}^{-1}[85]$.

Cabe ainda ressaltar um emprego bastante interessante de microeletrodos o qual está relacionado a estudos de cinética interfacial por meio da técnica denominada SECM ("scanning 
electrochemical microscopy") [86-88]. Nesta técnica uma ponta de prova (microeletrodo) posicionada diretamente sobre uma superfície coletora é polarizada no sentido de provocar uma reação de transferência de carga a partir de um precursor de interesse. Promove-se então uma competição entre a regeneração do precursor no eletrodo coletor (mantido em potencial apropriado) e a cinética do processo químico acoplado. A medição da corrente no microeletrodo e no eletrodo coletor em função da distância entre microeletrodo/coletor fornece informações sobre a velocidade da reação química.

Dentre os aspectos menos favoráveis vinculados à utilização de microeletrodos destacam-se os problemas referentes às baixas correntes monitoradas em eletrodos de área tão diminuta (principalmente no caso de microdiscos). Basicamente deve-se dispor de sistema apropriado para a medição de correntes na ordem de nA ou pA e em algumas situações a utilização de filtros de ruídos e gaiolas de Faraday torna-se indispensável para obter-se um sinal analítico livre de interferências. Outro aspecto desfavorável oriundo das dimensões microscópicas dos eletrodos relaciona-se à incerteza na geometria e maior dificuldade para polimentos e renovação da superficie ativa.

\subsection{Tipos de microeletrodos e métodos de fabricação}

\subsubsection{Microeletrodos de disco}

Satisfeita a condição relevante de que pelo menos uma dimensão seja micrométrica para garantir um fluxo uniforme de material eletroativo em direção ao eletrodo, várias geometrias têm sido idealizadas e empregadas na construção de microeletrodos [89]. Três delas são particularmente importantes pois graças às características geométricas existem condições para a sustentação de um campo de difusão esférico durante o processo de difusão semi-infinita. Este fenômeno ocorre no caso de superficies cujas dimensões são finitas em relação à espessura da camada de difusão, as quais abrangem microeletrodos de formato esférico ou de disco.

Microesferas (ou hemisferas) apresentam vantagens na elaboração de modelos matemáticos pois todos os pontos da superfície são igualmente acessíveis, o que os torna equivalentes no que tange à velocidade de difusão. Um exemplo relativamente útil destes eletrodos consiste em microeletrodos de disco aos quais deposita-se mercúrio; neste caso, hemisferas razoavelmente bem definidas são geradas. Todavia, a construção destes eletrodos de maneira regular constitui-se em tarefa de dificil execução e apesar de mais simples e rigorosos, os tratamentos matemáticos referentes à difusão em microesferas têm pouca utilidade prática. 
A exemplo das microesferas, microdiscos também apresentam como característica fundamental a capacidade de criar ao seu redor um campo de difusão convergente esférico durante processos eletródicos. Todavia, em face à não uniformidade do fluxo de material eletroativo (ocasionada pela descontinuidade da superficie delimitada pelo material isolante) o tratamento matemático é muito mais complicado e a corrente global é função de "médias setorizadas" obtidas em diferentes regiões do eletrodo. A equação abaixo representa a corrente limite para um processo governado por transporte de massa num microdisco de raio igual a $\mathrm{r}$. Observa-se que, a exemplo da equação 2, para tempos relativamente longos a corrente não é função do tempo, caracterizando uma condição de estado estacionário.

$$
\mathrm{I}=\mathrm{nFDCA} /(\pi \mathrm{Dt})^{1 / 2}+4 \mathrm{nFDCr}
$$

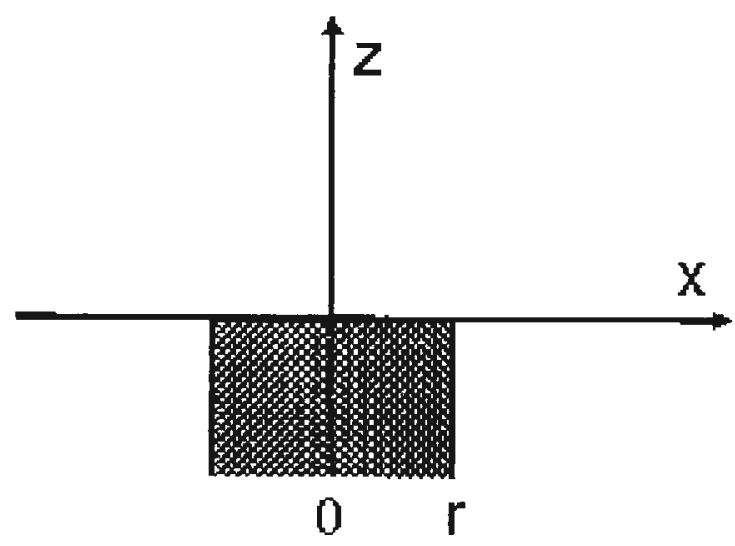

Figura 5. Representação esquemática das variáveis dimensionais num microdisco..

A facilidade da construção de microeletrodos de disco constitui-se em fator preponderante para sua popularização em estudos eletroquímicos. De maneira resumida, microfibras de diferentes materiais (platina, ouro, carbono, etc) são encapsuladas em capilares de vidro ou ponteiras de plástico por aquecimento ou com auxílio de resinas epóxi. O contato elétrico entre a microfibra e o fio de cobre ou liga $\mathrm{Ni} / \mathrm{Cr}$ pode ser feito por intermédio de resina condutora ou com mercúrio. $\mathrm{O}$ corte mecânico perpendicular ao eixo da fibra e posterior etapa de polimento manual finalizam o processo de fabricação do eletrodo. 
Um dos problemas decorrentes de investigações efetuadas com eletrodos de área reduzida diz respeito ao nivel extremamente baixo das correntes faradaicas obtidas. Apesar da sofisticação alcançada na instrumentação eletroquímica e do uso de filtros analógicos, cabos elétricos blindados e gaiolas de Faraday, a presença de ruídos eletrônicos em situações de correntes na faixa de pA ou fA (como é o caso de trabalhos com substâncias eletroativas em baixas concentrações) constitui-se em inequívoca desvantagem quando microeletrodos de disco são empregados. Nestes casos, microeletrodos de diferentes geometrias e configurações apresentamse como alternativa de interesse pois apesar da situação de estado estacionário não ser atingida em sua plenitude, varıtagens oriundas do tamanho micrométrico em uma de suas dimensões confere a estes eletrodos características especiais relacionadas à difusão convergente, aumentando-se a sensibilidade devido ao aumento da área dos microeletrodos. Nesta classe de microeletrodos podem ser enquadrados os eletrodos de banda, os de formato cilíndrico e aqueles fabricados com base no espaçamento definido entre discos de microeletrodos.

Conforme já foi comentado anteriormente, microeletrodos de disco são muito populares em virtude da relativa facilidade de fabricação a despeito das correntes relativamente baixas a serem monitoradas quando se compara com os sinais de correntes obtidos com outros tipos de microeletrodos. Há duas outras vantagens relacionadas aos microeletrodos de disco as quais justificam sua popularidade. Uma delas é relativa à possibilidade de definir com mais simplicidade os parâmetros envolvidos no processo de difusão radial e a outra diz respeito ao crescente interesse no desenvolvimento de sensores eletroquímicos miniaturizados.

A afirmação sobre a "facilidade" de fabricação de microeletrodos de disco restringe-se àqueles preparados com fibras de raio relativamente grande (raio $\geq 25 \mu \mathrm{m}$ ), quando a probabilidade dos microeletrodos conduzirem a resultados satisfatórios é bastante grande. $\mathrm{O}$ índice de bom funcionamento começa a diminuir à medida que se trabalha com fibras de dimensões menores devido principalmente à dificuldade de manuseio, aumento na probabilidade de rupturas e perda de contato elétrico.

Microeletrodos de fibra de platina, ouro, carbono e outros materiais têm sido fabricados com base em dois procedimentos clássicos. Quando se trabalha com tubos de vidro mole, a idéia básica consiste na fusão controlada da ponta do capilar de maneira que a microfibra fique totalmente envolta por uma camada vítrea [90]. O processo de fusão é conduzido com bico de Bunsen ou com auxílio de uma espiral de $\mathrm{Ni} / \mathrm{Cr}$ cujas pontas estão conectadas a um regulador de 
tensão com o qual se pode controlar a temperatura. No caso da utilização de ponteiras plásticas de pipetas, o revestimento e isolamento das microfibras pode ser efetivado com aditivos à base de epóxidos $[91,92]$. O contato elétrico das microfibras com o suporte elétrico apropriado (fios de $\mathrm{Ni} / \mathrm{Cr}$ ) pode ser efetuado com cola epóxi condutora (à base de pó metálico). No caso de fibras com raio superior a $12,5 \mu \mathrm{m}$, costuma-se enrolar a fibra em torno do fio de $\mathrm{Ni} / \mathrm{Cr}$ para melhorar ainda mais o contato elétrico antes do uso da cola condutora.

Etapa extremamente relevante para o bom desempenho de qualquer eletrodo sólido referese ao tratamento de sua superfície pois sabe-se que a atividade eletródica é função da energia superficial (relacionada à existência de sítios eletroquimicamente ativos) e que a resposta eletroquímica pode ser influenciada por camadas passivantes. A remoção destas camadas bloqueadoras (contaminantes, óxidos, partículas fisicamente adsorvidas) constitui o objetivo primordial do pré-tratamento da superficie de um eletrodo sólido. Com o intuito de promover uma efetiva limpeza, dois procedimentos clássicos são utilizados. Um deles está relacionado à limpeza mecânica [93] e para tanto partículas de material abrasivo de diferentes granulometrias podem ser usadas, iniciando-se o processo de polimento com as partículas de maior tamanho. $\mathrm{O}$ processo encerra-se com a remoção total dos grãos de alumina da superficie do eletrodo com auxílio de jatos de água ou pela imersão parcial dos eletrodos em banho de ultrassom. Após a fabricação e polimento, a inspeção da superfície dos microeletrodos com vídeo-microscópio pode ser utilizada objetivando a verificação da boa selagem da fibra e eventual presença de partículas do material usado na etapa de abrasão. O outro procedimento relaciona-se à aplicação de potenciais extremos, visando à remoção de substâncias aderidas à superficie do eletrodo [94].

Testes com o microeletrodo fabricado conforme os procedimentos acima descritos envolvem numa primeira etapa a obtenção de voltamogramas de estado estacionário em velocidade relativamente lenta empregando $\mathrm{Fe}(\mathrm{CN})_{6}{ }^{3-}$ como substância eletroativa. Em virtude da rápida velocidade de transferência de elétrons envolvendo o par ferri/ferrocianeto, o processo global de eletrodo é governado pelo transporte de massa valendo a equação (3) para a determinação da corrente limite associada ao voltamograma de estado estacionário (desprezandose o componente dependente do tempo). Duas verificações têm sido efetuadas para a comprovação do bom funcionamento do eletrodo e para fins de avaliar o raio do disco. Uma delas envolve a comparação da corrente limite obtida experimentalmente com aquela calculada utilizando a equação apropriada, onde utilizam-se valores bem estabelecidos na literatura para o 
coeficiente de difusão da espécie eletroativa, geralmente em meio de $\mathrm{KCl}$. O outro relaciona-se à análise da curva sigmoidal à luz da equação clássica utilizada em polarografia (equação 2). Para sistema controlado por difusão e considerando que o processo de redução do $\mathrm{Fe}(\mathrm{CN})_{6}{ }^{3-}$ envolve a transferência de 1 elétron, o coeficiente angular do gráfico relacionando $\mathrm{E}$ em função de $\log$ $\left(\mathrm{I} /\left(\mathrm{I}_{\mathrm{L}}-\mathrm{I}\right)\right)$ deve ser igual a $59 \mathrm{mV}$ trabalhando-se a $25^{\circ} \mathrm{C}$. Este segundo diagnóstico do funcionamento de um microeletrodo é geralmente empregado com o objetivo de demonstrar a relação entre potencial e corrente em experimentos eletroquímicos nos quais as espécies oxidada e reduzida coexistem em rápido equilíbrio na superfície do eletrodo e onde fatores associados à expansão da camada de difusão são desprezíveis (obtendo-se, portanto, voltamogramas de estado estacionário).

Um dos maiores problemas observados com microeletrodos de disco diz respeito à elevada dependência da corrente capacitiva em função da velocidade de varredura [95]. Tais efeitos têm sido atribuídos a imperfeições na selagem entre microfibra e material isolante, dando origem a espaços vazios ou bolhas de ar. Alternativas diversas podem ser empregadas para minimizar este problema e pode-se citar o recobrimento do corpo do eletrodo com folhas de alumínio [90], etapa prévia de silanização da ponta do eletrodo [96] e melhoria do processo de selagem trabalhando-se a vácuo [91].

A preparação de microeletrodos com fibras de raio inferior a $5 \mu \mathrm{m}$ consiste em trabalho de paciência e certa habilidade manual. Há, todavia, inúmeras outras alternativas para a fabricação de microeletrodos de disco e entre elas pode-se citar a eletrodeposição de polímeros orgânicos ao redor das microfibras, o uso de revestimentos à base de tintas especialmente depositadas ou com tecnologias de deposição a vapor e encapsulamento das microfibras em capilares de Teflon por meio de aquecimento controlado [97-99]. Microeletrodos com raios submicrométricos também têm sido fabricados e o procedimento usual envolve o desgaste eletroquímico das microfibras imersas em soluções apropriadas até se atingir a dimensão desejada ("electrochemical etching") [100,101]. Estas técnicas mais sofisticadas são especialmente apropriadas para a fabricação de microeletrodos em que a espessura da camada isolante que envolve a microfibra também possui dimensões micrométricas, viabilizando estudos em que o sensor é usado para a obtenção de dados eletroquímicos em ambientes microscópicos ou com volumes muito pequenos de amostra. 


\subsubsection{Microeletrodos de banda (ou linha)}

Microeletrodos de banda fornecem correntes maiores do que os eletrodos de disco e o processo de transporte de material eletroativo para a superficie do eletrodo mantém a característica de difusão não-linear. Tais eletrodos são construídos para serem microscópicos em uma de suas dimensões mas macroscópicos no comprimento, resultado em correntes relativamente elevadas. Processos de fabricação incluem a imobilização de películas de materiais condutores com placas isolantes e o uso de técnicas litográficas, de deposição a vácuo ou por "screen printing" [102-105].

Uma característica importante de microeletrodos de banda diz respeito ao fato dos mesmos não atingirem uma situação de estado estacionário em tempos relativamente curtos como acontece com as microesferas e os microdiscos. A equação 4, que prediz a dependência da corrente faradaica em função das dimensões do eletrodo conforme apresenta-se na Figura 6 , demonstra a influência direta do tamanho da banda no valor da corrente e que a influência da espessura da "linha" é pouco marcante. Este fato tem importância em determinações analíticas uma vez que a redução da espessura da banda implica menor área superficial (sem queda proporcional no sinal de corrente faradaica), contribuindo para a diminuição da corrente residual associada, entre outros fatores, a fenômenos capacitivos.

$$
\mathrm{I}=4 \pi \mathrm{nFDCl}[1 /(\ln 4 \theta)], \text { onde } \theta=\mathrm{Dt} / \mathrm{r}^{2}
$$

As características favoráveis relativas ao uso de microeletrodos de banda, associadas ao aumento da corrente em razão da existência de uma dimensão macroscópica, têm contribuído para o aumento do número de trabalhos envolvendo esta classe de eletrodos quer seja no desenvolvimento de novos procedimentos de fabricação ou no estudo de suas propriedades. No que tange à possibilidade de medição de correntes relativamente maiores destacam-se investigações de cunho estritamente analítico ou mesmo aquelas em que as espécies eletroativas possuem coeficientes de difusão muito baixos em virtude das características especiais do meio (por exemplo, elevada viscosidade). 


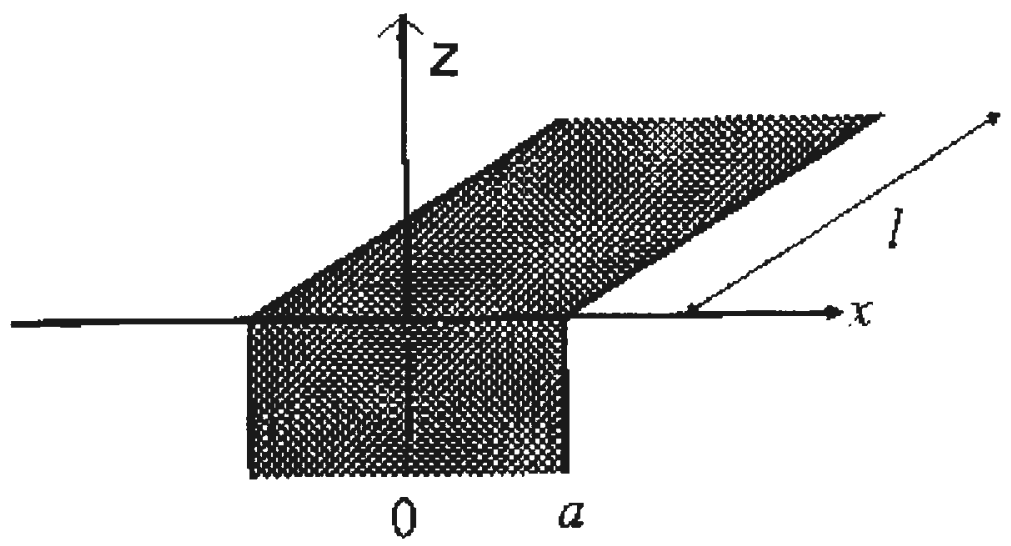

Figura 6. Representação esquemática das variáveis dimensionais num microeletrodo de banda (ou linha).

\subsubsection{Microeletrodos cilindricos}

A exemplo do que ocorre com os microeletrodos de banda, o campo de difusão originado por eletrodos de formato cilíndrico em que o raio do cilindro apresenta dimensão microscópica também é convergente, resultando em características bastante vantajosas. Soluções analíticas para o problema são muito complicadas mas a corrente medida certamente depende em larga extensão do comprimento da microfibra. Entretanto, estes eletrodos não podem ser polidos mecanicamente e são relativamente frágeis quando o comprimento da fibra ultrapassa alguns centímetros. Esta última desvantagem pode, todavia, ser minimizada prendendo-se as duas extremidades da fibra em suporte adequado [106]. Vale lembrar que, a exemplo dos microeletrodos de banda, para microeletrodos cilíndricos situações de estado estacionário não são nunca atingidas teoricamente pois nestes casos não há um componente independente do tempo, prevendo-se uma queda contínua da corrente ao longo dos experimentos. 


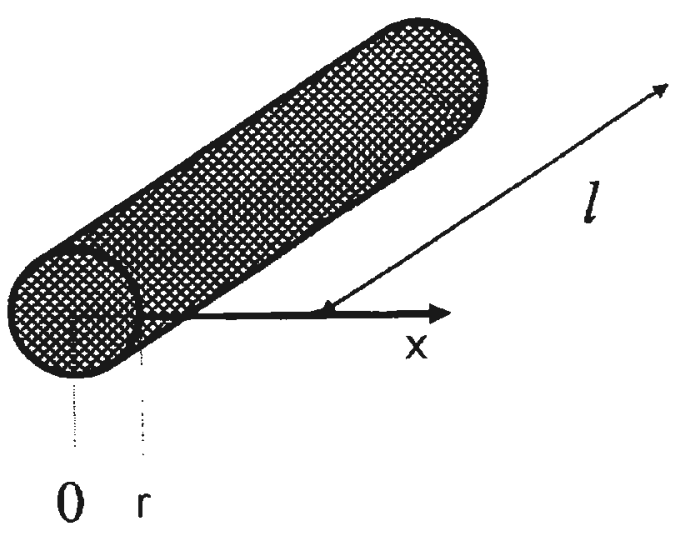

Figura 7. Representação esquemática das variáveis dimensionais num microeletrodo cilíndrico.

\subsubsection{Conjunto de microeletrodos ("arrays")}

Eletrodos de diferentes geometrias podem ser empregados na confecção dos chamados "arrays" de microeletrodos mas os mais comuns restringem-se às linhas e discos, ordenados de maneira não necessariamente regular sobre um mesmo plano. Um aspecto bastante importante ao se tratar desta classe de microeletrodos diz respeito à distância entre os microeletrodos individuais, a qual pode afetar os campos de difusão dependendo da escala de tempo do experimento. A figura abaixo representa um esquema onde 2 microeletrodos de disco de raio $a$ são separados pela distância $d$.

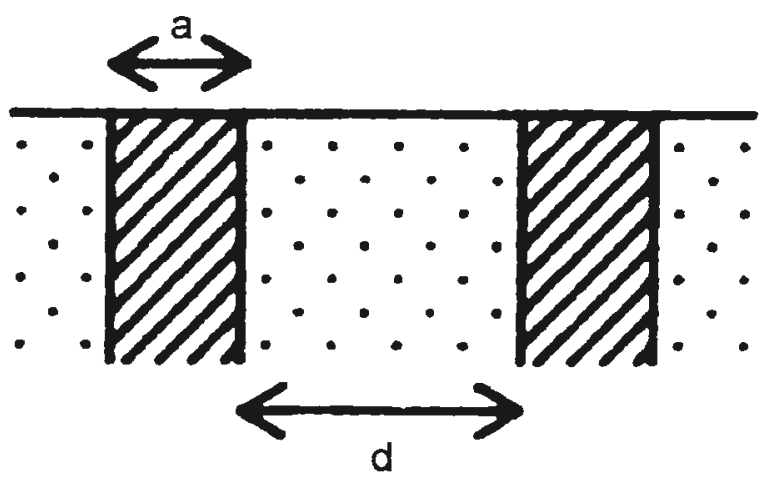

Figura 8. Representação esquemática de um conjunto de microeletrodos de disco de raio a separados pela distância $\underline{\text { d. }}$ 
Em experimentos eletroquímicos com velocidades de varredura altas ou tempos muito curtos os campos de difusão de arranjos de microeletrodos não se sobrepõem e prevalece a difusão linear. Voltamogramas semelhantes àqueles registrados com eletrodos de dimensão convencional são obtidos nestas condições. A situação é diferente para tempos mais longos, quando pode-se obter tanto voltamogramas sigmoidais (para microeletrodos suficientemente afastados) como voltamogramas com os componentes anódico e catódico (nos casos em que há interação entre os campos de difusão). Cálculos teóricos prevêem que para discos de raio $a$ montados de acordo com uma configuração de "array" de microletrodos, a interferência entre os campos de difusão ocorre desde que a distância entre os microdiscos seja inferior a $6 a$ [107].

Uma característica importante dos conjuntos de microeletrodos diz respeito à possibilidade de controle individual do potencial de cada eletrodo (ou pequeno grupo) de forma a se poder realizar determinações analíticas de maneira relativamente seletiva. Outra importante vantagem relaciona-se ao fator amplificador do sinal de corrente sem perda das características atraentes da difusão não radial ao se trabalhar com microeletrodos suficientemente afastados polarizados num mesmo potencial [108].

Há diversos métodos empregados na literatura [107-110] para a fabricação de conjunto de microeletrodos mas dois procedimentos se destacam pela originalidade. Num deles [111] microdiscos de ouro são obtidos após corte transversal em chips comerciais e posterior etapa de polimento até o aparecimento das microfibras. No outro [112] microeletrodos de platina de dimensões nanométricas são fabricados depositando-se platina em moldes dispostos em configuração hexagonal os quais são gerados pelas micelas existentes em meios contendo surfactantes apropriados.

\subsubsection{Outros tipos de microeletrodos}

Microeletrodos tubulares [113] ou na forma de anéis [114,115] também têm sido propostos na literatura, mas com menor destaque. No caso de microeletrodos de anel (assim como para microeletrodos de banda), vários estudos têm demonstrado a viabilidade da montagem e posterior utilização de configurações nas quais uma determinada espécie é eletroquimicamente gerada num microeletrodo e posteriormente coletada num outro microeletrodo posicionado de forma adjacente ao primeiro. Nestes casos, o conjunto de microeletrodos funciona à semelhança 
do eletrodo rotativo disco/anel e exemplos de estudos cinéticos investigados com anéis concêntricos e bandas paralelas de microeletrodos podem ser encontrados na literatura [116-121].

A engenhosidade na confeç̧ão de microeletrodos de diferentes formatos e tamanhos tem se mostrado crescente nos últimos anos. A disponibilidade de microesferas de ouro permitiu o desenvolvimento de método no qual se empacotam as partículas em capilares de vidro (diâmetro da ponta igual a alguns milimetros) para posterior etapa de imobilização dos grãos de ouro com auxílio de aquecimento e resinas epóxi [122]. Como vantagens associadas a este processo de fabricação podem ser citados o baixo preço das microesferas e a possibilidade de trabalho com grãos de dimensões ainda menores do que as de microfibras comercialmente disponíveis.

Outro exemplo bastante interessante sobre a construção de microeletrodos refere-se ao emprego de sóis contendo nanopartículas de ouro [123]. Por meio do revestimento interno de micropipetas de oríficio submicrométrico com ditióis, as nanopartículas de ouro são imobilizadas na ponta do capilar por interação química. Obtém-se, desta forma, esfera micrométrica na ponta do capilar a qual é composta por várias nanopartículas agregadas em razão da presença dos grupamentos SH dos ditióis. O tamanho das microesferas pode ser controlado com base no diâmetro do oríficio do capilar ou na concentração da solução de ditiol (responsável pelo agrupamento das partículas de ouro).

\subsection{Aplicações analíticas}

O uso de microeletrodos para fins analíticos baseia-se principalmente na possibilidade de se obter informações em situações de estado estacionário, portanto independentes do tempo. Nestas condições o elevado fluxo de material em direção ao eletrodo e a minimização da corrente oriunda de processos capacitivos permitem a determinação de espécies eletroativas em níveis mais baixos de concentração. Outras características importantes também impulsionaram o largo uso de microeletrodos no desenvolvimento de métodos analíticos e neste sentido os trabalhos nesta área podem ser divididos em 2 grandes grupos:

1. O uso de microeletrodos como sensores eletroquímicos é sem dúvida a área de maior progresso especialmente devido à possibilidade de se poder monitorar a concentração de espécies químicas em micro-ambientes, como por exemplo no interior de uma célula, ou com volumes muito pequenos de amostras. Para o crescimento desta linha de pesquisa as contínuas evoluções na área de nanomaterias certamente constituem-se em alicerce de 
importância. Um exemplo bastante interessante sobre os progressos recentes na área diz respeito a metabólitos de interesse biológico (como é o caso da determinação de lactato em ratos com microeletrodo de fibra de carbono em tempo real [124]) ou à detecção de ácido ascórbico pela inserção de microeletrodo de platina em frutas cítricas [125]. Cabe ainda destacar o uso de microeletrodos como sensores eletroquímicos em sistemas FIA [126,127] e de separação cromatográfica [128-130], nos quais meios de baixa condutividade elétrica são muitas vezes utilizados. Mesmo nestas condições, baixos valores de queda ôhmica são esperados em razão das dimensões micrométricas dos eletrodos. Procedimentos em fluxo aos quais se introduzem amostras contendo mais de uma substância eletroativa também podem ser otimizados utilizando-se microeletrodos. Para tanto, adaptações têm sido feitas na instrumentação para aquisição de dados de forma que voltamogramas sucessivos com elevadas velocidades de varredura sejam registrados durante a passagem da amostra pelo detector. Desta forma, informações sobre a composição da amostra, além da concentração dos analitos, podem ser obtidas [131-134].

2. A determinação de metais pesados por pré-concentração seguida de etapa de varredura de dissolução anódica/catódica ("stripping") constitui-se em método altamente sensível. Com o advento dos microeletrodos perspectivas ainda melhores são vislumbradas uma vez que a elevada taxa de transporte de material eletroativo em direção ao eletrodo ocorre em condição de ausência de agitação mecânica, fator certamente importante ao se avaliar a repetibilidade das determinações $[135,136]$. Como aspecto favorável vale também destacar a possibilidade de realização de experimentos em meios sem adição de eletrólito suporte, minimizando o ingresso de interferentes na solução de trabalho; esta situação é extremamente vantajosa ao se determinar íons metálicos em níveis de traços em matrizes como águas de chuva, águas de rio, bebidas, etc $[137,138]$.

Considerando que sensores são transdutores miniaturizados que seletivamente e reversivelmente respondem a compostos químicos ou ions e produzem sinais elétricos proporcionais à concentração, cabe também destacar vantagens teoricamente existentes do uso destes dispositivos comparando-se com análises realizadas por técnicas instrumentais. Entre elas pode-se citar: 
- Medições no campo, embora não necessariamente precisas ou exatas, podem ser realizadas devido à portabilidade da instrumentação. Neste contexto também enquadram-se pesquisas em locais remotos ou inacessiveis.

- O preço da instrumentação é relativamente barato, especialmente ao se tratar de medições eletroquímicas. A facilidade de automação e miniaturização da aparelhagem são fatores que também contribuem para a diminuição do custo das análises.

- Devido à resposta rápida ao se tratar de sensores eletroquímicos, dados em tempo real podem ser obtidos

Desta forma, um dos campos de futuro promissor na área de eletroanalítica deve estar associado à exploração das vantagens acima arroladas no sentido de ultrapassar obstáculos ainda encontrados ao se trabalhar com sensores. Entre outros pode se destacar a baixa reprodutibilidade das medições quando executadas em matrizes reais, estabilidade relativamente reduzida e resposta lenta $[139,140]$. Estes problemas são particularmente importantes em análises de campo, nas quais dados experimentais obtidos sem remoção da amostra têm significado muito mais expressivo [141-143]. 


\section{TRABALHOS DESENVOLVIDOS}

\subsection{Introdução}

Pretende-se nesta seção descrever de maneira simplificada os principais trabalhos realizados na linha de pesquisa relacionada à utilização de métodos eletroquímicos para a elucidação de processos eletródicos e no desenvolvimento de metodologias analíticas. Neste sentido, ênfase é dada a investigações que envolveram o uso de eletrodos modificados e microeletrodos, área de contínuo crescimento na eletroanalítica principalmente devido à possibilidade de construção de sensores miniaturizados cada vez mais sensíveis e seletivos. Dados relativos a estudos de sistemas cinéticos e catalíticos onde espécies químicas estão dissolvidas em solução são também apresentados à luz das perspectivas de elaboração de estratégias que permitam a quantificação de analitos de interesse biológico, industrial ou ambiental. $\mathrm{O}$ texto está apresentado com o objetivo de, numa primeira etapa, demonstrar o conhecimento adquirido sobre a natureza de diferentes processos eletródicos os quais foram investigados empregando-se técnicas eletroquímicas clássicas. Seguem-se então algumas aplicações práticas destes sistemas químicos resultando no desenvolvimento de métodos analíticos.

O acoplamento de sensores eletroquímicos a sistemas em fluxo tem se mostrado extremamente favorável em razão de vantagens tais como possibilidade de automação, preparação das amostras "on-line", melhoria na precisão e exatidão das medidas, aumento da vida útil do sensor em função da contínua passagem de eletrólito por sua superfície (minimizando problemas relativos à contaminação pela amostra) e melhoria na freqüência analítica. Estas características especiais de sistemas de análise por injeção em fluxo foram amplamente comprovadas em estudos descritos no final da seção, onde apresentam-se dados sobre o desenvolvimento de métodos analíticos empregando-se sensores eletroquímicos como detectores em sistemas FIA. 


\subsection{Estudos sobre o uso de microeletrodos em sistemas hidrodinâmicos}

As diversas vantagens do uso de microeletrodos como detectores amperométricos em sistemas estacionários têm sido uma das principais razões para o aumento do número de trabalhos nesta área. Todavia, poucos estudos demonstraram as eventuais vantagens da associação de microeletrodos em sistemas convectivos no que diz respeito à melhoria no limite de detecção das determinações [126]. Neste sentido, estudos foram realizados empregando-se ferrocianeto como substância eletroativa num fluxo carregador contendo $\mathrm{KCl}$ como eletrólito suporte; neste meio o processo de transferência heterogênea de carga é relativamente rápido e a oxidação anódica do ferrocianeto envolve 1 elétron [144].

Voltamogramas hidrodinâmicos de uma solução $0,5 \mathrm{mM}$ de $\mathrm{Fe}(\mathrm{CN})_{6}{ }^{-4}+\mathrm{KCl} 0,1 \mathrm{M}$ foram registrados com uma velocidade de varredura de $10 \mathrm{mV} \mathrm{s}^{-1}$ em solução estacionária e em situações de convecção forçada mantidas pela variação da velocidade do fluxo de material eletroativo. Para tanto, usou-se um sistema do tipo "wall-jet" ao qual adaptou-se uma bomba peristáltica Ismatec ISM 828. A Figura 9 mostra as curvas voltamétricas obtidas com um microeletrodo de $10 \mu \mathrm{m}$ de diâmetro e um eletrodo de tamanho convencional (diâmetro 1,5 mm). Nessa última situação, com o aumento do transporte de massa ocorre mudança no formato da curva voltamétrica obtendo-se curvas sigmoidais características referentes a condições de estado estacionário. Com o aumento da velocidade de fluxo, aumenta-se a quantidade de material eletroativo que atinge a superficie do eletrodo de trabalho, sendo que na velocidade máxima de fluxo usada $\left(3,8 \mathrm{ml} \mathrm{s}^{-1}\right)$ ocorre um aumento drástico da corrente limite. Isso não ocorre quando se usa um microeletrodo como eletrodo de trabalho porque a contribuição do efeito convectivo é minimizada devido à difusão radial característica para o microeletrodo. Então, como se pode observar na Figura 9, não ocorre um grande aumento na corrente limite das curvas em função do aumento da velocidade de fluxo. 


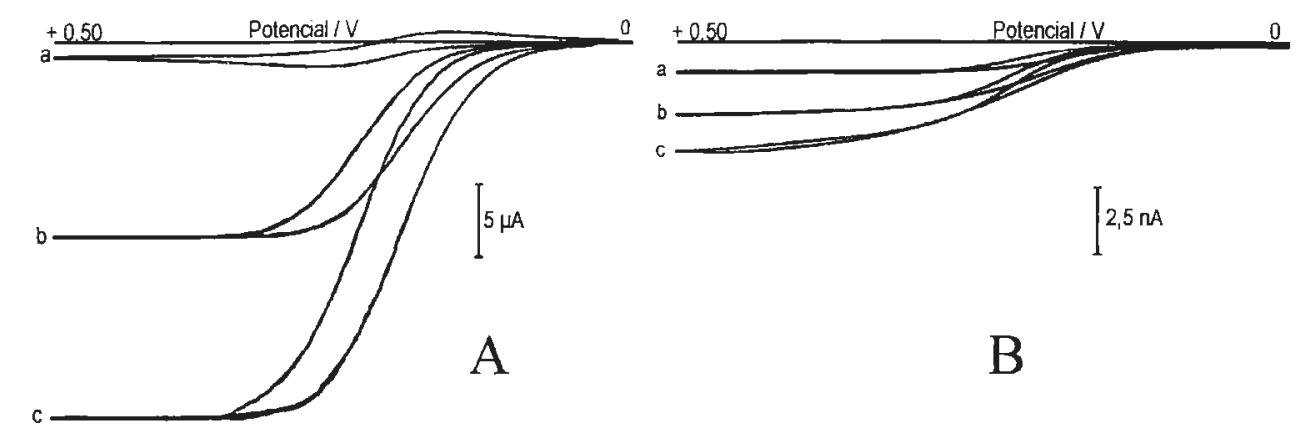

Figura 9: Voltamogramas hidrodinâmicos de uma solução de ferrocianeto $0,5 \mathrm{mM}$ em $\mathrm{KCl} 0,1 \mathrm{M}$ : solução estacionária (a), $2,4(b)$ e $3,8 \mathrm{ml} \mathrm{min}^{-1}$ (c). Eletrodos de trabalho: eletrodo de disco de platina (d $=1,5 \mathrm{~mm})($ A) e microeletrodo de disco de platina $(\mathrm{d}=10 \mu \mathrm{m})(B)$.

A corrente limite medida em voltamogramas hidrodinâmicos de uma espécie eletroativa em uma célula do tipo "wall-jet" depende da velocidade do líquido transportador, de algumas propriedades químicas do sistema (concentração, viscosidade, coeficiente de difusão) e alguns parâmetros físicos (dimensão da superfície do eletrodo). Trabalhos na literatura [145] relatam que o sinal de corrente é função linear da velocidade de fluxo elevado a um expoente, cujo valor é 0,5 para um microeletrodo e 0,75 para eletrodo de tamanho convencional. A razão $I_{n} / I_{0}$ foi calculada de forma que $I_{n}$ é a corrente limite obtida para um voltamograma em uma dada velocidade de fluxo e $\mathrm{I}_{0}$ é a corrente limite do voltamograma obtido em solução estacionária. A Figura 10 mostra o gráfico da dependência da razão $I_{n} / I_{0}$ em função da raiz quadrada da velocidade de fluxo. Dados para microeletrodos de 3 tamanhos diferentes são mostrados assim como os resultados obtidos com o eletrodo de platina de tamanho convencional. Para o eletrodo de tamanho convencional usou-se o valor de $\mathrm{I}_{0}$ quando se tem uma velocidade de fluxo de $0,4 \mathrm{ml} \mathrm{s}^{-1}$, pois nessa condição é possível medir a corrente limite de estado estacionário no voltamograma. Para os microeletrodos de diâmetro 10 e $25 \mu \mathrm{m}$ os dados experimentais são concordantes com a teoria e para o microeletrodo de diâmetro $50 \mu \mathrm{m}$ uma pequena variação foi observada. Entretanto, a dependência exponencial é diferente de 0,5 para o eletrodo de diâmetro $1,5 \mathrm{~mm}$, portanto na Figura 10 apresenta-se um gráfico em anexo para esse eletrodo onde representou-se graficamente a razão $I_{n} / I_{0}$ em função da vazão elevada a um expoente de 0,75 , obtendo-se dados mais concordantes com a teoria. 


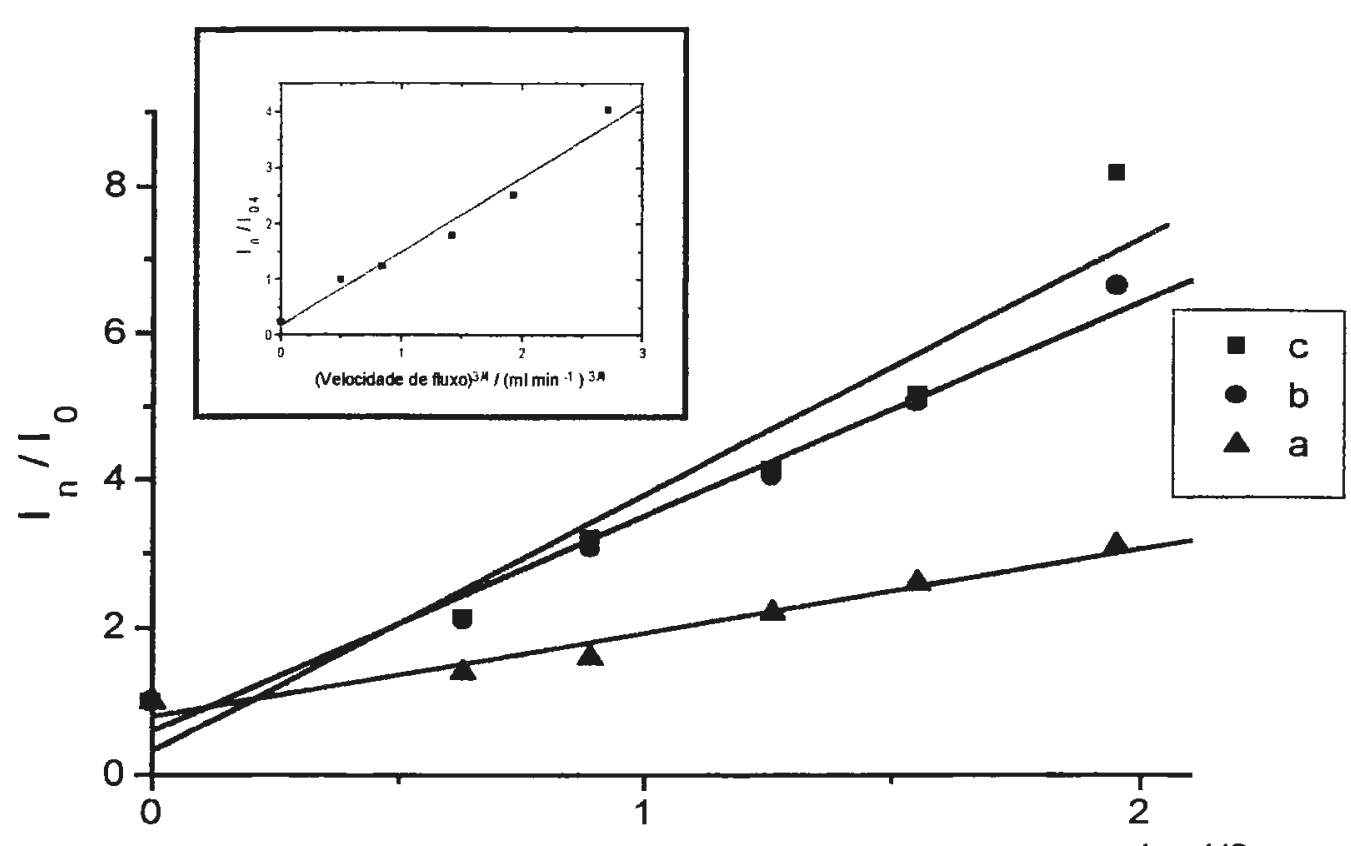

Raiz quadrada da velocidade de fluxo $/\left(\mathrm{ml} \mathrm{min}^{-1}\right)^{1 / 2}$

Figura 10: Dependência da razão $I_{n} / I_{0}$ em função da raiz quadrada da velocidade de fluxo para os microeletrodos de diâmetro 10 (a), 25 (b) e $50 \mu \mathrm{m}$ (c). O gráfico inserido mostra a dependência para o eletrodo de diâmetro $1,5 \mathrm{~mm}$. $I_{n}$ corresponde à corrente limite no estado estacionário dos voltamogramas de uma solução de ferrocianeto $0,5 \mathrm{mM}+K C l 0,1 \mathrm{M} \mathrm{em}$ fluxo e $I_{0}$ é o valor da corrente em uma solução estacionária, exceto para o eletrodo de diâmetro $1,5 \mathrm{~mm}$ onde $I_{0}$ corresponde à corrente limite para o voltamograma hidrodinâmico obtido com uma velocidade de fluxo de $0.4 \mathrm{ml} \mathrm{min}{ }^{-1}$.

Estudos envolvendo a dependência da densidade de corrente em função dos diâmetros dos eletrodos foram efetuados injetando-se soluções de ferrocianeto de concentrações variadas no líquido transportador de $\mathrm{KCl}$ com uma velocidade de $2,0 \mathrm{ml} \mathrm{min} \mathrm{m}^{-1}$ e potencial aplicado de $+0,5$ V. Os picos de corrente foram obtidos em triplicata para cada concentração de ferrocianeto e foram normalizados com base nos cálculos das respectivas densidade de corrente (Figura 11). Os valores de densidade de corrente aumentam quanto menor o raio do eletrodo devido ao transporte de massa mais eficiente, propriedade inerente para eletrodos de dimensões micrométricas. Focalizando aspectos analíticos, a sensibilidade corrigida (a razão entre a densidade de corrente e concentração) para ambos os eletrodos $(d=10 \mu \mathrm{m}$ e $1,5 \mathrm{~mm})$ foi calculada pelos picos de 
corrente dos fiagramas obtidos por injeções de soluções de ferrocianeto 0,2 a $1 \mu \mathrm{M}$ na solução transportadora de $\mathrm{KCl} 0,1 \mathrm{M}$. Baseando-se na inclinação da reta do gráfico corrente versus concentração de ferrocianeto calculou-se a sensibilidade corrigida para o microeletrodo de diâmetro $10 \mu \mathrm{m}$, obtendo-se o valor de $21,4 \mathrm{~mA} \mathrm{~m}^{-2} \mu \mathrm{M}$. Tal valor é 5 vezes maior que o valor obtido para o eletrodo de tamanho convencional, de acordo com os dados mostrados na Figura 11.

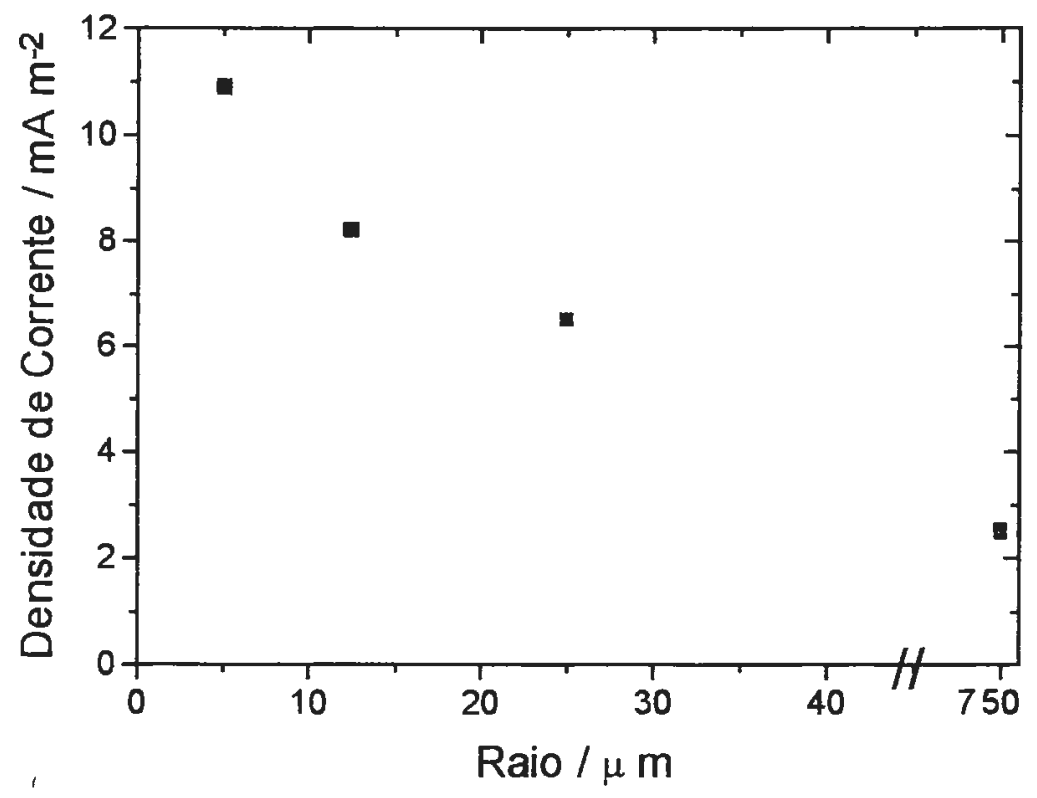

Figura 11: Dependência da densidade de corrente em função do raio dos eletrodos. Correntes foram medidas em fiagramas obtidos pela injeção de soluções de ferrocianeto $0.5 \mu M$ no sistema FLA. $E=+$

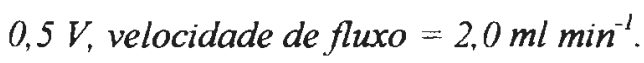

Com o objetivo de avaliar o limite de detecção com a configuração proposta em FIA usando ferrocianeto como espécie eletroativa, experimentos comparativos foram realizados com alguns microeletrodos de diferentes tamanhos e com o eletrodo de tamanho convencional. A Figura 12 mostra os resultados de injeções em triplicata de soluções de ferrocianeto na faixa de concentração de 0,05 a $1 \mu \mathrm{M}$ usando-se 2 diferentes eletrodos como detectores amperométricos (1,5 mm e $10 \mu \mathrm{m}$ de diâmetro). Pela análise da Figura 12 é possível verificar que a melhor discriminação entre o sinal faradaico e a linha de base é obtida com o microeletrodo, justificando 
seu uso como detector amperométrico para concentrações baixas da espécie eletroativa. $O$ limite de detecção para a configuração onde usou-se o microeletrodo foi calculado como o sinal correspondente a 3 vezes o desvio padrão do ruído da linha de base, obtendo-se o valor de $0,03 \mu \mathrm{M}$. Demonstra-se assim que o uso de microeletrodos como sensores amperométricos em sistemas FIA certamente constitui-se em procedimento de interesse principalmente quando a espécie eletroativa está presente em baixas concentrações. Cabe salientar que neste estudo o limite de detecção foi governado pelos ruídos eletrônicos associados à medição de sinais em escala tão baixa de corrente. Entretanto, tal inconveniente pode ser facilmente superado empregando-se eletrodos sob os quais prevalece o regime de difusão radial mas com dimensões superficiais mais elevadas, como é o caso de eletrodos de banda ou para conjuntos de microletrodos.

\section{$\mathrm{I}=0$}
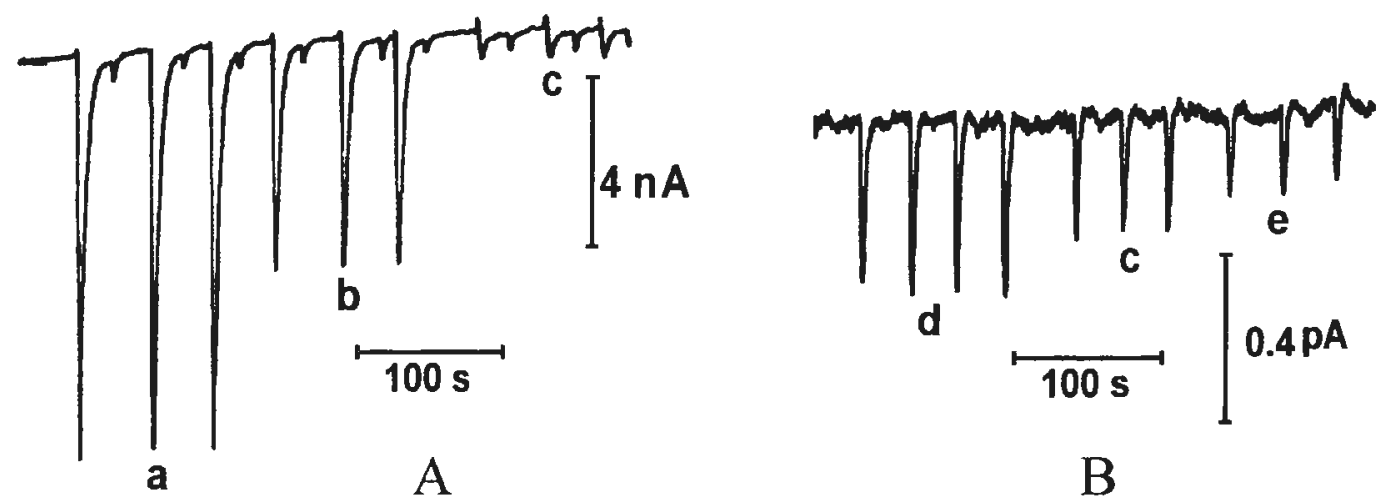

Figura 12: Fiagramas de soluções de ferrocianeto em $0,1 \mathrm{M}$ de $\mathrm{KCl}$ em célula "wall-jet" nas concentrações 1 (a); 0.5 (b); 0,1 (c); 0,2 (d) e 0,05 (e) $\mu \mathrm{M}$. Eletrodos de trabalho: discos de platina de

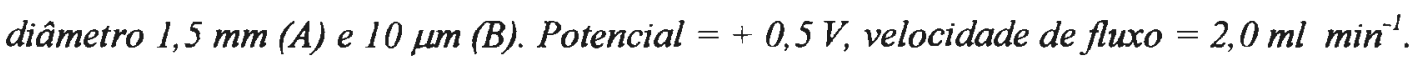




\subsection{Utilização de técnicas eletroquímicas para a caracterização de processos eletródicos}

\subsubsection{Oxidação do iodeto em microeletrodos de platina}

O processo de oxidação anódica do iodeto em eletrodos sólidos envolve a formação de iodo com a transferência de 2 elétrons. Todavia, em meio contendo excesso de iodeto pode ocorrer a formação de triiodeto e nestes casos o perfil voltamétrico deve ser diferente uma vez que a estequiometria da reação de eletrodo é alterada. Desta forma, o presente estudo teve como objetivo investigar o processo eletródico envolvendo a oxidação do iodeto em microeletrodos de platina. $\mathrm{O}$ trabalho com eletrodos nos quais o processo de difusão é essencialmente radial permite a obtenção de voltamogramas de estado estacionário, podendo-se aplicar equações apropriadas para averiguar o comportamento da corrente em função do potencial aplicado.

Experimentos preliminares com solução de $\mathrm{Fe}(\mathrm{CN})_{6}{ }^{3-}$ em meio de $\mathrm{KCl} 1,0 \mathrm{M}$ foram desenvolvidos utilizando-se microeletrodos de Pt com raios de 5, 12,5 e $25 \mu \mathrm{m}$ no intuito de caracterizar a reversibilidade do processo eletroquímico de redução e adequação à equação que rege o processo eletródico pela determinação da inclinação da reta referente ao gráfico $\mathrm{E}$ versus $\log \left(\mathrm{I} /\left(\mathrm{I}_{\mathrm{L}}-\mathrm{I}\right)\right)$. Para todos os microeletrodos a análise logarítmica conduziu a retas na região compreendendo o pé da onda e início do patamar de corrente, com valores de coeficiente angular muito próximos ao teoricamente esperado $(59 \mathrm{mV} / \mathrm{n})$.

O mesmo não foi observado para os voltamogramas obtidos com soluções de iodeto em meio de $\mathrm{Na}_{2} \mathrm{SO}_{4}$ 0,1 M. Para soluções contendo iodeto em concentrações superiores a $4 \mathrm{mM}$ foram observadas anomalias nos voltamogramas em razão da deposição de iodo na superfície do eletrodo, ratificando dados da literatura [146]. Tal fenômeno não foi observado para soluções mais diluídas como pode ser observado na Figura 13, onde apresenta-se o voltamograma obtido com microeletrodo de raio $=12,5 \mu \mathrm{m}$ para solução $2 \mathrm{mM}$ em iodeto, assim como o gráfico representando os resultados da análise logarítmica. Observa-se uma onda bem definida devido à oxidação eletroquímica do iodeto, com potencial de meia-onda $=460 \mathrm{mV}$. Entretanto, a representação gráfica de $E$ versus $\log \left(\mathrm{I} /\left(\mathrm{I}_{\mathrm{L}}-\mathrm{I}\right)\right)$ não conduziu a uma reta no intervalo de potenciais compreendendo 400 a $550 \mathrm{mV}$, levando à conclusão de que o processo relacionado à oxidação do iodeto no microeletrodo de platina não envolve uma simples transferência de elétrons. Explicações para tal fato podem basear-se na formação da espécie $\mathrm{I}_{3}{ }^{-}$em potenciais 
correspondentes ao pé da onda, onde iodo e iodeto coexistem na superficie do eletrodo. A reação química posterior à eletrooxidação do iodeto é representada pela seguinte equação:

$$
\mathrm{I}^{-}+\mathrm{I}_{2} \rightleftharpoons \mathrm{I}_{3}^{-}
$$

e considerando que o equilíbrio entre as espécies se estabelece rapidamente na camada de difusão, a reação global no eletrodo seria descrita pela equação:

$$
3 \mathrm{I}^{-} \rightleftharpoons \mathrm{I}_{3}{ }^{-}+2 \mathrm{e}^{-}
$$

Em regiões mais positivas de potencial $\left(E>E_{1 / 2}\right)$ a reação química posterior ao processo eletródico não ocorre em larga extensão e a espécie gerada eletroquimicamente consiste no iodo, de acordo com a seguinte equação:

$$
2 \mathrm{I}^{-} \rightleftharpoons \mathrm{I}_{2}+2 \mathrm{e}^{-}
$$
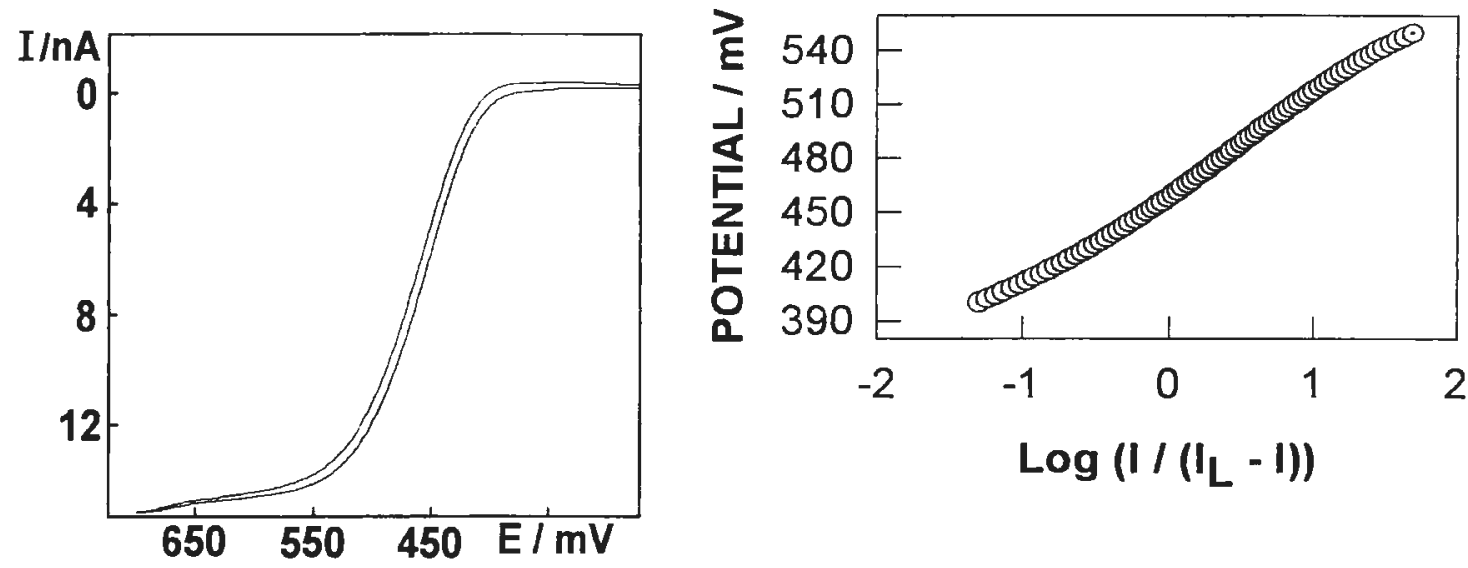

Figura 13. Voltamograma de solução de iodeto $2 \mathrm{mM}$ em $\mathrm{Na}_{2} \mathrm{SO}_{4}$ O,I $\mathrm{M}$ (microeletrodo de Pt $\left.(r=12,5 \mu \mathrm{m}), v=10 \mathrm{mV} \mathrm{s}^{-1}\right)$ e análise logaritmica dos pontos obtidos entre 400 e $550 \mathrm{mV}$.

Análises logarítmicas apropriadas dos dados obtidos a partir de curvas voltamétricas devem levar em conta as estequiometrias das reações envolvendo a oxidação de iodeto a iodo (equação 7) e triiodeto (equação 6), não sendo possível empregar-se a clássica relação E versus $\log \left(\mathrm{I} / \mathrm{I}_{\mathrm{L}}-\mathrm{I}\right)$ ) em virtude da razão entre reagentes e produtos não ser unitária em nenhum dos 2 processos eletródicos. Foram desenvolvidas expressões apropriadas e para o caso da formação de triiodeto (equação 6) obteve-se equação que relaciona o potencial com a expressão $\log \left(\mathrm{I} /\left(\mathrm{I}_{\mathrm{L}}-\mathrm{I}\right)^{3}\right)$, prevendo-se a obtenção de reta com coeficiente angular de $29,6 \mathrm{mV}$ a $25^{\circ} \mathrm{C}$. 
Confirmou-se a hipótese de interação química entre iodo e iodeto na superficie do microeletrodo analisando-se dados experimentais obtidos com microeletrodo de raio $=12,5 \mu \mathrm{m}$ para potenciais correspondentes ao pé da onda voltamétrica (400 a $450 \mathrm{mV}$ ), representando-se graficamente E versus $\log \left(\mathrm{I} /\left(\mathrm{I}_{\mathrm{L}}-\mathrm{I}\right)^{3}\right)$ (Figura 14). Nesta região de potencial predomina o processo eletródico envolvendo oxidação de iodeto a triiodeto e os dados apresentados revelam a excelente concordância com a equação proposta, obtendo-se como inclinação da reta ajustada o valor de 32 $\mathrm{mV}$ (valor teórico $=29,6 \mathrm{mV}$ ). Resultados similares foram obtidos com os microeletrodos de raios 5 e $25 \mu \mathrm{m}$.

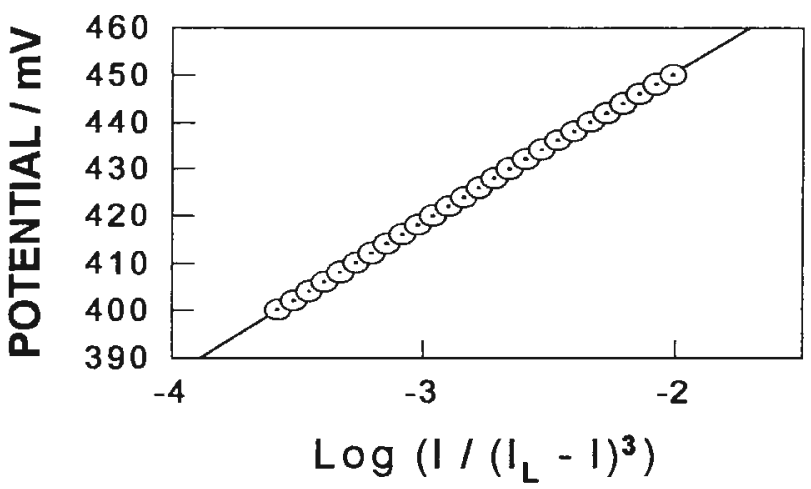

Figura 14. Análise logaritmica de pontos experimentais obtidos em voltamograma de solução de iodeto 2 $\mathrm{mMem} \mathrm{Na}_{2} \mathrm{SO}_{4}$ 0,1 M (microeletrodo de Pt $(r=12,5 \mu \mathrm{m}), v=10 \mathrm{mV} \mathrm{s}^{-1}$ ).

Expressão similar para o processo envolvendo a eletrooxidação do iodeto a iodo (equação 7) prevê a obtenção de reta com coeficiente angular de $29,6 \mathrm{mV}$ ao traçar-se gráfico de potencial em função de $\log \left(\mathrm{I} /\left(\mathrm{I}_{\mathrm{L}}-\mathrm{I}\right)^{2}\right)$. Dados experimentais correspondentes à região próxima ao patamar (470 a $520 \mathrm{mV}$ ) foram analisados com base na expressão acima explicitada e obteve-se reta com coeficiente angular de $33 \mathrm{mV}$, concordando com as previsões teóricas e ratificando a menor extensão de reação de formação de triiodeto em potenciais mais positivos. 


\subsubsection{Determinação do coeficiente de difusão do NO}

O NO tem estado em evidência recentemente por ser uma importante molécula biorregulatória em processos fisiológicos. Apesar do conhecimento total das funções do NO ser incompleto, sabe-se que o radical livre do NO causa atividade no fator de relaxação no endotélio (EDRF), age como um neurotransmissor, previne agregação de plaquetas e é a maior molécula de defesa de células imunes contra tumores das células e bactérias intracelulares [147-149]. Vários processos patológicos, tais como hipertensão aguda, esquimia e arterosclerose estão associados com anomalias do EDRF. Em adição para estas funções biorregulatórias, o aumento da concentração de NO tem sido usado como justificativa para doenças tais como choque séptico, a destruição da produção de insulina nas células, doença de Parkinson e mal de Alzheimer. Por estes fatos a determinação da concentração de NO em fluidos biológicos tem se tornado de grande importância.

Há vários métodos empregados para a determinação de NO e entre eles destacam-se os eletroquímicos, uma vez que medições em tempo real podem ser feitas com boa sensibilidade [150152]. O gás é extremamente reativo na presença de oxigênio; entretanto, em concentrações relativamente baixas (micromolar), o tempo de meia-vida do NO é da ordem de alguns minutos pois a cinética da reação de oxidação é de terceira ordem [153], permitindo a medição da concentração do analito em fluidos biológicos. Qualquer que seja o método empregado na quantificação de NO há necessidade de se preparar soluções de concentração conhecida do analito. Usualmente adota-se o valor de $2 \mathrm{mM}$ como a concentração da substância em soluções saturadas e a partir destas preparam-se então as soluções de trabalho [154].

No contexto acima apresentado, descrevem-se a seguir as etapas relacionadas à determinação da concentração de uma solução de NO preparada em tampão fosfato $(\mathrm{pH}=7,4)$ com base em dados resultantes de experimento cronoamperométrico realizados com microeletrodo de platina. Utilizando-se equações apropriadas as quais descrevem o comportamento da corrente durante pulso de potencial na região onde o NO é eletroativo pôde-se determinar tanto o coeficiente de difusão da espécie eletroativa como o valor da concentração da solução.

Os estudos preliminares envolveram a determinação do raio real de vários microeletrodos de disco de platina, em etapa executada pela medição da corrente limite de estado estacionário referente à oxidação anódica de ferrocianeto em concentração conhecida (equação 3, usando o componente independente do tempo). Etapa seguinte incluiu a determinação do coeficiente de difusão do ferrocianeto empregando-se a metodologia cronoamperométrica proposta por Denuault e 
colaboradores [155] para fins de testes com sistema químico conhecido. Para tempos relativamente longos $(0,05<t<10 \mathrm{~s})$ o gráfico da dependência da razão entre $I_{t}$ e $I_{s s}$ (onde $I_{t}$ é a corrente no tempo $t$ e $I_{s s}$ é a corrente no estado estacionário) em função de $t^{-1 / 2}$ deve conduzir a uma reta de acordo com a seguinte equação:

$$
\mathrm{I}_{\mathrm{t}} / \mathrm{I}_{\mathrm{ss}}=1+\left(2 / \pi^{3 / 2}\right) \mathrm{a}(\mathrm{Dt})^{-1 / 2}
$$

A Figura 15 apresenta os dados referentes à oxidação potenciostática do $\mathrm{Fe}(\mathrm{CN})_{6}{ }^{4-}$ em meio de $\mathrm{KCl} 1 \mathrm{M}$ utilizando-se microeletrodo de platina $(r=25 \mu \mathrm{m})$, em região de potencial $(+0,5 \mathrm{~V})$ onde o processo é governado por transporte de massa. Conforme as predições teóricas, a reta obtida tem coeficiente linear próximo a $1\left(\mathrm{I}_{\mathrm{t}} / \mathrm{I}_{\mathrm{ss}}=0,93+0,35 \mathrm{t}^{-1 / 2}, \mathrm{r}^{2}=0,998\right)$ e considerandose o valor do coeficiente angular determinou-se $\mathrm{D}=(6,5 \pm 0,9) \times 10^{-6} \mathrm{~cm}^{2} \mathrm{~s}^{-1}$. Este resultado é coincidente com outros valores relatados na literatura $[144,155]$, corroborando a metodologia proposta para a determinação de coeficientes de difusão.

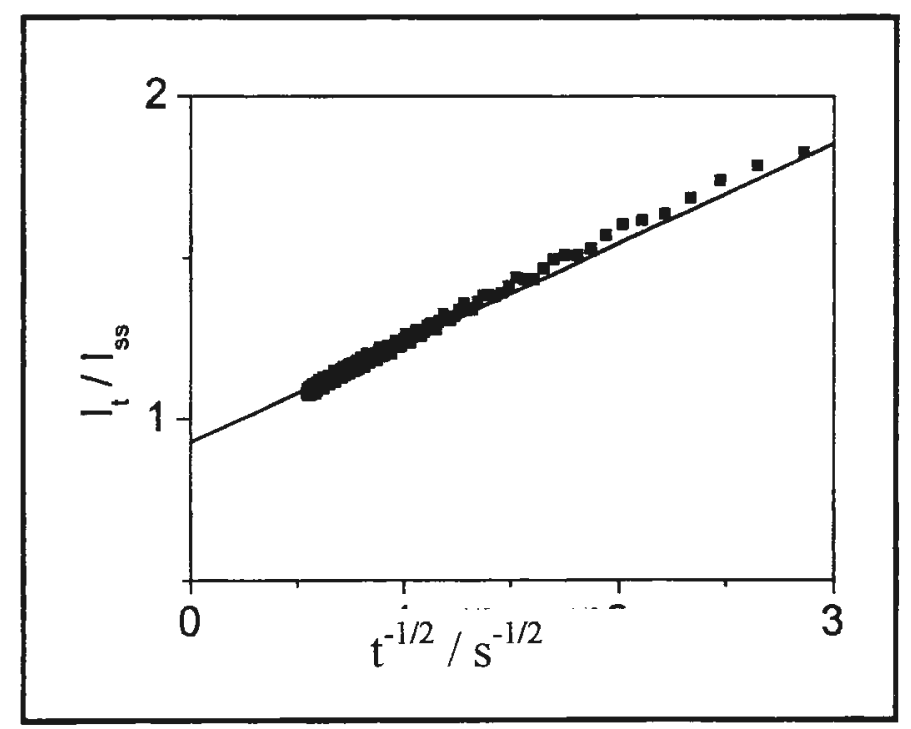

Figura 15. Gráfico da dependência de $I_{t} / I_{s s}$ em função de $t^{-1 / 2}$ para a oxidação eletroquimica de $\mathrm{Fe}(\mathrm{CN})_{6}^{4-} 20 \mathrm{mM} \mathrm{em} \mathrm{KCl} I \mathrm{M}$ em experimento realizado com microeletrodo de platina $(r=$ $25 \mu \mathrm{m})$ polarizado em $+0,5 \mathrm{~V}$. 
Conforme já foi esclarecido anteriormente, a preparação de soluções saturadas em NO consiste em tarefa de dificil execução em face à facilidade de oxidação com formação de $\mathrm{NO}_{2}$. Em virtude do custo relativamente elevado de cilindros contendo o gás e devido à formação de $\mathrm{NO}_{2}$ em pressões elevadas, $\mathrm{NO}$ foi gerado de acordo com base na reação de redução de $\mathrm{HNO}_{3}$ com raspas de cobre em meio isento de oxigênio e usando-se solução de $\mathrm{NaOH}$ como retentora de possíveis traços do gás ácido $\mathrm{NO}_{2}$. $\mathrm{O}$ aparato abaixo descrito foi montado e utilizado com sucesso. Testes químicos para verificar a eficácia do procedimento envolveram o borbulhamento do gás gerado em tubo de ensaio contendo solução de iodeto desoxigenada em meio de ácido acético e algumas gotas de solução de amido. Uma vez que o NO não oxida o iodeto, pôde-se comprovar a ausência de $\mathrm{NO}_{2}$ pois após o borbulhamento não se observou a formação de solução azulada, característica do complexo iodo/amido. Para fins de comprovação, permitiu-se a entrada de ar no tubo de ensaio e imediatamente a solução adquiriu a coloração azul, ratificando a oxidação do $\mathrm{NO}$ a $\mathrm{NO}_{2}$ e subseqüente formação de iodo.

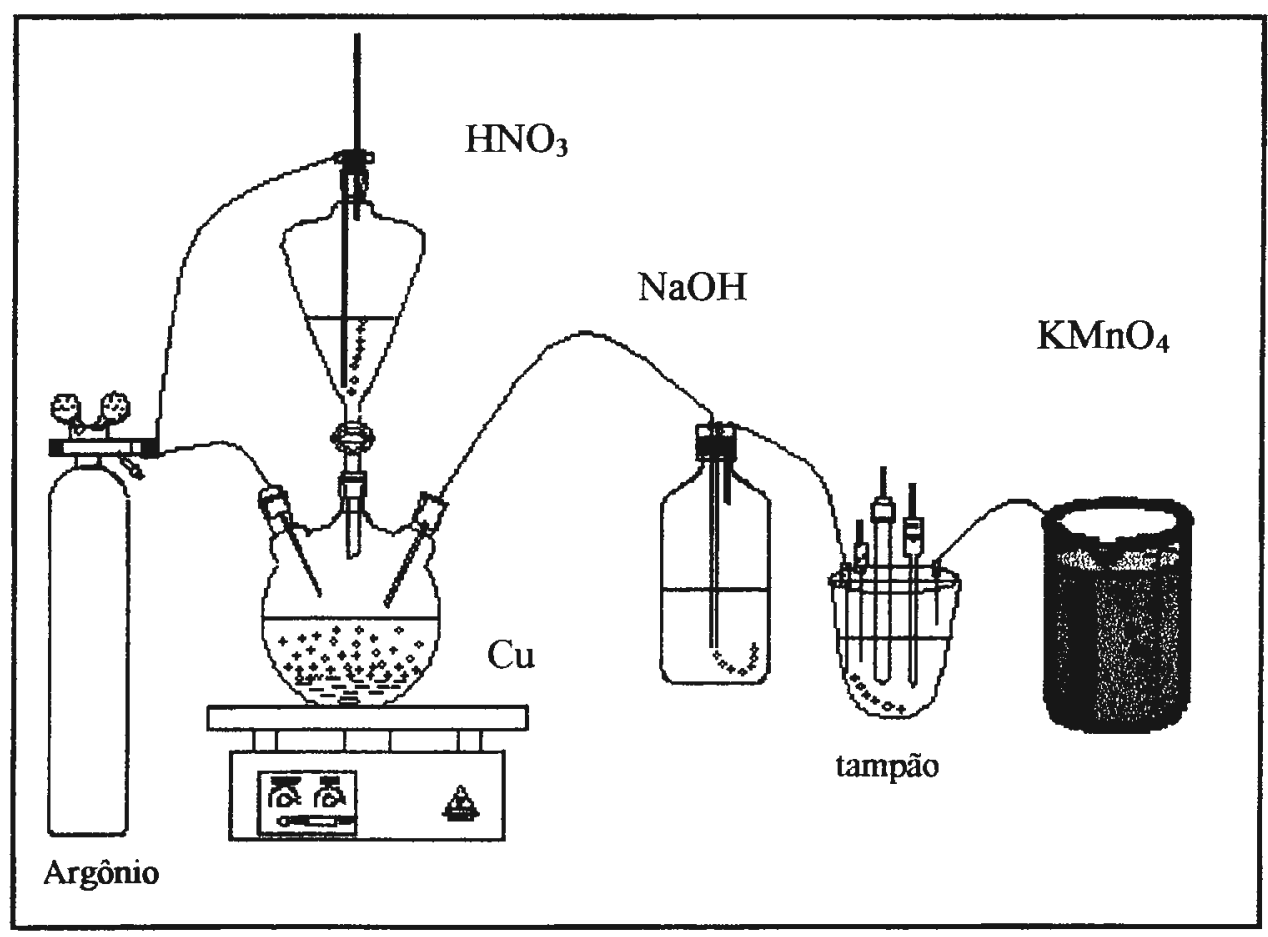

Figura 16. Esquema da aparelhagem usada na preparação de NO e saturação da solução tampão. 
$\mathrm{O}$ processo de oxidação eletroquímica do NO ocorre em potenciais próximos a $0,8 \mathrm{~V}$, a exemplo do que ocorre com nitrito. A Figura 17 apresenta voltamogramas em tampão fosfato registrados antes e após o borbulhamento de NO no eletrólito suporte. O processo representado pelo voltamograma $\mathrm{B}$ refere-se à oxidação do $\mathrm{NO} \mathrm{a} \mathrm{NO}^{+}$, de acordo com a seguinte equação:

$$
\mathrm{NO} \rightleftharpoons \mathrm{NO}^{+}+\mathrm{e}^{-}
$$

O cátion nitrosônio só é formado em meio muito ácido, condição na qual ele é estabilizado. Nas condições de $\mathrm{pH}$ em que se trabalhou forma-se nitrito, como segue:

$$
\mathrm{NO}^{+}+\mathrm{H}_{2} \mathrm{O} \rightleftharpoons \mathrm{HNO}_{2}+\mathrm{H}^{+}
$$

Uma vez que nitrito também pode ser oxidado em potenciais similares, verificou-se sua ausência na solução removendo-se totalmente o NO pela passagem de argônio na solução de trabalho. $O$ voltamograma $\mathrm{C}$ da Figura 17 comprova que nitrito não foi gerado na solução tampão durante o borbulhamento do $\mathrm{NO}$, reforçando as conclusões anteriores sobre a eficácia do procedimento empregado para a preparação do gás e saturação da solução.

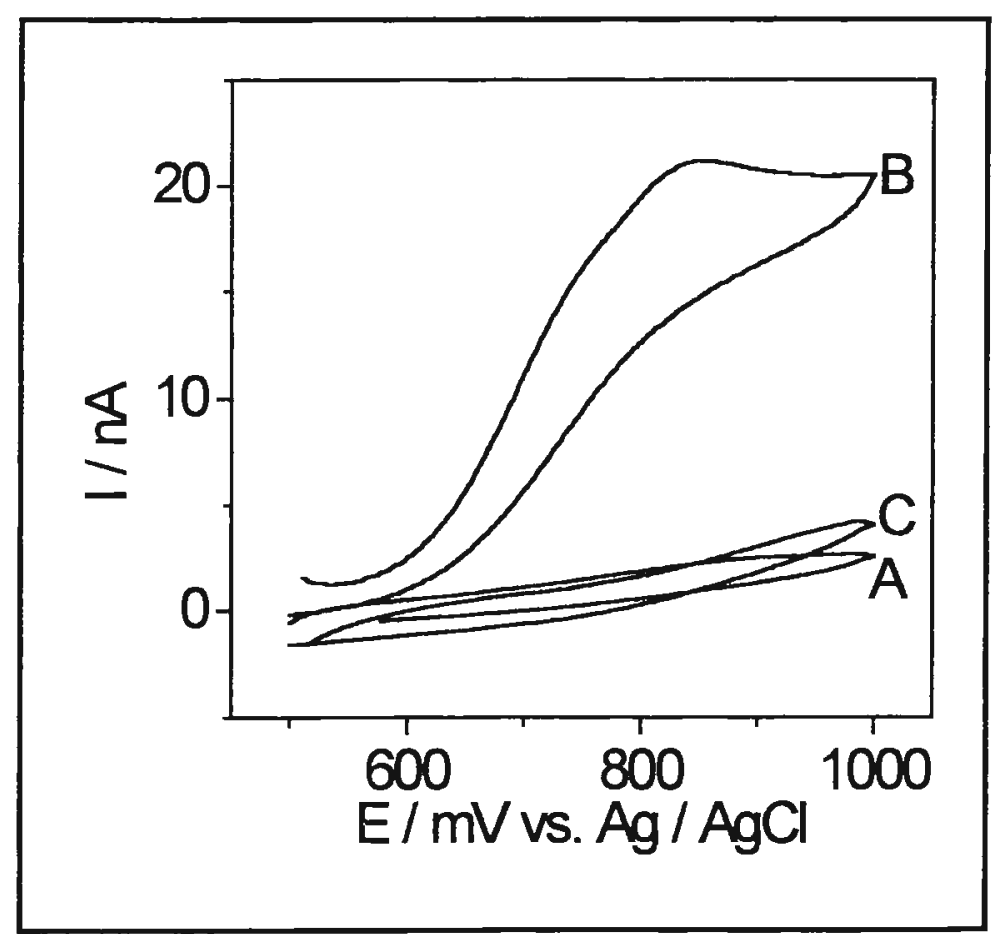

49
Figura 17. Voltamogramas obtidos com microeletrodo de disco de platina $(r=25 \mu \mathrm{m})$ em solução tampão fosfato antes (A) e após (B) saturação com NO. $O$ voltamograma $C$ foi registrado após remoção total do NO pelo borbulhamento do tampão com argônio por 15 minutos. Velocidade de varredura $=5 \mathrm{mVs}^{-1}$. 
A determinação do coeficiente de difusão empregando-se o método proposto pressupõe que o processo de eletrodo é governado por difusão. $O$ trabalho com microeletrodos de disco de diferantes raios permite que se altere o coeficiente de transporte de massa à semelhança do que ocorre com eletrodo rotativo e estudos similares já foram realizados no caso da oxidação anódica de nitrito [156]. Desta forma, investigações em solução saturada de NO foram efetuadas medindo-se a corrente limite para voltamogramas registrados em baixas velocidades de varredura utilizando-se vários microeletrodos de platina. Os dados apresentados na Figura 18 confirmam que o processo eletródico referente à oxidação do NO é controlado pelo transporte de massa.

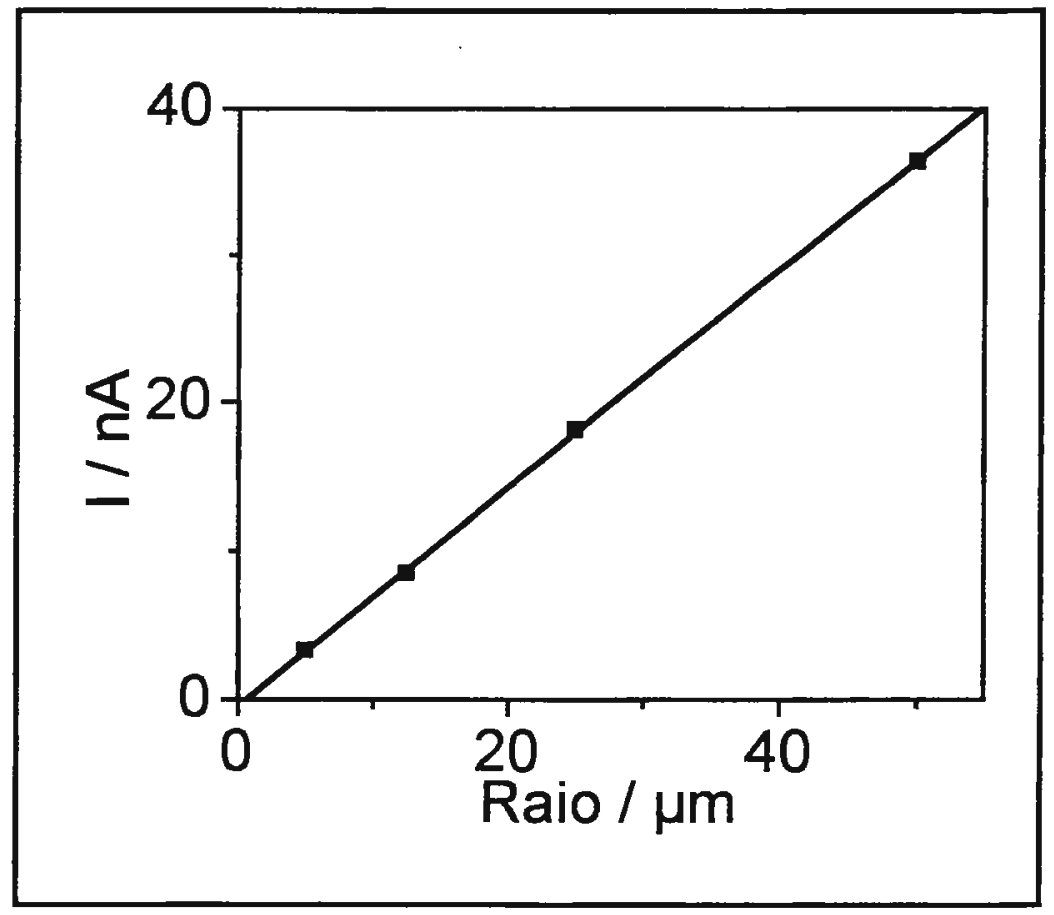

Figura 18. Dependência da corrente limite medida em $+0,9$ V para voltamogramas registrados em solução saturada de $N O(E=0,9 \mathrm{~V})$ em função do raio dos microeletrodos de platina.

Empregando o mesmo procedimento adotado para a determinação do coeficiente de difusão do ferrocianeto, experimentos foram então realizados com a solução saturada de NO. A Figura 19 mostra os dados obtidos e observa-se que a reta resultante $\left(\left(\mathrm{I}_{\mathrm{t}} / \mathrm{I}_{\mathrm{ss}}=0,97+0,26 \mathrm{t}^{-1 / 2}, \mathrm{r}^{2}\right.\right.$ $=0,997$ ) apresenta coeficiente linear próximo de 1 . $\mathrm{O}$ valor de $\mathrm{D}$ calculado com base no coeficiente angular foi $(1,2 \pm 0,1) \times 10^{-5} \mathrm{~cm}^{2} \mathrm{~s}^{-1}$, em concordância com valor citado na literatura após adequada correção da viscosidade da solução para fins de comparação [157]. Levando em 
consideração o valor da corrente de estado estacionário e o valor do coeficiente de difusão obtido calculou-se a concentração da solução saturada de NO com base na equação que descreve a corrente limite para um microeletrodo de disco, obtendo-se como resultado $(2,1 \pm 0,3) \mathrm{mM}$. Este valor foi comparado procedendo-se a análises volumétricas da solução saturada de NO por meio de adição de alíquota conhecida de solução padronizada de $\mathrm{KMnO}_{4}$ e subseqüente titulação potenciométrica do excesso do oxidante com solução padrão de $\mathrm{Fe}$ (II). O resultado obtido foi $(1,95 \pm 0,02) \mathrm{mM}$, em boa concordância com o valor resultante do uso do método cronoamperométrico e com dados obtidos relativos à solubidade de gases em líquidos [158,159].

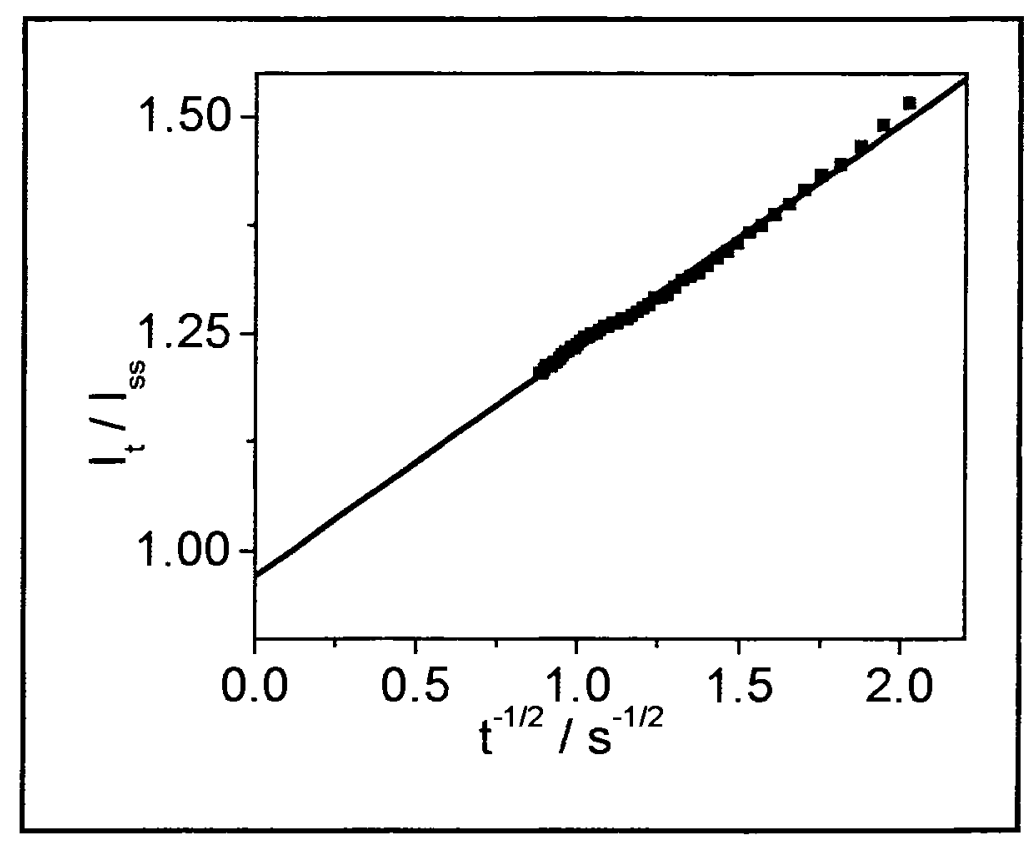

Figura 19. Gráfico da dependência de $I_{t} / I_{s s}$ em função de $t^{-1 / 2}$ para a oxidação eletroquímica de NO presente em solução saturada em experimento realizado com microeletrodo de platina $(r=25 \mu m)$ polarizado em $+0,9 \mathrm{~V}$.

Os resultados apresentados demonstram que o método cronoamperométrico pode ser uma alternativa eficaz para a determinação da concentração de soluções contendo uma espécie eletroativa cujo coeficiente de difusão é desconhecido. Vale ressaltar que no caso do NO a determinação deste parâmetro (D) é particularmente importante uma vez que a difusibilidade do metabólito em fluidos biológicos tem implicações relacionadas a reações com oxigênio e outras substâncias e à distância percorrida desde sua sintese [160]. 
3.3.3 Utilização de microeletrodos na determinação de constantes cinéticas em processos catalíticos envolvendo espécies químicas em solução

Em estudos realizados em meio de $\mathrm{HCOOH} 0,1 \mathrm{M}$ verificou-se a existência de processo catalítico na redução de $\mathrm{Ru}(\mathrm{III})$ em presença de íons nitrito devido à reação entre $\mathrm{Ru}(\mathrm{II})$ eletroquimicamente gerado e o substrato conforme apresentado no seguinte esquema catalítico (Figura 20) [161]:

$$
\begin{array}{ll}
\mathrm{Ru}(\mathrm{III})+\mathrm{e}^{-} \rightleftharpoons \mathrm{Ru}(\mathrm{II}) & \text { etapa eletroquímica } \\
\mathrm{Ru}(\mathrm{II})+\mathrm{NO}_{2}^{-} \rightleftharpoons \mathrm{Ru}(\mathrm{III})+\mathrm{NO}(?) & \text { etapa química }
\end{array}
$$

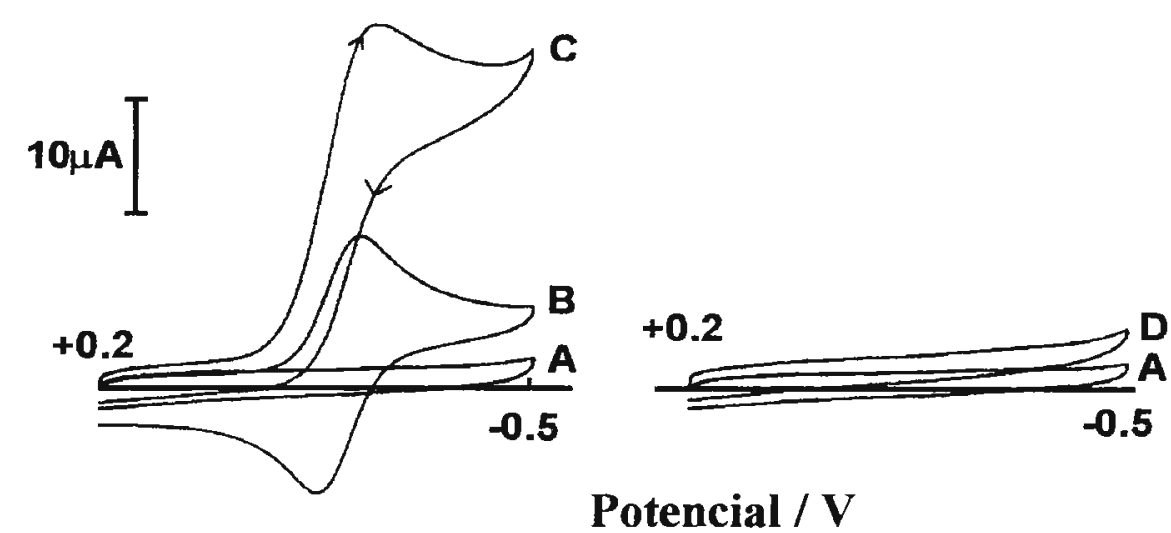

Figura 20. Voltamogramas de solução de $\mathrm{KCl}$ 0,1 M+HCOOH $50 \mathrm{mM}(\mathrm{A}), A+R u$ (III) $1 \mathrm{mM}(\mathrm{B}), B+$ nitrito $10 \mathrm{mM}(C)$. O voltamograma $D$ corresponde ao eletrólito suporte contendo nitrito $10 \mathrm{mM}$. Eletrodo de carbono vitreo, $v=50 \mathrm{mVs}^{-1}$.

Com vistas à construção de eletrodo modificado contendo rutênio como catalisador para a redução de nitrito, estudou-se o sistema com auxílio de microeletrodos. Um dos parâmetros importantes na caracterização do processo eletródico diz respeito à determinação da constante cinética da reação envolvendo a espécie imobilizada e o substrato. Neste sentido, o uso de microeletrodos constitui-se em ferramenta valorosa em estudos cinéticos uma vez que pode-se controlar o fluxo de material variando-se o raio do microeletrodo, estabelecendo-se desta forma competição entre as velocidades de regeneração química da espécie eletroativa e de difusão da espécie gerada eletroquimicamente no eletrodo [57,58]. Observa-se na Figura 21 o efeito da 
diminuição do raio do microeletrodo no valor da razão $I_{k} / I_{d}$; quanto menor o raio, mais eficiente é o transporte do $\mathrm{Ru}(\mathrm{II})$ eletroquimicamente gerado para o seio da solução, com a conseqüente diminuição da extensão da reação de regeneração de Ru(III).
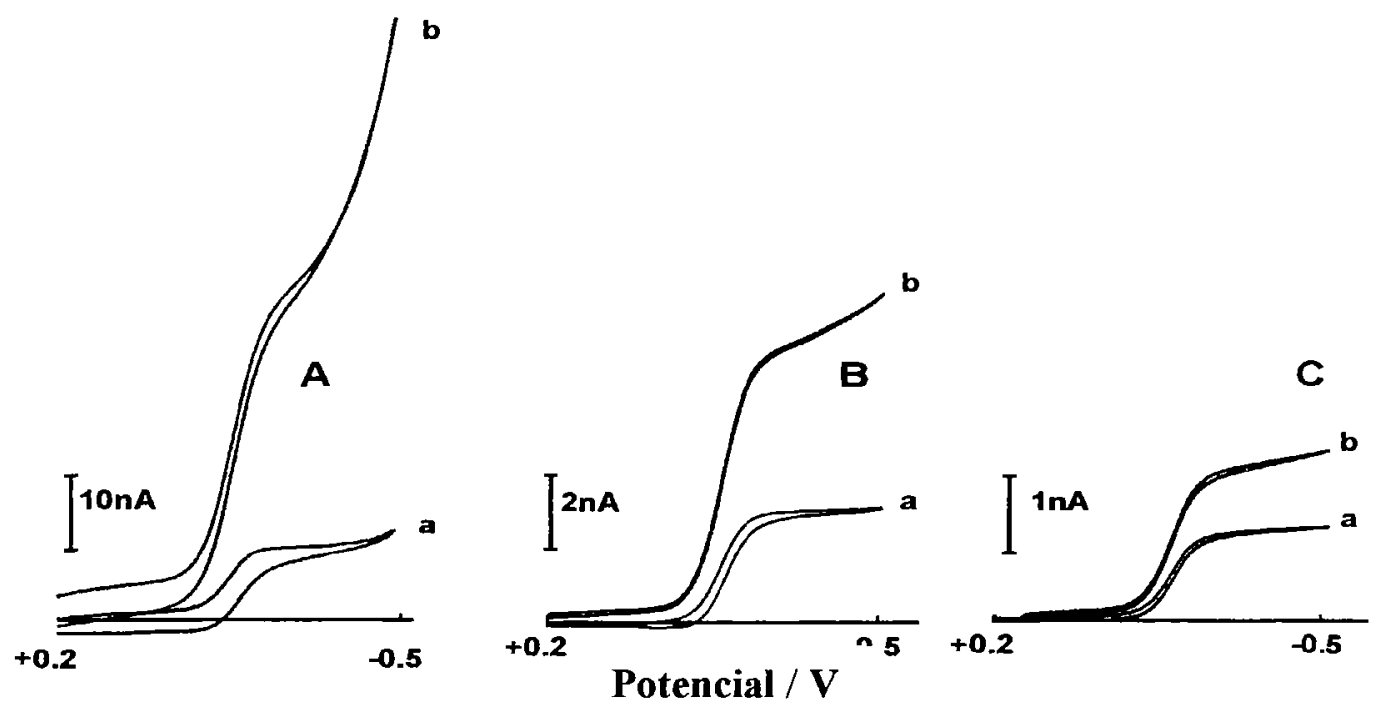

Figura 21. Voltamogramas de solução de Ru (III) $1 \mathrm{mM}+\mathrm{HCOOH} \mathrm{0,1} \mathrm{M+KCl} \mathrm{0,1} \mathrm{Mantes} \mathrm{(a)} \mathrm{e} \mathrm{após}$ (b) adição de nitrito $30 \mathrm{mM}$ empregando-se microeletrodos de Au de diferentes raios: (A) 30, (B) $12,5 \mathrm{e}$ (C) $5 \mu m .\left(v=10 \mathrm{mVs}^{-1}\right)$.

A constante cinética da reação química pode ser determinada utilizando-se a equação que relaciona a corrente de estado estacionário referente a processo eletroquímico de uma espécie Ox num microeletrodo na ausência $\left(\mathrm{I}_{d}\right)$ e presença $\left(\mathrm{I}_{k}\right)$ do substrato $Z$ [81]:

$$
\frac{I_{k}}{I_{d}}=1+\frac{\pi r}{4}\left(\frac{k C}{D}\right)^{1 / 2}
$$

onde $\mathrm{r}=$ raio do microeletrodo, $\mathrm{k}=$ constante de velocidade da reação quimica entre o produto da redução de $\mathrm{Ox}$ e $Z, C$ = concentração do substrato $(Z)$ e $D=$ coeficiente de difusão da espécie eletroativa. Desta forma, gráficos envolvendo a dependência da razão $I_{k} / I_{d}$ em função da concentração do substrato (Figura 22) ou do raio do microeletrodo (Figura 23) devem apresentar retas com coeficiente linear $=1$ e coeficiente angular contendo o valor da constante a ser 
determinada. Com base nos dados obtidos o valor da constante de velocidade da reação envolvendo $\mathrm{Ru}(\mathrm{II})$ e nitrito em meio de $\mathrm{HCOOH} \mathrm{0,1} \mathrm{M}$ foi estimada como sendo da ordem de $4 \times 10^{2} \mathrm{M}^{-1} \mathrm{~s}^{-1}$.

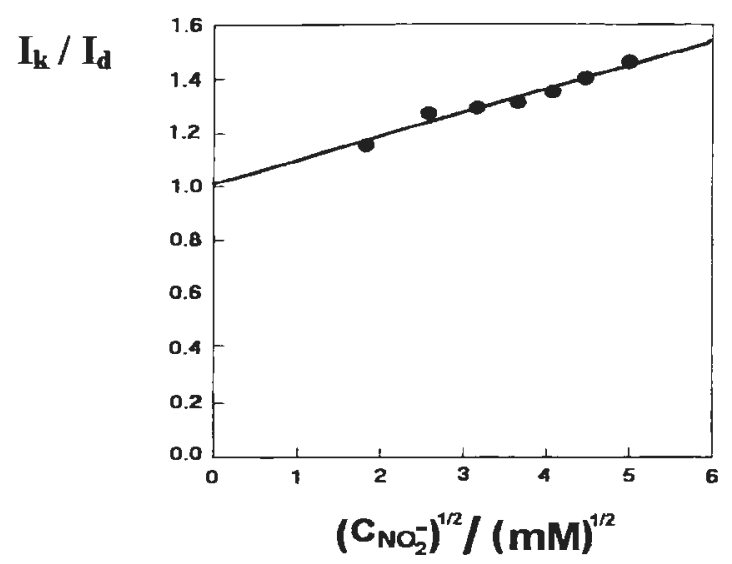

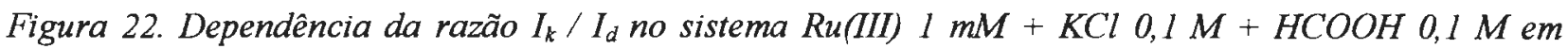
função da raiz quadrada da concentração de nitrito. Microeletrodo de $\mathrm{Au}(r=5 \mu \mathrm{m}), v=20 \mathrm{mV} \mathrm{\textrm {s } ^ { - I }}$.

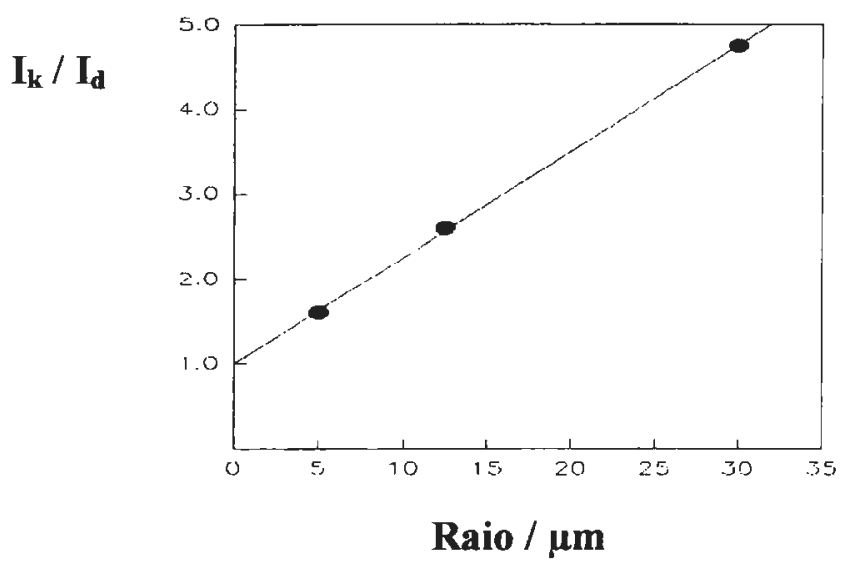

Figura 23. Dependência da razão $I_{k} / I_{d}$ em função do raio do microeletrodo de $A u I_{d}=$ corrente limite para sistema Ru (III) $1 \mathrm{mM}+\mathrm{KCl} 0,1 \mathrm{M}+\mathrm{HCOOH} 0.1 \mathrm{M}, \mathrm{I}_{k}=$ corrente limite após adição de nitrito 30 $m M)$. 
Outro processo catalítico estudado de maneira semelhante consiste na redução do iodo em meio contendo excesso de nitrito. Este processo catalítico é particularmente importante pois nosso grupo de pesquisa tem se valido da reação entre o oxidante e iodeto no desenvolvimento de métodos analíticos para a quantificação indireta de nitrito monitorando-se a quantidade de triiodeto formada. No presente caso o sistema catalítico pode ser expresso pelas seguintes equações:

$$
\begin{array}{ll}
\mathrm{I}_{2}+2 \mathrm{e}^{-} \rightleftharpoons 2 \mathrm{I}^{-} & \text {etapa eletroquímica } \\
2 \mathrm{I}^{-}+2 \mathrm{NO}_{2}^{-}+4 \mathrm{H}^{+} \longrightarrow \mathrm{I}_{2}+2 \mathrm{NO}+2 \mathrm{H}_{2} \mathrm{O} & \text { etapa química }
\end{array}
$$

Portanto, em experimentos eletroquímicos envolvendo a redução de iodo, forma-se iodeto o qual na presença do íon nitrito é reoxidado a iodo. Devido a esse processo catalítico ocorre um aumento na corrente limite. A Figura 24 mostra o resultado dos voltamogramas cíclicos da solução contendo $1 \mathrm{mM}$ de iodo em $25 \mathrm{mM}$ de ácido sulfúrico antes e depois da adição de 10 $\mathrm{mM}$ de nitrito. Um eletrodo de platina de tamanho convencional $(\mathrm{r}=0,75 \mathrm{~mm})$ e microeletrodos $(r=5$ e $50 \mu \mathrm{m})$ foram usados para confirmar o efeito da difusão radial sobre a corrente catalítica e conforme o esperado observa-se que com diminuição do raio do microeletrodo, a espécie eletroquimicamente gerada (iodeto) é mais eficientemente removida das proximidades da superficie do eletrodo e a contribuição catalítica é minimizada.

A aproximação usada na determinação da constante de velocidade foi baseada na suposição de que a reação homogênea é de pseudo - primeira ordem. Che e Dong [81] têm relatado que ao se usar microeletrodos esta condição é dependente da razão entre as concentrações do substrato e da espécie eletroativa, do raio do microeletrodo e da constante de velocidade. Reações de pseudo-primeira ordem são obtidas diminuindo-se o raio do microeletrodo, aumentando a concentração do substrato ou para reações com baixa constante de velocidade $(k)$, valendo então a equação (13).

Usando um microeletrodo de raio nominal $=25 \mu \mathrm{m}$, voltamogramas no estado estacionário foram registrados para soluções contendo $1 \mathrm{mM}$ de iodo e $25 \mathrm{mM}$ de $\mathrm{H}_{2} \mathrm{SO}_{4}$ e várias concentrações de nitrito de 0 a $10 \mathrm{mM}$. $O$ gráfico da razão $I_{k} / I_{d}$ em função da raiz quadrada da concentração de nitrito conduziu a reta com coeficiente linear próximo de $1\left(I_{k} / I_{d}=1,03+11,4\right.$ 
$\mathrm{C}^{1 / 2}$ nitrito). A constante cinética foi determinada com base no coeficiente angular da reta, obtendose um valor de $\mathrm{k}=320 \mathrm{M}^{-1} \mathrm{~s}^{-1}$. Nos cálculos utilizou-se $D_{\text {iodo }}=9,43 \times 10^{-6} \mathrm{~cm}^{2} \mathrm{~s}^{-1}$ [146] e raio real do microeletrodo $=24,8 \mu \mathrm{m}$.

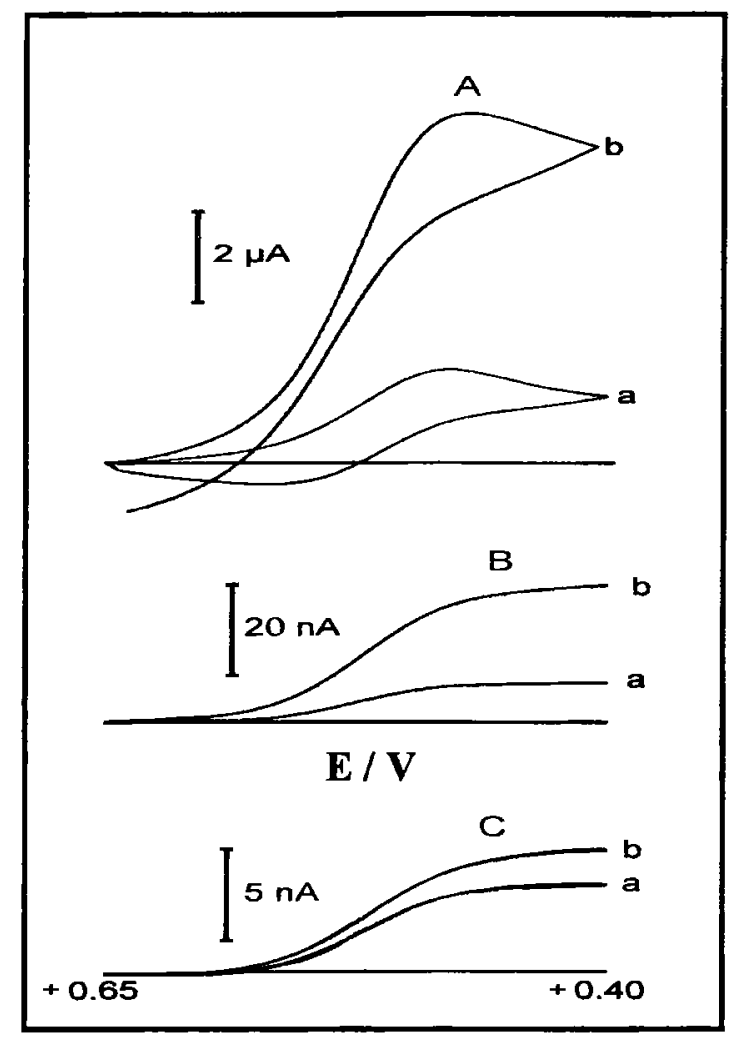

Figura 24. Voltamogramas das soluções contendo $1 \mathrm{mM}$ de iodo $e$ $25 \mathrm{mM}$ de ácido sulfúrico antes (a) $e$ depois (b) da adição de $10 \mathrm{mM}$ de nitrito, usando eletrodos de diferentes raios: $\quad A=750 \mu \mathrm{m}, \quad B$ $=50 \mu \mathrm{m}$ e $C=5 \mu \mathrm{m}$. Velocidade de varredura $5 \mathrm{mVs}^{-1}$.

De acordo com a literatura [162], para uma reação catalítica ser considerada de pseudo primeira ordem a razão entre a concentração do substrato (nitrito) e a espécie eletrogerada (iodeto) na superficie do eletrodo deve ser maior que $6,7 \mathrm{D}_{\text {iodeto }} / \mathrm{D}_{\text {nitrito. }} \mathrm{A}$ concentração de iodeto nas proximidades da superficie do eletrodo depende tanto da extensão da camada de difusão (efeito do raio do microeletrodo) como da camada de reação (efeito da constante cinética). Uma vez que a constante cinética não é muito grande e o microeletrodo tem raio relativamente pequeno, a concentração de iodeto na superfície do eletrodo é provavelmente muito menor que a concentração de nitrito em todos os experimentos. Esta suposição pode ser confirmada analisando-se as curvas calculadas nos trabalhos de Che e Dong [81], as quais mostram o efeito do raio dos microeletrodos e da constante de velocidade sobre a razão entre a concentração do substrato e a espécie eletrogerada na superficie do eletrodo. De acordo com 
esses dados, reações químicas com constantes de velocidade menores que $10^{3} \mathrm{M}^{-1} \mathrm{~s}^{-1}$ podem ser satisfatoriamente tratadas como se fossem de pseudo - primeira ordem trabalhando-se com microeletrodos de raio não superior a $25 \mu \mathrm{m}$, justificando o uso da equação [13] neste trabalho.

A reação química entre iodo e nitrito foi também investigada preliminarmente empregando-se a associação onde se usa um microeletrodo como detector eletroquímico em sistema convectivo. Esta combinação é particularmente útil pois possibilita a determinação de constantes de velocidade extremamente elevadas em função do eficiente transporte de material na solução [85]. Assim sendo, voltamogramas hidrodinâmicos de uma solução $0,5 \mathrm{mM}$ em $\mathrm{I}_{2} \mathrm{em}$ meio ácido foram registrados com uma velocidade de varredura de $10 \mathrm{mV} \mathrm{s}^{-1}$, numa faixa de potencial de $+0,60 \mathrm{a}+0,35 \mathrm{~V}$, em solução estacionária e em situação de convecção forçada mantida pela variação da velocidade do fluxo do material eletroativo.

A Figura 25 mostra um gráfico onde a corrente do estado estacionário para voltamogramas hidrodinâmicos de iodo na presença e ausência de nitrito foi medida em várias velocidades de fluxo, usando como eletrodo de trabalho um eletrodo de platina de tamanho convencional $(r=0,75 \mathrm{~mm})$ e um microeletrodo $(r=5 \mu \mathrm{m})$. O efeito da convecção sobre a razão $\mathrm{I}_{\mathrm{k}} / \mathrm{I}_{\mathrm{d}}$ é pouco notado para um microeletrodo, onde prevalece a difusão radial como modo predominante de transporte de massa. Estes resultados demonstram que estudos em sistemas catalíticos com constantes cinéticas muito elevadas, os quais demandariam microeletrodos de raios sub-micrométricos, podem ser adequadamente realizados aumentando-se ainda mais a eficiência no transporte de massa trabalhando-se em fluxo.

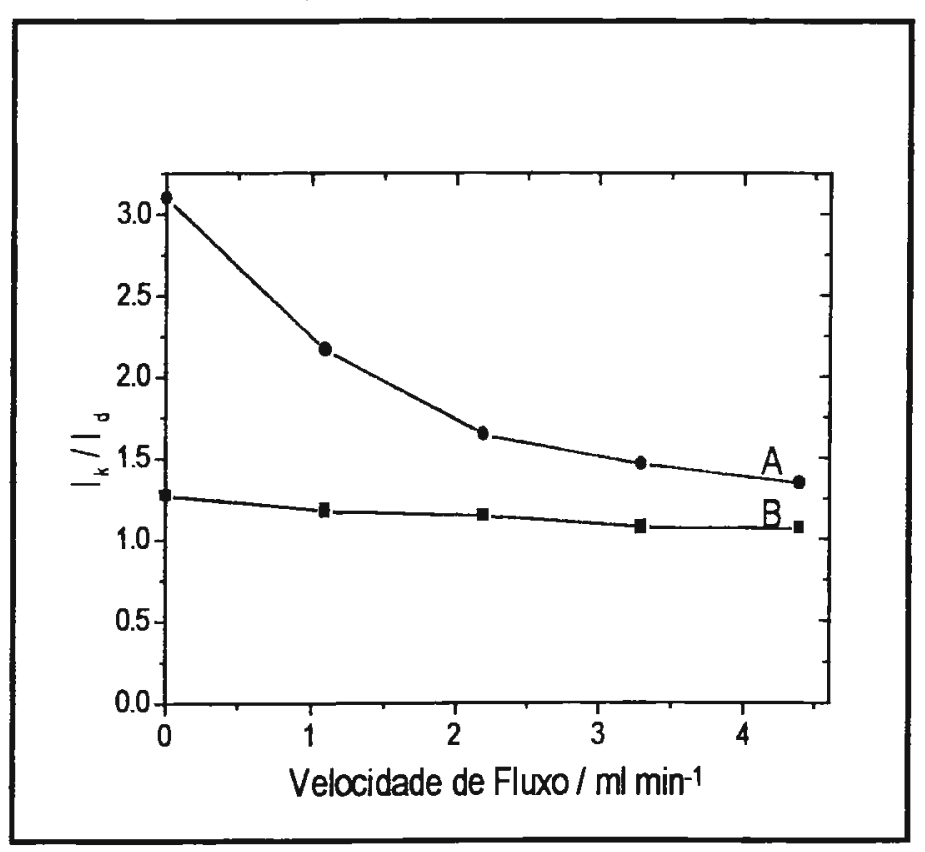

Figura 25. Gráfico da dependência de $I_{k}$ $I_{d} I_{d}=$ corrente limite para solução transportadora contendo iodo $1 \mathrm{mM}+$ ácido sulfúrico $25 \mathrm{mM}, I_{k}=$ corrente limite para a solução transportadora contendo também nitrito $10 \mathrm{mM}$ ) em função da velocidade de fluxo. Registros dos voltamogramas hidrodinâmicos com um eletrodo de tamanho convencional ( $r$ $=0,75 \mathrm{~mm})(A)$ e um microeletrodo $(r=$ 5 um) (B). Velocidade de fluxo = $10 \mathrm{mVs}^{-1}$. 
3.3.4 Determinação de constantes de velocidades por cronoamperometria de duplo degrau de potencial

A importância da molécula de $\mathrm{NO}$ em organismos vivos tem sido reconhecida nos últimos anos em razão de sua ação em diversos mecanismos regulatórios. Neste contexto, a busca de compostos que permitam a liberação controlada desta substância são de interesse e um dos focos de investigações tem sido a síntese de estruturas que tenham atividade similar a enzimas como a nitrito reductase. Neste trabalho são apresentados os resultados de estudos eletroquímicos sobre a redução de complexos $\left[\mathrm{Ru}\left(\mathrm{NH}_{3}\right)_{4} 4-\mathrm{L} \mathrm{NO}\right]^{3+}$ em meio ácido. Estudos anteriores demonstraram que a reatividade da molécula, no que diz respeito à liberação do NO, pode ser controlada em função da interação do outro ligante (em posição trans em relação ao NO) com o centro metálico [163]. Empregando-se técnica cronoamperométrica de duplo degrau de potencial foram obtidos dados cinéticos referentes à dissociação do NO em compostos onde $\mathrm{L}=$ Pic (picolina) e Py (piridina).

$\mathrm{O}$ voltamograma cíclico do composto $\left[\mathrm{Ru}\left(\mathrm{NH}_{3}\right)_{4} 4-\mathrm{Pic} \mathrm{NO}\right]^{3+}$ registrado a $5 \mathrm{mV} \mathrm{s}^{-1} \mathrm{em}$ meio de $\mathrm{CF}_{3} \mathrm{COOH}(\mathrm{pH}=1)$ apresenta $\mathrm{E}_{\mathrm{pc}}=-0.30 \mathrm{~V} \mathrm{e} \mathrm{E}_{\mathrm{pa}}=-0,07 \mathrm{~V}$ e neste processo de eletrodo ocorre a redução do $\mathrm{NO}^{+}$(coordenado ao centro metálico) a NO [164]. Após a etapa de transferência de elétrons, pode ocorrer dissociação da molécula de NO caracterizando o processo $\mathrm{EC}$ de acordo com as equações:

$$
\begin{aligned}
& {\left[\mathrm{Ru}\left(\mathrm{NH}_{3}\right)_{4} 4-\mathrm{L} \mathrm{NO}\right]^{3+}+\mathrm{e}-\rightleftharpoons\left[\mathrm{Ru}\left(\mathrm{NH}_{3}\right)_{4} 4-\mathrm{L} \mathrm{NO}\right]^{2+}} \\
& {\left[\mathrm{Ru}\left(\mathrm{NH}_{3}\right)_{4} 4-\mathrm{L} \mathrm{NO}\right]^{2+}+\mathrm{H}_{2} \mathrm{O} \rightleftharpoons\left[\mathrm{Ru}\left(\mathrm{NH}_{3}\right)_{4} 4-\mathrm{L} \mathrm{H}_{2} \mathrm{O}\right]^{2+}+\mathrm{NO} \quad \text { (etapa química) }}
\end{aligned}
$$

$\mathrm{Na}$ determinação da constante de velocidade da etapa química com a técnica de duplo pulso de potencial (limites $=+0,20 \mathrm{~V} \mathrm{e}-0,45 \mathrm{~V}$ ) monitorou-se a variação da corrente durante os processos catódico e anódico e com base em curvas de trabalho descritas na literatura [165] calculou-se $\mathrm{o}$ valor de $\mathrm{k}=1,0 \times 10^{-2} \mathrm{~s}^{-1}$. Experimentos semelhantes foram realizados para $\mathrm{o}$ composto de rutênio contendo Py como segundo ligante e o valor obtido foi de $\mathrm{k}=2,4 \times 10^{-3} \mathrm{~s}^{-1}$. Estas diferenças estão relacionadas à estrutura dos ligantes coordenados ao centro metálico; uma vez que a picolina possui efeito indutivo mais efetivo no sentido de doação de elétrons do que a piridina, é de se esperar uma substituição mais fácil do NO por molécula de $\mathrm{H}_{2} \mathrm{O}$ quando o ligante localizado em posição trans no complexo for a picolina. Estudos no sentido de imobilizar 
os compostos de rutênio contendo diferentes ligantes em eletrodos sólidos estão sendo realizados e poderão viabilizar o desenvolvimento de sensor para a determinação do NO em matrizes de interesse biológico.

3.3.5 Investigações eletroquimicas sobre a formação de Cu(III) em meio complexante com eletrodo rotativo disco-anel

O estado trivalente de oxidação do cobre aparece em determinados compostos, em sua maioria não estáveis em solução aquosa [166]. Certos ligantes são capazes de estabilizar o Cu (III) gerado pela oxidação do $\mathrm{Cu}$ (II) via oxigênio dissolvido, em processo mediado por determinados substratos [167], ocorrendo, porém, posterior autoxidação do ligante. Outra forma de geração dessa espécie consiste na decomposição catalisada de $\mathrm{OCl}^{-}$e $\mathrm{OBr}^{-}$por hidróxido de cobre (II), em um processo envolvendo duas etapas, no qual ocorre a formação de um intermediário amarelado atribuído por Taylor e colaboradores a um complexo dimérico de hidróxido de cobre (III) [168]. Além desses, existem também complexos de $\mathrm{Cu}$ (III) azuis ou roxos, sintetizados na presença de ligantes apropriados e caracterizados por espectrofotometria [169].

No presente trabalho estudou-se a formação de $\mathrm{Cu}$ (III) via oxidação do $\mathrm{Cu}$ (II) complexado à tetraglicina [CuG4] pelo oxigênio dissolvido em processo catalisado pelo sulfito[170]. Uma vez que o par $\mathrm{Cu}(\mathrm{II}) / \mathrm{Cu}(\mathrm{III})$ em meio complexante apresenta ondas voltamétricas bem definidas com correntes limites dependentes da proporção relativa das espécies, experimentos com eletrodo rotativo anel-disco foram realizados objetivando-se a caracterização do processo eletródico.

A Figura 26 apresenta os voltamogramas obtidos em solução de [CuG4] em tampão pH 10 antes (A) e após (B) a adição de $\mathrm{SO}_{3}{ }^{2-}$ utilizando um eletrodo rotativo de disco de carbono vítreo. Nota-se a existência de um componente anódico de corrente na Figura 26A, indicando que a espécie coordenada de $\mathrm{Cu}$ (II) pode sofrer processo eletroquímico de oxidação gerando a espécie trivalente. $\mathrm{Na}$ presença de sulfito (Figura 26B), o voltamograma não apresenta antecipação nem postergação de seu $E_{1 / 2}$, indicando que o processo de eletrodo permanece o mesmo. Porém, em relação à corrente, observa-se a diminuição da intensidade do componente anódico, com conseqüente compensação pelo aparecimento de um componente catódico. Tal fato 
demonstra haver a formação química de Cu (III) com a adição de sulfito à solução, aparecendo o sinal catódico de corrente relativo à redução dessa espécie; a redução na quantidade de $\mathrm{Cu}$ (II) provoca a diminuição de seu sinal de oxidação eletroquímica.

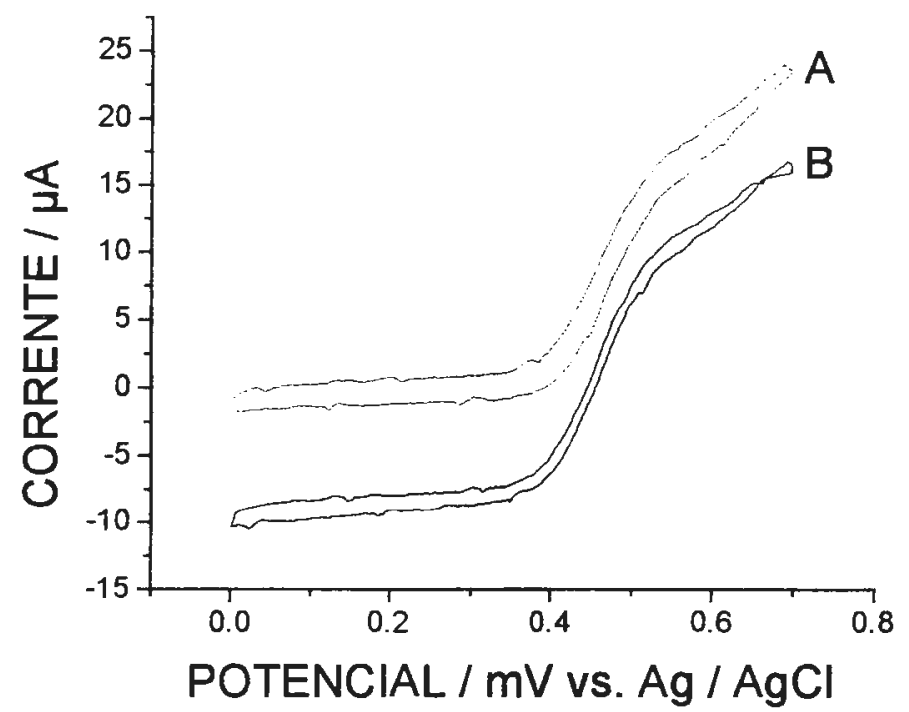

Figura 26. Voltamogramas cíclicos obtidos em solução tampão borato $\mathrm{pH} 10$, contendo $2.10^{-4} \mathrm{M}$ de [CuG4], com eletrodo rotativo de carbono vitreo a $900 \mathrm{rpm}$ antes (A) e após (B) adição de sulfito até concentração final de $1.10^{-4} \mathrm{M}$. Velocidade de varredura $=50 \mathrm{mV} \mathrm{s}^{-1}$.

Para estudo da cinética do processo eletroquímico de geração do $\mathrm{Cu}(\mathrm{III})$, bem como de sua redução a $\mathrm{Cu}$ (II), empregou-se técnica de eletrodo rotativo disco-anel. A Figura 27 apresenta os voltamogramas obtidos com eletrodo rotativo disco-anel com 100 (B e C) e 900 rpm (A e D) em solução contendo [CuG4]. Pode-se observar que o sinal de corrente de redução no eletrodo de anel ocorre em função do aparecimento de sinal de oxidação no eletrodo de disco. Nota-se, também, que o aumento na velocidade de rotação ocasiona um aumento nos sinais de corrente do disco e do anel devido ao fator convectivo. 


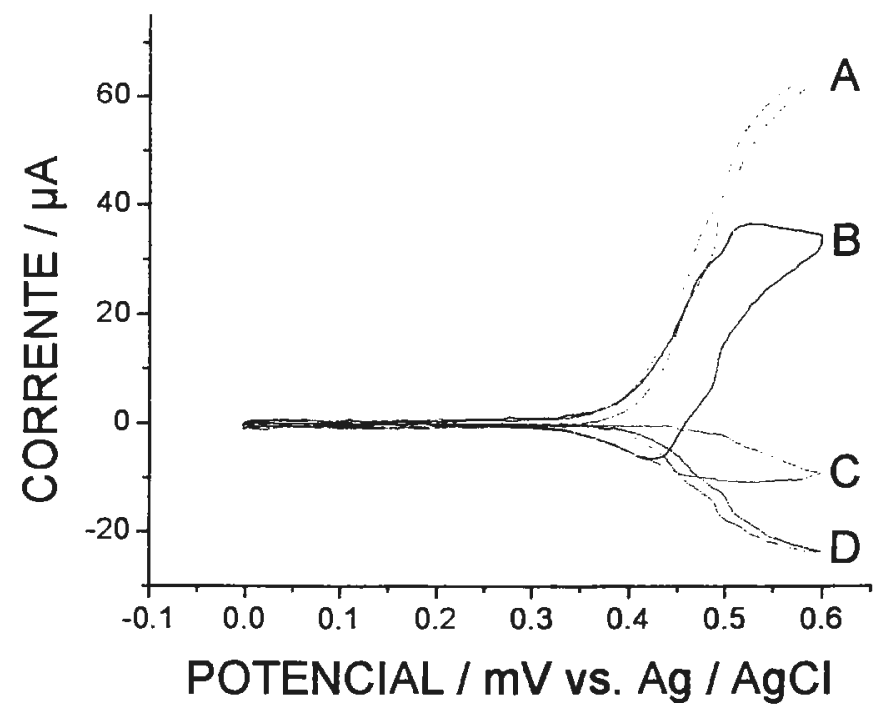

Figura 27. Voltamogramas com eletrodo rotativo disco-anel em solução de[CuG4] $1 \mathrm{mM}$ em pH 10 obtidos com velocidade de varredura de $50 \mathrm{mV} \mathrm{s}^{-1}$ : Disco: $A=900 \mathrm{rpm}$ e $B=100 \mathrm{rpm}$; Anel (potencial mantido fixo em $+0,1 \mathrm{~V}): C=100 \mathrm{rpm}$ e $D=900 \mathrm{rpm}$.

No caso da redução do Cu (III) (Figura 28B) e da oxidação do Cu (II) (Figura 28A), podese observar uma linearidade na dependência do processo eletroquímico com a raiz quadrada da velocidade de rotação do eletrodo somente para velocidades baixas, concordante com o trabalho de Woltman e colaboradores [171]. Desta forma, pode-se concluir que o processo não é controlado pelo transporte de massa em diferentes condições experimentais possivelmente devido à existência de etapa química de dissociação do complexo previamente à oxidação do $\mathrm{Cu}$ (II). As razões entre as intensidades de correntes de disco e de anel obtidas (fatores de coleta) variaram para as diferentes velocidades de rotação entre 0,26 (100 rpm) e 0,37 (4900 rpm), demonstrando a possibilidade de existência de uma etapa química ou de adsorção lenta entre a geração eletroquímica do $\mathrm{Cu}$ (III) e sua redução no anel, uma vez que tal processo de redução eletroquímica foi proporcionalmente mais significativo utilizando-se elevadas velocidades de rotação. Cabe frisar que estudos similares efetuados em solução de $\mathrm{Fe}(\mathrm{CN})_{6}{ }^{4}$ em $\mathrm{KCl} 0,1 \mathrm{M}$ conduziram a fatores de coleta $=0,37$ em larga faixa de velocidades de rotação. Ratificam-se portanto as conclusões sobre a existência de processo químico subseqüente à transferência eletrônica no sistema $\mathrm{Cu}(\mathrm{II}) / \mathrm{Cu}(\mathrm{III})$ em meio de tetraglicina. 


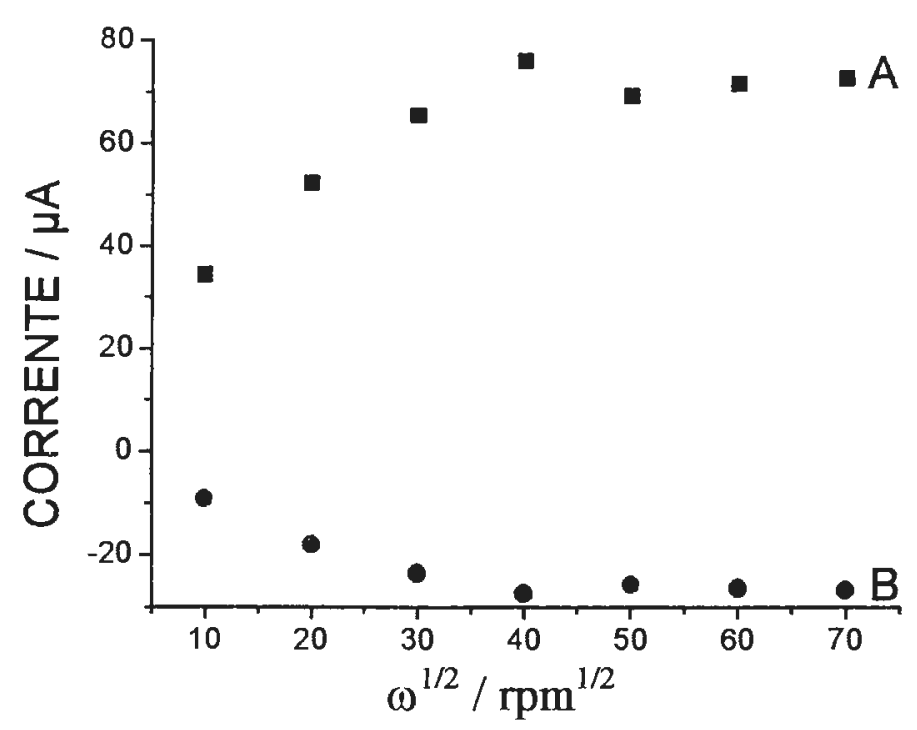

Figura 28. Dependência das correntes limite medidas em voltamogramas de solução contendo o complexo de Cu(II) com tetraglicina em função da raiz quadrada da velocidade de rotação: oxidação do Cu(II) no disco (A) e redução do Cu (III) no anel (B). 


\subsection{Estudos eletroquímicos relacionados a eletrodos modificados}

4.4.1 Deposição de filmes de óxidos de molibdênio em eletrodos sólidos: estudos estruturais, dinâmicos e cinéticos

A redução catalisada de oxiânions por compostos que possuem molibdênio, tungstênio, vanádio e urânio como sítios ativos tem sido alvo de interesse contínuo. Particularmente no que diz respeito ao molibdênio, estudos polarográficos têm demonstrado o efetivo papel de formas reduzidas deste íon metálico na catálise de processos redox envolvendo nitrato, clorato, bromato e perclorato [172-174]. Em todos estes casos, tem sido evocada a participação de $\mathrm{Mo}(\mathrm{III})$, Mo(IV) e Mo(V) (espécies geradas eletroquimicamente a partir de Mo(VI)) no processo catalítico; todavia, não há resultados conclusivos sobre a natureza da espécie catalítica. Este assunto é bem discutido por Lahr e colaboradores [175], os quais concluíram que o par de elétrons desemparelhados do átomo central do substrato é responsável pela ligação química com o catalisador na formação de intermediário lábil. Devido à maior polarizabilidade do bromo, a transferência de um átomo de oxigênio é mais facilitada no caso do bromato, explicando a alta reatividade deste substrato em comparação com clorato e nitrito.

Além de atuar como mediador de processos redox em solução, o molibdênio também pode facilitar a eletrorredução de certos substratos quando imobilizado em eletrodos sólidos. Nestes processos de fixação de materiais catalíticos na superficie de eletrodos há várias possibilidades, uma das quais sendo a deposição de compostos metálicos com estado de valência mista, excelentes mediadores de elétrons e transportadores de átomos de oxigênio $[176,177]$. Exemplo bastante citado na literatura consiste na deposição de filmes de óxidos de tungstênio em eletrodos sólidos; suas propriedades catalíticas [178] e eletrocrômicas [179] são largamente reconhecidas e investigadas.

Óxidos de molibdênio incluem-se na classe de modificadores de eletrodos acima citados e para tanto contribuem propriedades importantes justificando o uso na indústria de sensores e "displays" eletrocrômicos [180-182]. Apesar de haver vários métodos para a síntese destes compostos como deposição química a vácuo [183], "sputtering" [184] e oxidação térmica de sulfetos de molibdênio [185], métodos eletroquímicos apresentam vantagens relacionadas ao baixo custo da instrumentação e simplicidade do processo de deposição. Todavia, as características do filme gerado durante o processo eletroquímico são fortemente influenciadas 
pelos parâmetros experimentais, os quais levam à formação de compostos onde o íon metálico apresenta-se com diferentes níveis de oxidação [186].

A literatura tem mostrado que tais compostos podem ser depositados eletroquimicamente a partir de soluções de Mo(VI) em condições de acidez adequada [187-189]. Nestes casos são formados óxidos do tipo $\mathrm{MoO}_{3-\mathrm{x}}$, embora haja citações sobre a formação de compostos denominados "bronzes de molibdênio" $\left(\mathrm{H}_{\mathrm{y}} \mathrm{MoO}_{3}\right)$ onde o átomo de hidrogênio é inserido na molécula contendo molibdênio como átomo central [190]. Estudos sobre a estrutura cristalográfica, condutividade e propriedades eletrocrômicas destes bronzes são bastante difundidos na literatura [191-195]. Características atraentes destes filmes inorgânicos incluem elevada porosidade, condutividade eletrônica, relativa estabilidade química e seletividade na resposta eletroquímica para determinados oxiânions.

Conforme citado anteriormente, a ciclagem consecutiva de potencial em solução de $\mathrm{Mo}$ (VI) de $\mathrm{pH}$ apropriado conduz à deposição de material eletroativo conforme apresenta-se na Figura 29. Estes filmes foram caracterizados por técnica de análise de superfície (Rutherford Back Scattering), resuitando em composto com fórmula mínima $\mathrm{MoO}_{2,78}$ e revelando a existência de átomos de molibdênio com estado de oxidação misto. A técnica permitiu a determinação da quantidade de átomos de molibdênio no filme preparado pela deposição com 10 ciclos de potencial a partir de solução de Mo(VI) $1 \mathrm{mM}$. Com base neste valor e na carga obtida no voltamograma do eletrodo modificado registrado em eletrólito suporte pôde-se estimar a quantidade de monocamadas que compõem o filme assim preparado $(\sim 3800$, levando em conta que 1 monocamada $=10^{-10} \mathrm{~mol} \mathrm{~cm}^{-2}$ ).

A presença de centros não-estequiométricos no filme é responsável pela atividade catalítica no que diz respeito à redução de ânions oxigenados como iodato [196 ]. A Figura 30 mostra voltamogramas cíclicos em que a capacidade do filme imobilizado no sentido de mediar a redução do substrato é constatada, observando-se intensificação do sinal catódico e desaparecimento do sinal anódico em razão do consumo das formas reduzidas de molibdênio as quais participam do processo químico envolvendo iodato. 


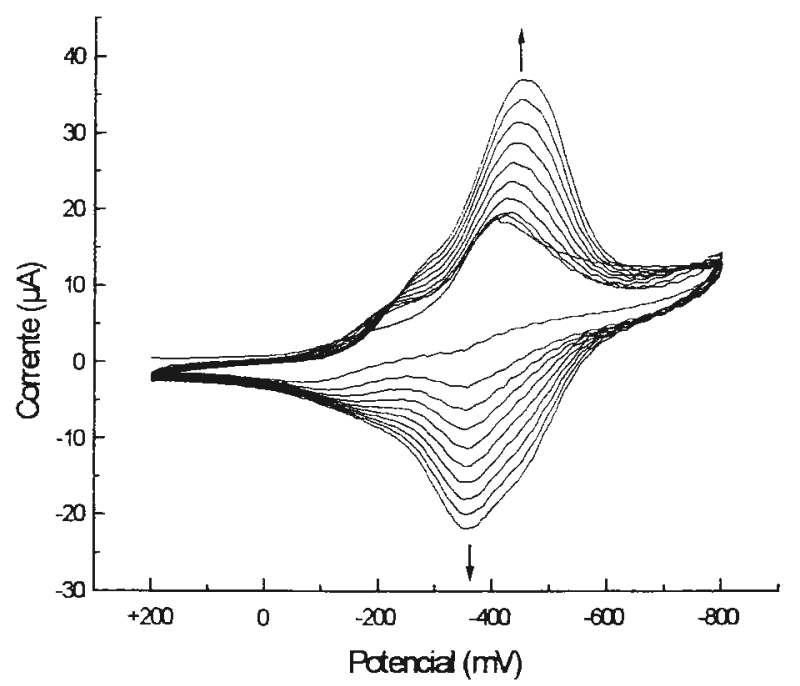

Figura 29. Voltamogramas consecutivos em solução de $\mathrm{Na}_{2} \mathrm{MoO}_{4} 1 \mathrm{mM}$ em $\mathrm{Na}_{2} \mathrm{SO}_{4} 50 \mathrm{mM}$ (pH 2,5). Velocidade de varredura $=50 \mathrm{mV} \mathrm{s}^{-1}$. Eletrodo de disco de carbono vitreo.

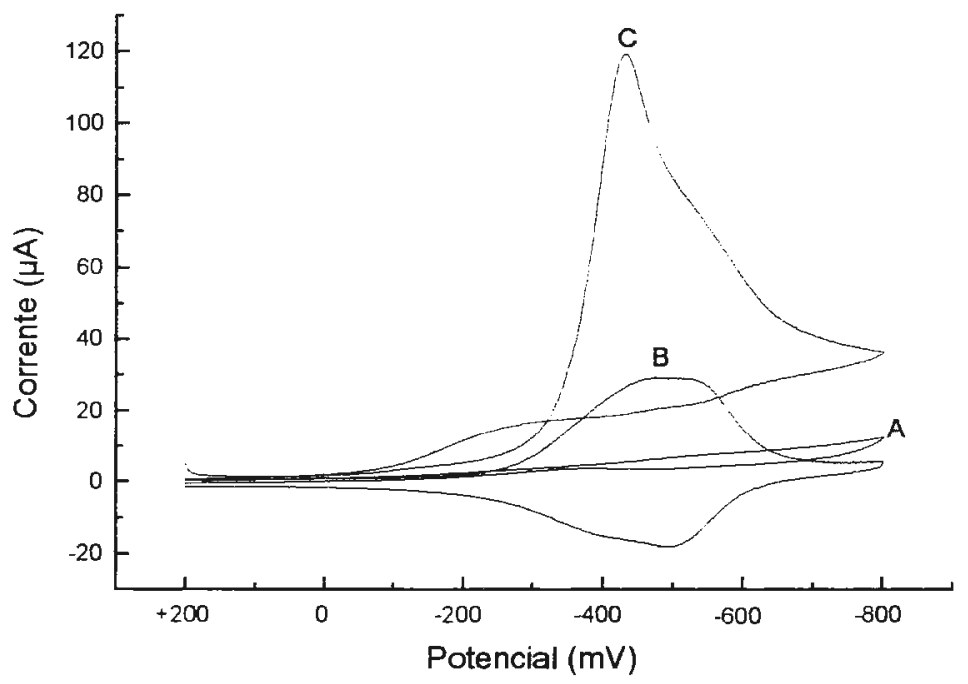

Figura 30. Voltamogramas de solução de $\mathrm{Na}_{2} \mathrm{SO}_{4} 50 \mathrm{mM}$ em $\mathrm{pH}=2,5$ antes (B) e após (C) adição de iodato $1 \mathrm{mM}$ (concentração final em solução) registrados com eletrodo modificado por óxidos de molibdênio. Em A apresenta-se o voltamograma obtido com eletrodo polido no eletrólito suporte contendo iodato. Velocidade de varredura $=50 \mathrm{mV} \mathrm{s}^{-1}$. 
Estudos envolvendo o processo catalítico foram realizados empregando-se eletrodo rotativo, observando-se que o processo é governado pelo transporte de massa do substrato uma vez que existe dependência linear da corrente limite em função da raiz quadrada da velocidade de rotação. Experimentos em meio mais ácido $(\mathrm{pH}=1,8)$ foram também executados e a Figura 31 apresenta valores da razão $I_{k} / I_{D}$ em função da velocidade de rotação do eletrodo para soluções de Mo(VI) com e sem iodato. $\mathrm{O}$ aumento nos valores de $\mathrm{I}_{\mathrm{k}} / \mathrm{I}_{\mathrm{D}}$ para maiores velocidades de rotação descarta a idéia de que eventuais formas solúveis de molibdênio tenham influência no processo catalítico e confirma o papel do filme de óxidos de molibdênio imobilizado na superficie do eletrodo no processo catalítico.

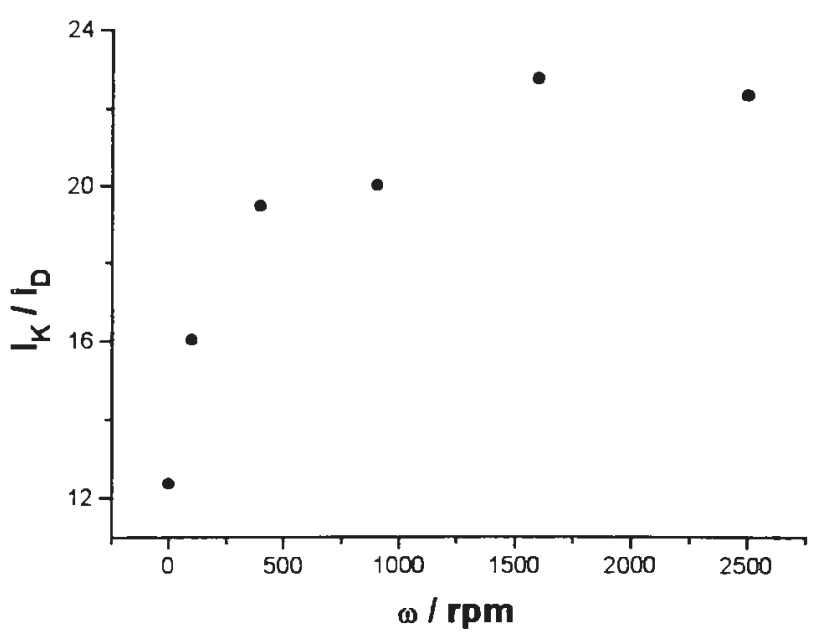

Figura 31. Dependência da razão $I_{k} I_{D}\left(I_{k}=\right.$ corrente catalítica na presença de iodato $3,0 \mathrm{mM}, I_{D}=$ corrente na ausência de iodato) com a velocidade de rotação para voltamogramas obtidos em solução de $\mathrm{Mo}(\mathrm{VI}) \mathrm{ImM}, \mathrm{Na}_{2} \mathrm{SO}_{4} 50 \mathrm{mM}$ em $\mathrm{pH}=1,8$. Correntes limites medidas em $-550 \mathrm{mV}$.

As interações químicas específicas que ocorrem entre os sítios catalíticos do filme de molibdênio e o orbital $\mathrm{p}$ dos átomos de oxigênio do substrato devem envolver a formação de um estado de transição complexo por mecanismo de transferência de elétrons de esfera interna. Sendo o iodo um átomo relativamente grande, pode-se prever que as reações com o iodato sejam relativamente rápidas, conduzindo à formação de iodeto em um processo envolvendo a transferência de seis elétrons de acordo com a equação:

$$
\mathrm{IO}_{3}^{-}+6 \mathrm{H}^{+}+6 \mathrm{e}^{-} \rightleftharpoons \mathrm{I}^{-}+3 \mathrm{H}_{2} \mathrm{O}
$$


Objetivando a verificação da formação de iodeto na redução catalisada do iodato, experimentos iniciais foram realizados com o eletrodo modificado e em presença de iodeto (Figura 32A). Os picos catódico e anódico ao redor de $-450 \mathrm{mV}$ representam a redução e posterior oxidação do material imobilizado e, ao redor de $+500 \mathrm{mV}$, o comportamento eletroquímico típico do iodeto é observado. O voltamograma obtido com eletrodo modificado e em presença de iodato é apresentado na Figura 32B; o aumento no componente catódico de corrente na região de $-450 \mathrm{mV}$ se deve à ação catalítica do filme perante o iodato, regenerando quimicamente a forma oxidada. Do mesmo modo, o desaparecimento do componente anódico se deve ao consumo da espécie eletrorreduzida de molibdênio por reação química com iodato. $\mathrm{O}$ aparecimento de sinal voltamétrico na região de $+500 \mathrm{mV}$ indica a presença de iodeto na superficie do eletrodo, comprovando a formação desta espécie na redução do iodeto.

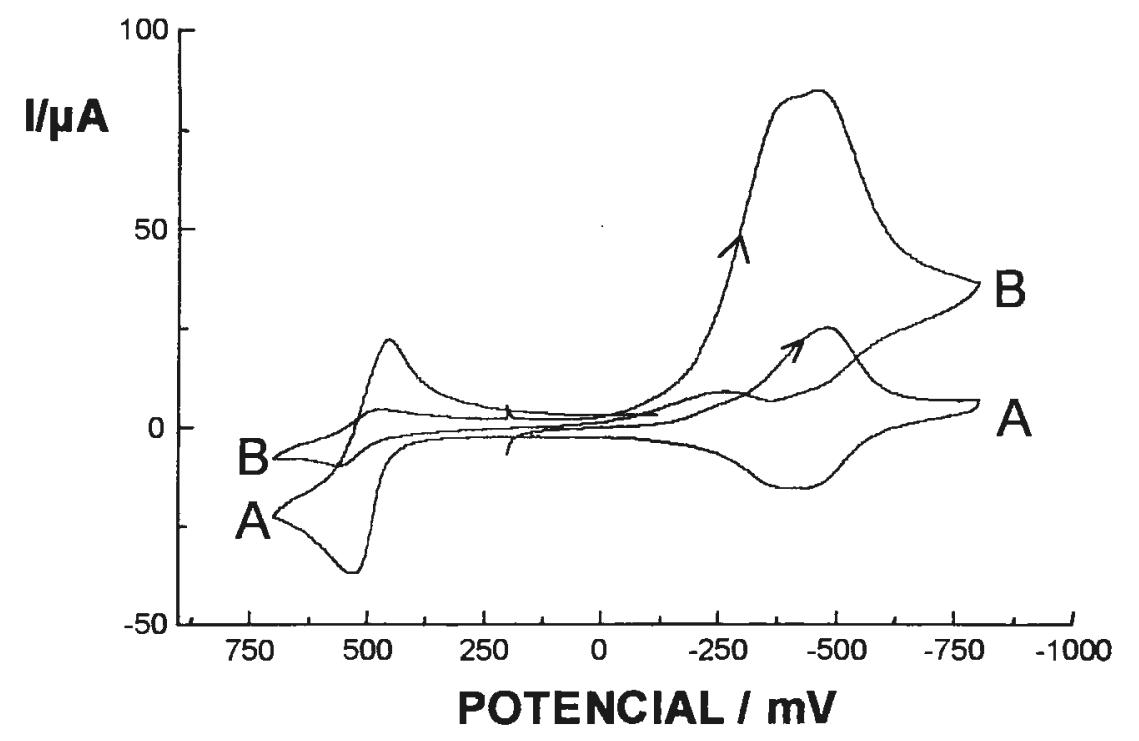

Figura 32. Voltamogramas ciclicos obtidos em $50 \mathrm{mV} \mathrm{s} \mathrm{s}^{-1}$ com eletrodo modificado por óxidos de molibdênio em solução de iodeto $\mathrm{ImM}$ (A) e iodato $1 \mathrm{mM}$ (B). Eletrólito suporte $=\mathrm{Na}_{2} \mathrm{SO}_{4} 50 \mathrm{mM}$ em $\mathrm{pH}$ $=2.5$. 
Um detalhe peculiar no que se refere a este processo catalítico foi observado nos estudos envolvendo experimentos com eletrodo rotativo. Objetivando-se investigar parâmetros cinéticos na redução do iodato em soluções contendo $\mathrm{Mo}(\mathrm{VI})$, estudos foram realizados em meio de $\mathrm{pH}=$ 1,8 mediante convecção forçada e controlada. Os voltamogramas mostrados na Figura 33 indicam a ocorrência de fenômeno químico na superfície do eletrodo uma vez que ao se inverter o sentido de varredura observa-se um aumento no sinal de corrente catódica. A dependência dessa cinética de transformação com o tempo é apresentada na Figura 34, onde se observa um aumento no sinal de corrente ao longo do tempo para experimentos realizados em potencial constante. Estes dados sugerem a existência de equilíbrio químico entre fases distintas do filme, o qual é deslocado no sentido da formação de óxido mais catalítico perante a redução homogêna do substrato ao trabalhar-se em condições de transporte de massa mais vigorosas. Hipotése alternativa refere-se à deposição de maior quantidade de material catalítico à medida que o experimento transcorre, facilitando a transferência de elétrons para o substrato com conseqüente aumento de corrente.

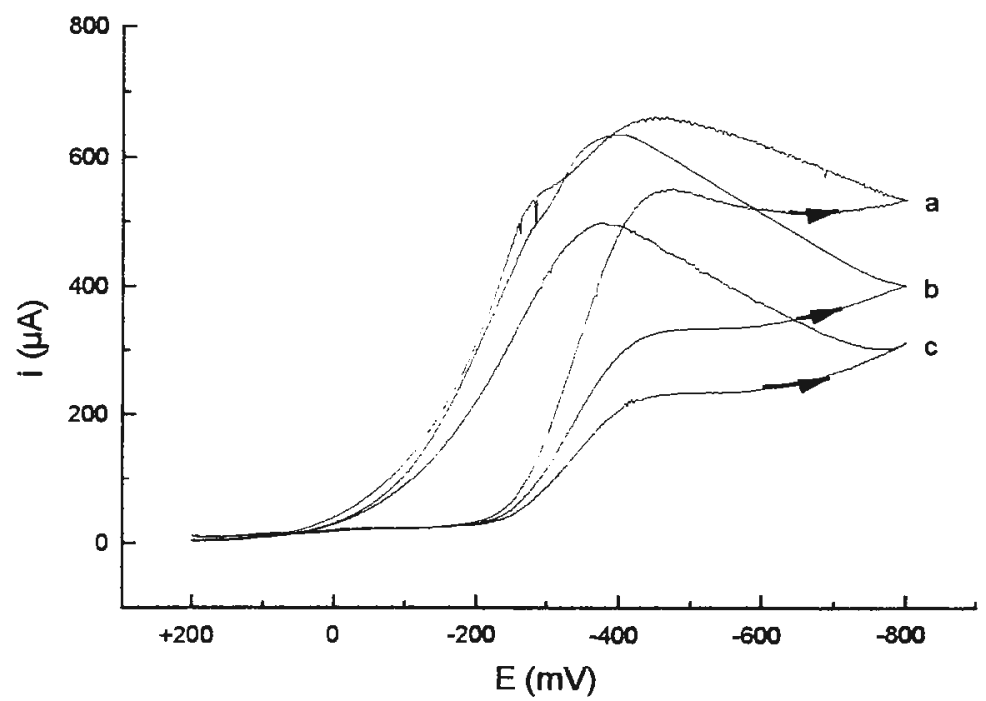

Figura 33. Voltamogramas ciclicos de solução de $\mathrm{Mo}(\mathrm{VI})$ I mM, $\mathrm{Na}_{2} \mathrm{SO}_{4} 50 \mathrm{mM}, \mathrm{KIO}_{3} 3,0 \mathrm{mM}$ em pH 1,8 com eletrodo de carbono vítreo submetido à rotação de $2500 \mathrm{rpm}$ e com velocidades de varredura de potencial de 20 (a), 50 (b) e $100 \mathrm{mVs}^{-1}$ (c). 


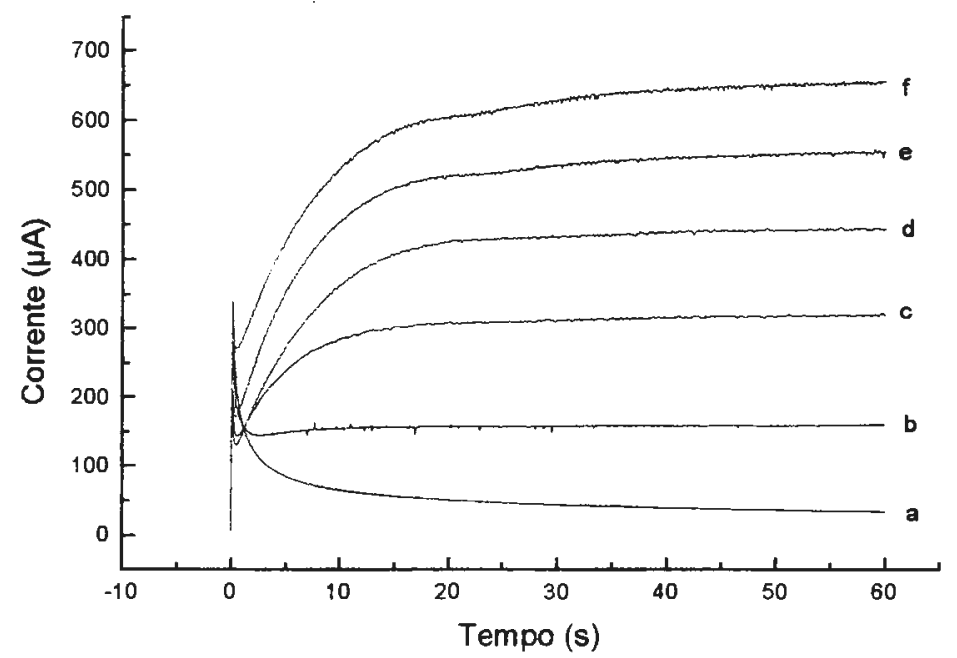

Figura 34. Cronoamperogramas de solução de $\mathrm{Mo}(\mathrm{VI})$ l mM, $\mathrm{Na}_{2} \mathrm{SO}_{4} 50 \mathrm{mM}$ e $\mathrm{KIO}_{3} 3,0 \mathrm{mM}(\mathrm{pH}=1,8)$, com eletrodo de carbono vitreo polarizado em -0,6 V e submetido à rotação de 0 (a), 100 (b), 400 (c), $900(d), 1600$ (e) e $2500 \mathrm{rpm}(f)$.

Estudos relacionados a filmes de óxidos de molibdênio foram também executados no que diz respeito a processos de oxidação de substratos como nitrito e NO. A Figura 29 mostra que o filme é eletroativo em potenciais negativos, quando ocorre a formação de espécies reduzidas (bronzes ou óxidos não estequiométricos). Todavia, em regiões positivas de potencial o filme não possui atividade eletroquímica, ratificando trabalhos anteriores que definem o filme como não-condutor nestas circunstâncias [197,198]. Testes preliminares envolveram a verifịcação de processos redox de substâncias de comportamento eletroquímico conhecido, como o ferrocianeto e o iodeto. Para filmes preparados com 10 ciclos de potencial observou-se que o sinal voltamétrico para ferrocianeto era bastante inferior àquele obtido com eletrodo de carbono vítreo polido e com filmes mais espessos o sinal caía praticamente a zero, demonstrando a) que o filme não é permeável a espécies relativamente volumosas e b) que o filme não é condutor em faixas de potencial positivas. Esta segunda conclusão confirma estudos efetuados por outros autores sobre a pobre capacidade condutora de óxidos metálicos quando totalmente oxidados $[199,200]$. Cabe ressaltar que a situação é significativamente diferente em potenciais negativos, quando elétrons são injetados no filme: nestes casos o fluxo de contra-íons $\left(\mathrm{H}^{+}\right.$ou alcalinos terrosos) necessários para equilibrar a carga dentro do filme (ao se tratar de bronzes do tipo 
$\mathrm{H}_{\mathrm{x}} \mathrm{MoO}_{3}$ ) ou a presença de orbitais $\pi$ não totalmente preenchidos (para óxidos não estequiométricos, $\mathrm{MoO}_{3-\mathrm{x}}$ ) conferem à estrutura a capacidade de transferência de elétrons.

Apesar de não ser um bom condutor em potenciais positivos, observou-se que o processo de oxidação anódica de substratos como nitrito e NO ocorre de maneira facilitada ao se trabalhar com superficies modificadas pelos óxidos de molibdênio. Em ambos os casos explicações preliminares estão relacionadas a uma primeira etapa em que ocorre passagem do substrato pelo filme para posterior transferência eletrônica diretamente na superfície do eletrodo. Estudos utilizando iodeto como substrato demonstraram que o filme é relativamente permeável a espécies químicas de menor tamanho, pois os voltamogramas registrados com o eletrodo antes e após a modificação foram essencialmente iguais. Como neste caso o processo de oxidação envolve simplesmente uma transferência eletrônica, o filme não apresenta papel de destaque no processo global de eletrodo. Já para substratos como nitrito e NO a situação é diferente pois para a formação do produto de oxidação (nitrato), à etapa de transferência de carga deve estar associada uma etapa de transferência de átomos de oxigênio. Desta forma, a presença do filme de óxidos de molibdênio na superficie do eletrodo pode explicar a melhoria do sinal obtido para processos anódicos envolvendo nitrito e NO; em ambos os casos, a ruptura da ligação Mo-O e posterior transferência de átomo de oxigênio do filme para a forma oxidada gerada na superfície do eletrodo poderia ser mais eficiente do que a formação do produto final via participação de moléculas de água. Neste contexto, cabe citar os trabalhos de Johnson e colaboradores [201-204], os quais têm demonstrado o poder catalítico de óxidos metálicos totalmente oxidados via mecanismos em que átomos de oxigênio são transferidos do filme hidratado para o substrato.

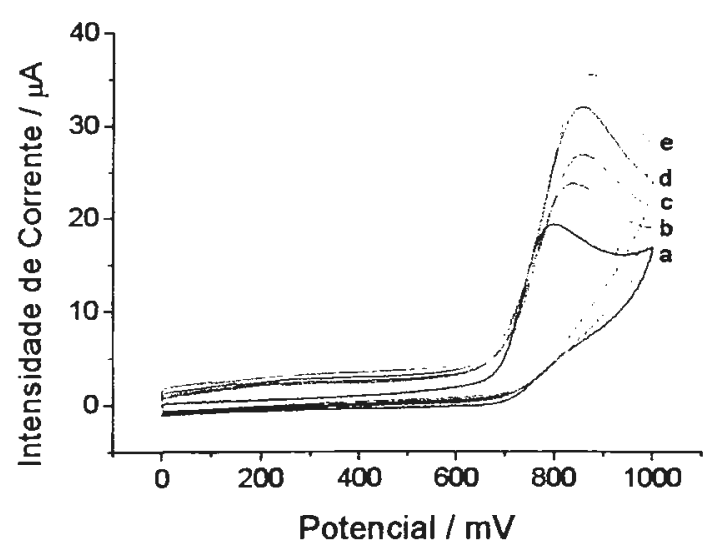

Figura 35. Voltamogramas ciclicos obtidos em solução de nitrito $1 \mathrm{mM}$ com eletrodo polido (a) e modificado por $b=10$ ciclos, $c=20$ ciclos, $d=$ 30 ciclos e e $=40$ ciclos de potencial em solução de Mo(VI).Velocidade de varredura $=50 \mathrm{mV} \mathrm{s}^{-1}$. 
Com o objetivo de avaliar a importância da presença de moléculas de água no filme durante o processo redox referente à oxidação do nitrito, estudos preliminares foram efetuados com eletrodo modificado o qual permaneceu em dessecador por 3 dias sob pressão reduzida. Com o filme "seco", trabalhou-se então em meio de acetonitrila e comprovou-se a não existência de sinal voltamétrico para o nitrito nestas condições, demonstrando que a ausência de água decresce acentuadamente a porosidade do filme de forma a restringir o acesso do substrato à superficie eletródica. Estudos comparativos no mesmo meio mas com o eletrodo polido ratificam tais resultados pois observou-se sinal de corrente na região próxima a $1 \mathrm{~V}$; moléculas de água só são essenciais após a transferência de elétrons, quando $\mathrm{NO}_{2}$ é transformado posteriormente em nitrato.

Outro aspecto diferenciador quando se compara a oxidação dos dois substratos no filme de óxidos de molibdênio diz respeito à capacidäde dó filme em acumular NO. Tâl conciùuãō resultou de experimentos nos quais gerou-se o gás em eletrólito suporte ao qual estava imerso o eletrodo modificado para posterior remoção pela passagem de argônio. Observou-se a manutenção do sinal voltamétrico característico do NO na ausência da espécie química em solução, indicando a necessária pré-concentração do material no interior do filme. Em estudos voltamétricos com o material acumulado no eletrodo modificado realizados com baixa velocidàde de varredura $\left(1 \mathrm{mV} \mathrm{s}^{-1}\right)$ não observou-se sinal de corrente no segundo ciclo de potencial. Confirma-se portanto tratar-se de processo de adsorção de uma espécie química de comportamento eletroquímico irreversível, havendo consumo completo do material após o primeiro ciclo de potencial trabalhando-se em escala de tempo relativamente larga.

Estudos posteriores visando à elucidação da natureza da interação química entre o filme de molibdênio e o NO serão realizados empregando-se técnicas espectroscópicas de análise. Estas investigações poderão fornecer subsídios importantes para pesquisas subseqüentes relacionadas à possibilidade de desenvolvimento de sensor para NO por meio de modificação de microeletrodos com filmes à base de óxidos de molibdênio. 
4.4.2 Estudos eletroquimicos envolvendo a oxidação do nitrito em eletrodos modificados com porfirinas metálicas

O uso de porfirinas metálicas na catálise de processos eletródicos é bastante disseminado devido às excelentes propriedades condutoras destes compostos [205-207]. Assim sendo, a modificação de eletrodos sólidos com porfirinas apresenta-se como estratégia de destaque no campo da eletroanalítica uma vez que processos que ocorrem com elevada sobretensão em superfícies polidas podem ser facilitados após a etapa de modificação. Exemplo bastante pertinente ocorre no caso da oxidação anódica do nitrito em eletrodos modificados pela deposição de porfirinas tetra-rutenadas de cobalto (via "dip-coating") [208,209]. O processo envolve a deposição de $1 \mu \mathrm{L}$ da porfirina cationnica CoTRBP no eletrodo de carbono vítreo e posterior deposição de $1 \mu \mathrm{L}$ da porfirina aniônica ZnTPPS, a qual serve como contra-íon e minimiza processos de solubilização da porfirina de cobalto em meio aquoso. A Figura 36 demonstra este fato pela verificação do sinal voltamétrico para nitrito empregando-se o eletrodo modificado. Cabe ressaltar que em eletrodo polido o processo de oxidação ocorre em potenciais mais positivos e que a corrente é significativamente maior ao se modificar o eletrodo, conforme será demonstrado adiante.

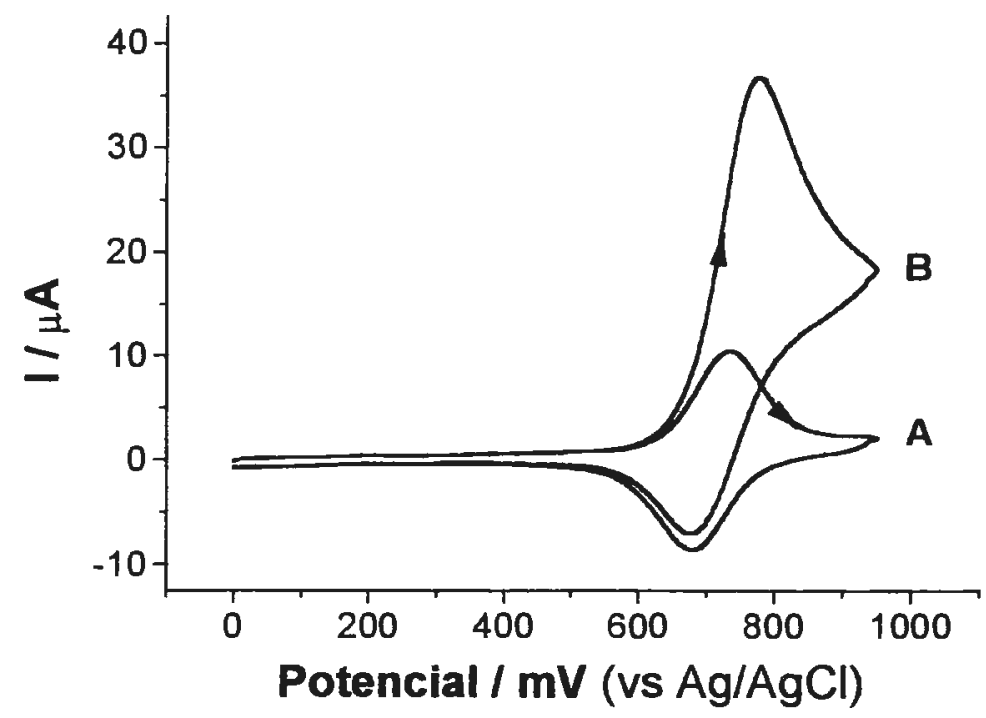

Figura 36. Voltamogramas registrados com o eletrodo modificado com l bicamada pelas porfirinas CoTRBP/ZnTPPS em solução de tampão acetato, $p H=4,7$, antes e após adição de nitrito (concentração final $=1 \mathrm{mM}$ ). Velocidade de varredura $=20 \mathrm{mV} \mathrm{s}^{-1}$. 
Com o objetivo de investigar a natureza do processo cinético envolvendo a oxidação catalisada do nitrito, investigações preliminares foram direcionadas no sentido de avaliar a velocidade da etapa de transferência de carga no eletrodo modificado por técnica cronoamperométrica em solução contendo somente o eletrólito suporte. A dependência da corrente em função de $\mathrm{t}^{-1 / 2}$ segue o comportamento esperado para processos controlados pela equação de Cottrell, em que prevalece a difusão semi-infinita, mas observa-se pela análise da Figura 37 que isto só ocorre em tempos relativamente curtos. Nestas condições avaliou-se o valor da constante $\mathrm{D}^{1 / 2} \mathrm{C}(\mathrm{D}=$ velocidade do processo de transferência da carga por "electron-hopping" e C $=$ concentração da espécie catalítica no filme), obtendo-se um valor de $3,4 \times 10^{-9} \mathrm{~mol} \mathrm{~cm}^{-2} \mathrm{~s}^{-1 / 2}$. Tais resultados podem também ser correlacionados às observações de que valores de $\Delta E_{\text {pico }}$ aumentam significativamente ao trabalhar-se com velocidades de varredura mais elevadas, indicando que alguma complicação cinética associada ao transporte de elétrons ou de contra-íons seja de magnitude relevante.

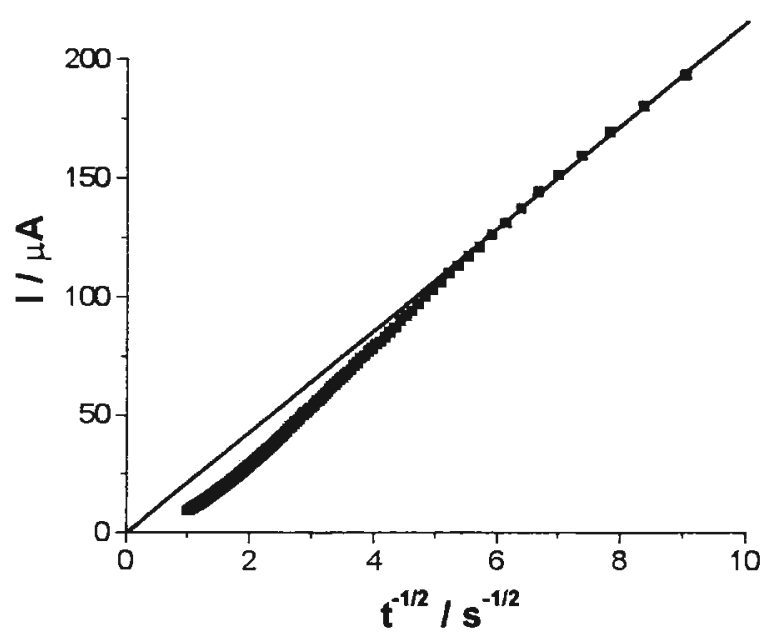

Figura 37. Dependência da corrente em função de $t^{-1 / 2}$ para eletrodo modificado por uma bicamada das porfirinas CoTRBP/ZnTPPS após pulso de potencial de 0 a 1,0 V em tampão acetato, $p H=4,7$. A linha corresponde à regressão dos dados coletados no intervalo de tempo de 10 a $40 \mathrm{~ms}$.

Estudos referentes à cinética do processo eletródico envolvendo a oxidação do nitrito no eletrodo modificado foram efetuados utilizando-se eletrodo de disco rotativo. Este procedimento é útil pois podem ser obtidos dados em condições de regime de estado estacionário, nos quais o sinal medido é independente do tempo facilitando a elaboração de equações descritivas dos 
fenômenos observados [12]. Desta maneira, experimentos onde se empregou o eletrodo modificado submetido a diferentes velocidades de rotação foram realizados em solução contendo o substrato. A Figura 38 apresenta os resultados obtidos trabalhando-se em solução contendo nitrito $1 \mathrm{mM}$ e na Figura 39A apresentam-se os dados na forma da equação de Levich, onde observa-se que o processo não é governado pelo transporte de massa. Cabe ressaltar que experimentos similares foram efetuados empregando-se ferrocianeto como substrato e os resultados indicaram que neste caso o processo é controlado por difusão numa ampla faixa de concentrações $(0,1$ a $10 \mathrm{mM}$ de ferrocianeto) e velocidades de rotação (100 a $3600 \mathrm{rpm})$.

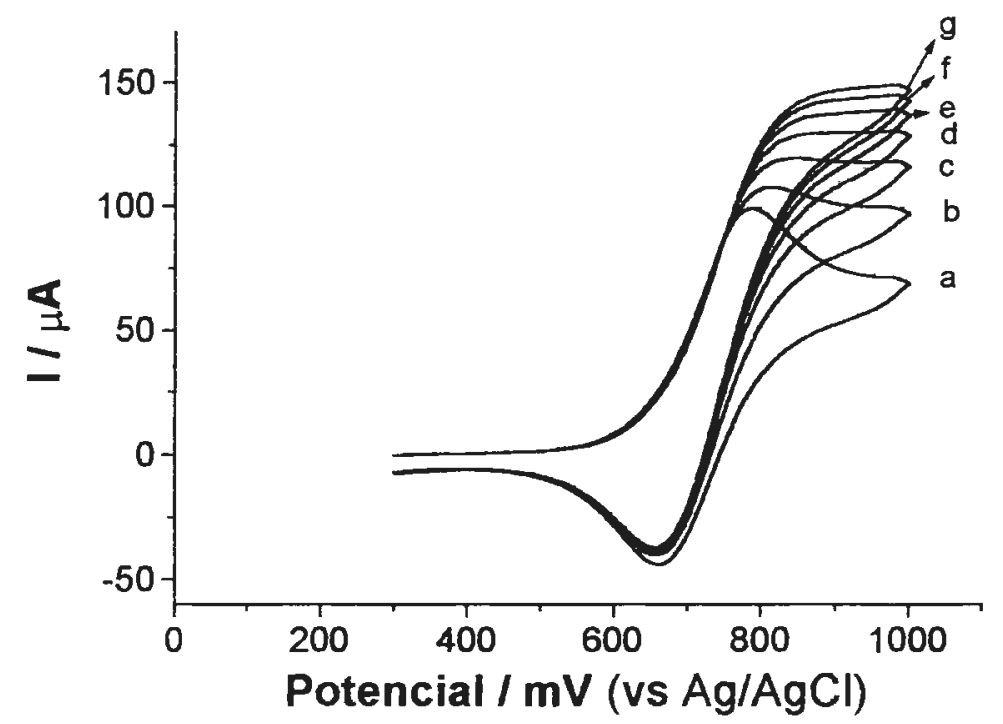

Figura 38. Voltamogramas registrados com eletrodo rotativo modificado com uma bicamada das porfirinas CoTRBP/ZnTPPS em solução de eletrólito suporte (tampão acetato, $\mathrm{pH}=4$,7) contendo nitrito $1 \mathrm{mM}$. Velocidades de rotação: 100 (a), 400 (b), 900 (c), 1600 (d), 2500 (e), 3600 (f) and $4900 \mathrm{rpm}$ (g). Velocidade de varredura $=50 \mathrm{mV} \mathrm{s}^{-1}$.

Informações quantitativas sobre a cinética do processo de oxidação do nitrito no eletrodo modificado foram obtidas analisando-se os valores de corrente limite dos voltamogramas registrados em diferentes velocidades de rotação na forma preconizada pela equação de Koutecky-Levich (equação 19). A Figura 39B apresenta os dados obtidos e pelos valores de coeficiente linear das retas referentes às várias concentrações de nitrito obteve-se o valor da constante cinética da reação envolvendo a oxidação deste substrato no eletrodo modificado $(\mathrm{k}=$ $\left.3,4 \times 10^{3} \mathrm{~mol}^{-1} \mathrm{~L} \mathrm{~s}^{-1}\right)$. 


$$
\left(\mathrm{I}_{\lim }\right)^{-1}=(\mathrm{nFAk \Gamma C})^{-1}+\left(0,62 \mathrm{nFAD}{ }^{2 / 3} v^{-1 / 6} \mathrm{C}^{1 / 2}\right)^{-1}
$$

Nestes cálculos adotou-se $\Gamma=3.5 \times 10^{-9} \mathrm{~mol} \mathrm{~cm}^{-2}$, valor obtido pela medição do componente anódico do voltamograma registrado em baixa velocidade de varredura com o eletrodo modificado em solução de eletrólito suporte.
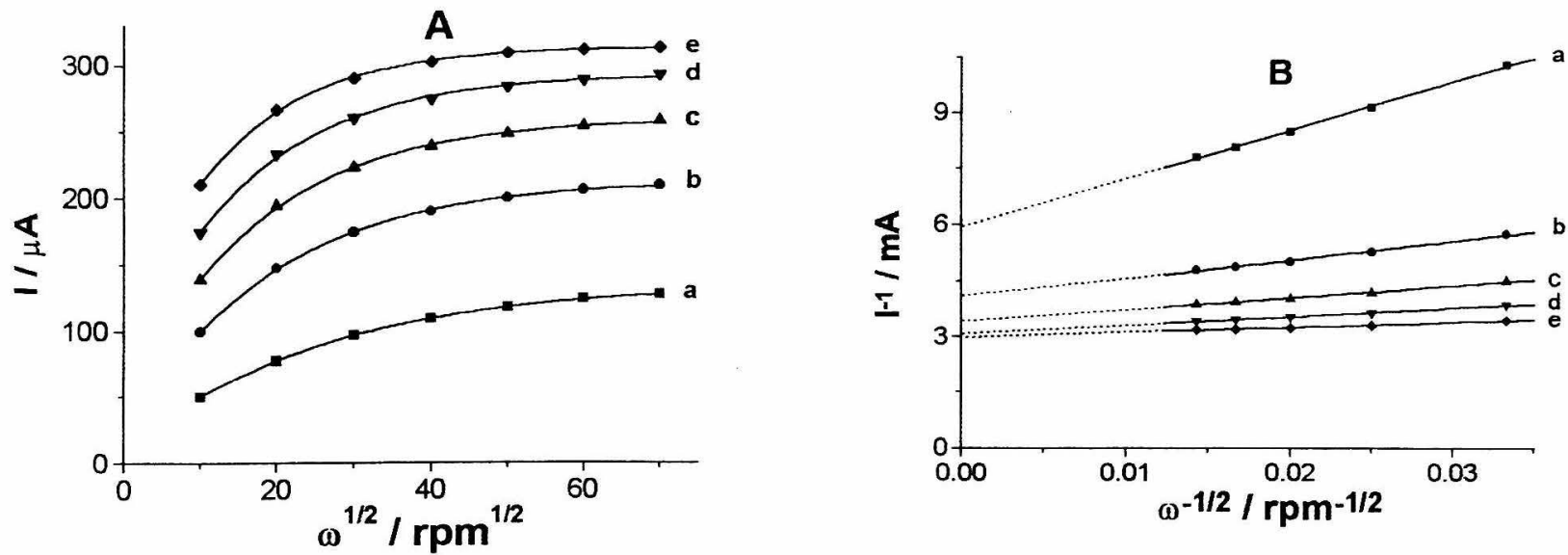

Figura 39. Gráficos referentes à dependência da corrente limite medida em voltamogramas registrados com o eletrodo modificado no modo rotativo em solução contendo nitrito em várias concentraçães ( $a=1$, $b=2, c=3, d=4, e=5 \mathrm{mM}$ ) em função de $\omega$ (equação de Levich, (A)) e $\omega^{-1 / 2}$ (equação de KouteckyLevich, (B)).

Como conclusão destes estudos pode-se dizer que o processo de transferência de carga é relativamente mais rápido do que a reação catalítica envolvendo o nitrito. Desta forma, somente sítios catalíticos presentes na interface filme/solução parecem participar ativamente do processo de transferência de elétrons para o substrato, confirmando estudos realizados sobre a dependência da corrente catalítica em função da espessura do filme. Observou-se que filmes mais espessos diminuem a eficiência do processo, o que leva à conclusão de que o transporte de carga passa a ser dificultado assim como a difusão do nitrito pelo filme. Pode-se concluir também que a dinâmica da reação de oxidação do nitrito mediada pelo filme CoTRBP/ZnTPPS enquadra-se no subcaso "SR" na nomenclatura sugerida por Saveant e colaboradores [12], segundo a qual a corrente limite depende da velocidade da reação e ocorre essencialmente na vizinhança exterior do filme em contato com a solução. 


\subsection{Desenvolvimento de metodologias analíticas associadas a sistemas de análise em fluxo}

\subsubsection{Processos envolvendo a oxidação de iodeto a triiodeto e aproveitamento analitico}

A reação de oxidação química do iodeto leva à formação de triiodeto em meio aquoso contendo excesso de iodeto. Uma vez que o triiodeto consiste em espécie eletroativa facilmente monitorada em potenciais relativamente pouco positivos e sua formação química pode ser efetivada a partir da reação com alguma substâncias de interesse analítico, foram idealizados alguns procedimentos os quais envolveram a quantificação indireta dos analitos via determinação amperométrica do triiodeto.

$\mathrm{Na}$ Figura 40 apresentam-se voltamogramas registrados durante a adição de nitrito a uma solução contendo iodeto em meio ligeiramente ácido. Observa-se que durante as adições aparece um componente catódico com conseqüente formação de onda composta devido à presença simultânea de iodeto e triiodeto em solução. A equação abaixo descreve a reação em solução durante a adição de pequena quantidade de nitrito em relação ao iodeto:

$$
2 \mathrm{NO}_{2}^{-}+3 \mathrm{I}^{-}+4 \mathrm{H}^{+} \longrightarrow \mathrm{I}_{3}^{-}+2 \mathrm{H}_{2} \mathrm{O}
$$

Adições sucessivas de nitrito conduzem a voltamogramas para os quais a corrente total é continuamente menor. Tal fato foi satisfatoriamente explicado levando-se em consideração que à medida que a "titulação" prossegue a reação em solução tende à formação de iodo devido à menor quantidade de iodeto livre em solução [210]. Nestas condições, a estequiometria da reação química é alterada e como o coeficiente de difusão do iodo é significativamente menor do que o do iodeto, a corrente dos voltamogramas resultantes quando há pouco iodeto em solução torna-se menor.

Analisando-se a Figura 40 percebe-se que a oxidação anódica do iodeto só se inicia em em potenciais mais positivos do que $0,4 \mathrm{~V}$ e que em regiões de potencial mais negativas do que este valor pode-se monitorar adequadamente triiodeto (ou iodo) sem interferência do sinal anódico. Uma vez que o processo de oxidação do nitrito só ocorre em potenciais relativamente positivos ( $>0,8 \mathrm{~V}$ ) em superfícies não modificadas, desenvolveu-se método indireto amperométrico para a determinação deste analito em matrizes de diversas procedências [210]. Para tanto, numa primeira etapa trabalhou-se com sistema estacionário monitorando-se a corrente 
em potencial de $0,2 \mathrm{~V}$, suficientemente negativo para evitar problemas com a oxidação anódica do iodeto e relativamente afastado da região onde o oxigênio constituir-se-ia em interferente não desprezível.

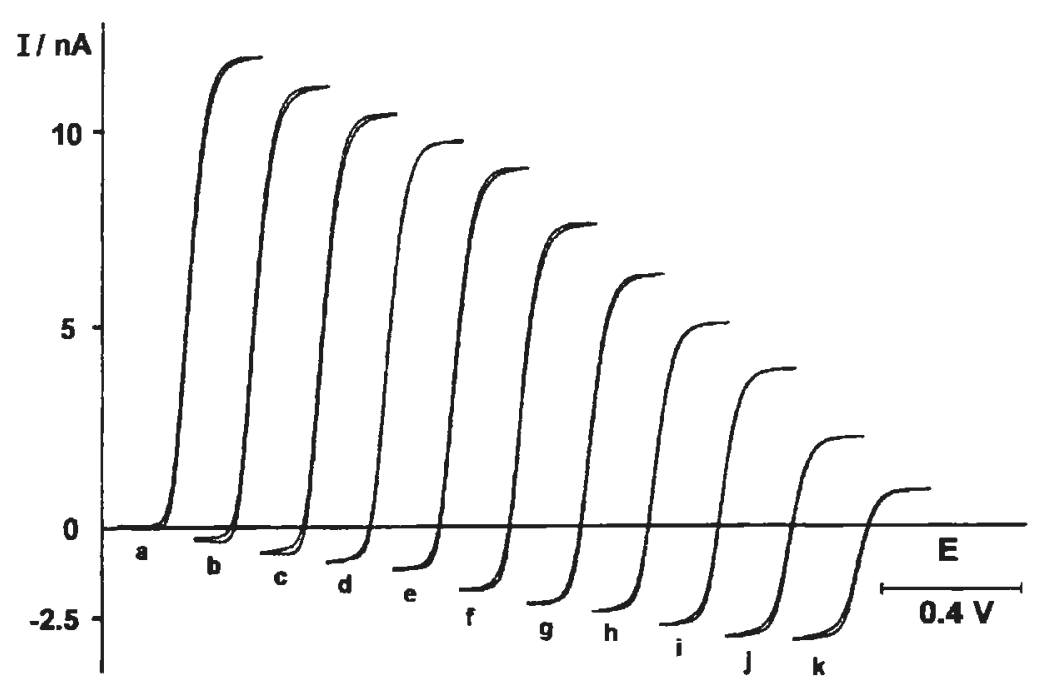

Figura 40. Voltamogramas registrados com microeletrodo de platina $(r=5 \mu \mathrm{m})$ em solução contendo iodeto $2 \mathrm{mM}+\mathrm{H}_{2} \mathrm{SO}_{4}$ 0,1M (10.0 ml) antes (a) e após adição de l (b), 2 (c), 3(d), 4(e), $6(f), 8(\mathrm{~g}), 10(\mathrm{~h})$, 12 (i), 15 (j) e 18 umols de nitrito (k) em atmosfera de nitrogênio. Potencial inicial $=0,3 \mathrm{~V}$, potencial final $=0,7 \mathrm{~V}$, velocidade de varredura $=10 \mathrm{mV} \mathrm{s}^{-1}$.

Devido à difusão convergente inerente a eletrodos de raios micrométricos, medições de corrente no potencial selecionado usando microeletrodos propiciaram sinais independentes do tempo e permitiram a determinação de nitrito em águas de lagos e amostras de saliva empregando-se método da adição de padrão [210]. A minimização de eventual interferências associadas a outras espécies presentes na matriz que poderiam oxidar iodeto (por exemplo, $\mathrm{Cu}(\mathrm{II})$ ou $\mathrm{Fe}(\mathrm{III})$ ) baseou-se na adição de EDTA à solução de trabalho e a boa concordância com resultados provenientes do uso de metodologia normatizada (método de Griess [211]) validou o procedimento proposto.

Em razão das vantagens já destacadas referentes à deteç̧ão amperométrica com microeletrodos em procedimentos em fluxo [212], desenvolveu-se posteriormente método para a análise de nitrito e nitrato via geração de triiodeto. Construiu-se célula na configuração "wall-jet" 
e a diferenciação entre os 2 analitos foi viabilizada pela passagem da amostra por coluna redutora de $\mathrm{Cd} / \mathrm{Cu}$, na qual converte-se quantitativamente nitrato a nitrito (Figura 41).

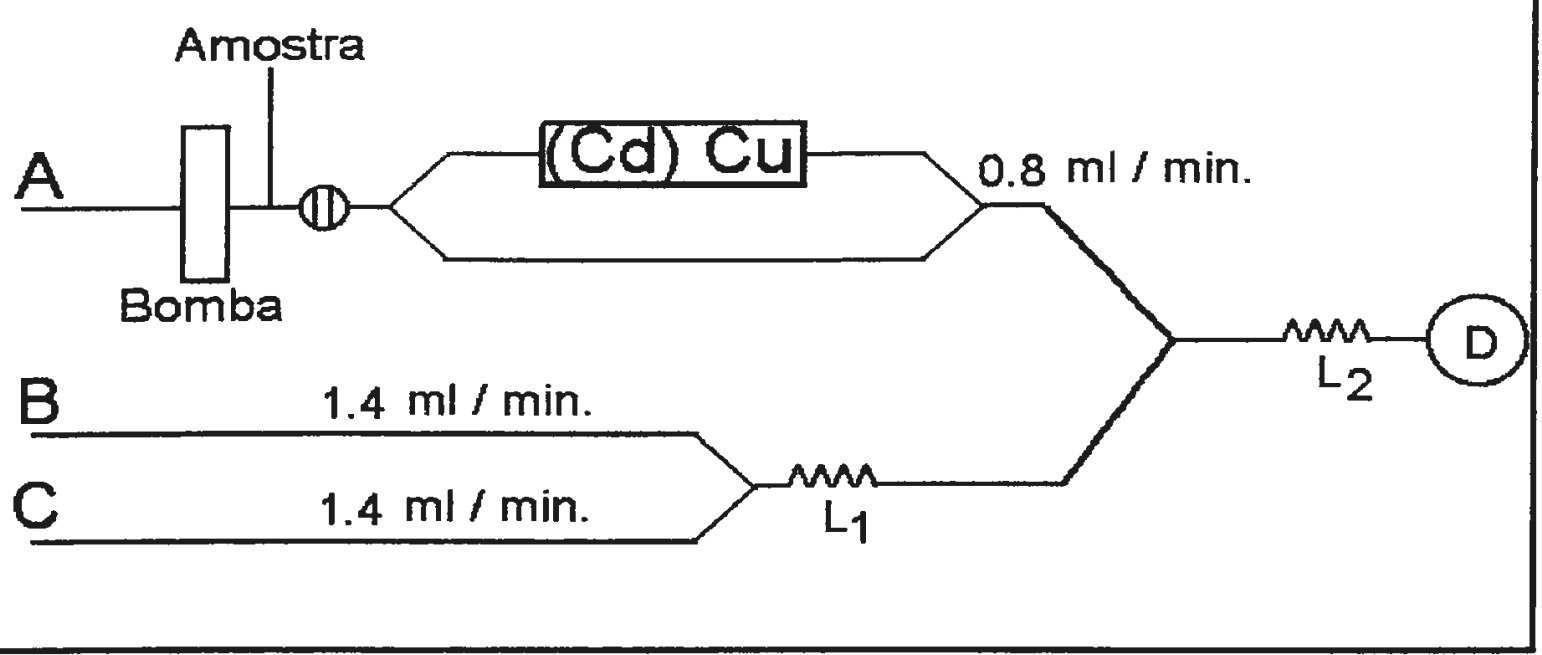

Figura 41. Esquema do sistema usado na determinação de nitrato e nitrito. Soluções transportadoras: $\mathrm{NH}_{4} \mathrm{Cl} 40 \mathrm{mM}$ em pH 9 mantido com $\mathrm{NH}_{4} \mathrm{OH}(\mathrm{A}), \mathrm{KI} 20 \mathrm{mM}$ (B) e $\mathrm{H}_{2} \mathrm{SO}_{4} 0,2 \mathrm{M}$ (C). $L_{1}$ e $L_{2}$, são bobinas de reação; $D$, célula do tipo "wall-jet" com detector amperométrico (microeletrodo de $\phi=10 \mu \mathrm{m}$ ).

Estudos sistemáticos foram realizados com o intuito de avaliar a melhor composição das soluções que constituem o eletrólito carregador, tamanho dos percursos analíticos, velocidade de fluxo e capacidade do "loop" de amostra para efetuar as determinações de nitrito. Observa-se na Figura 41 que as soluções de iodeto e ácido são mantidas separadas com o objetivo de minimizar a formação de iodo via oxidação do iodeto pelo oxigênio dissolvido, a qual é facilitada em meio ácido. Estudos referentes à otimização das condições experimentais para a efetiva redução de nitrato a nitrito também foram executados e a Figura 42 mostra que o grau de conversão é bastante próximo a $100 \%$.

Com a configuração mostrada na Figura 41 testes foram realizados com soluções de nitrato e nitrito e limites de deteç̧ão de 0,25 e $0,07 \mu \mathrm{M}$ respectivamente foram alcançados para estes 2 analitos, demonstrando a elevada sensibilidade da metodologia proposta. $O$ bom desempenho analítico também pôde ser atestado verificando-se a excelente repetibilidade das determinações e a boa freqüência analítica [213]. 


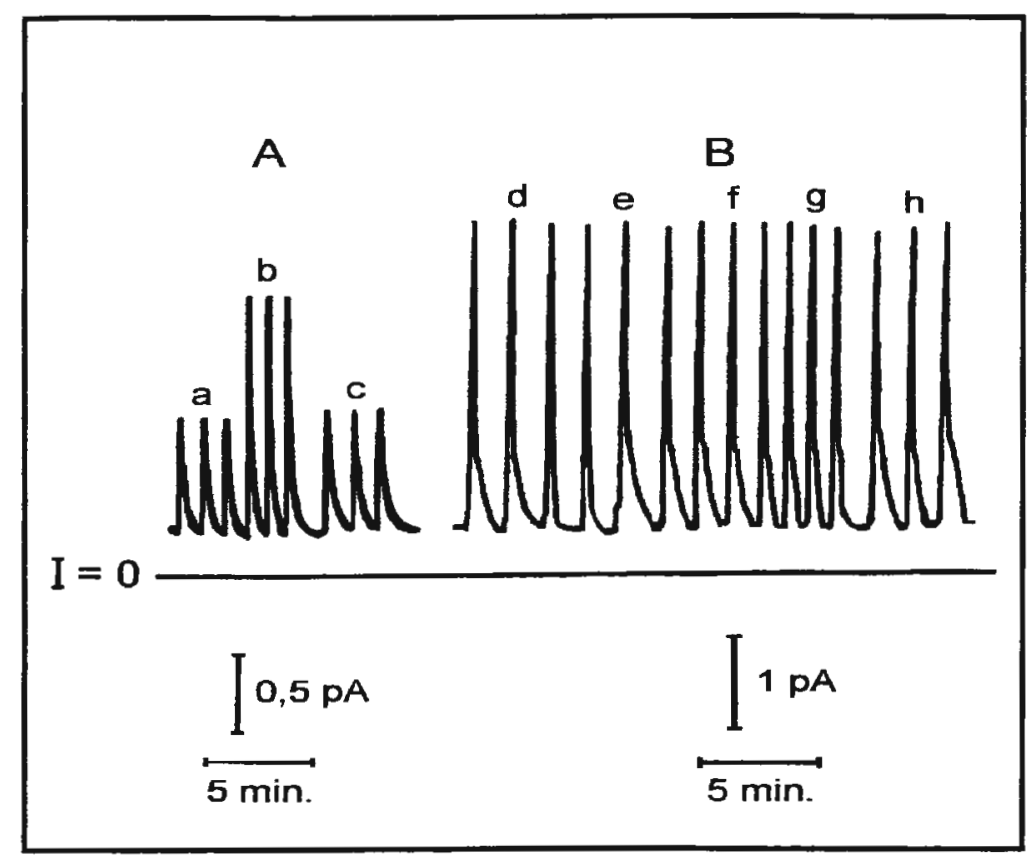

Figura 42. Fiagramas das injeções de soluções de $1 \mu \mathrm{M}$ de nitrato (a), $1 \mu \mathrm{M}$ de nitrato $+1 \mu \mathrm{M}$ de nitrito (b) e $1 \mu M$ de nitrito (c) (A). Em B têm-se fiagramas em triplicata das soluções com seguintes composições (nitrato / nitrito): 4,0/0 (d); 3,5/0,5 (e); 3,0/1,0 (f);2,5/1,5(g) e 2,0 $\mu \mathrm{M} / 2.0 \mu \mathrm{M}$ (h). Potencial $+0,20 \mathrm{~V}$. Microeletrodo de raio $=5 \mu \mathrm{m}$, velocidade de fluxo $=1,5 \mathrm{ml} \mathrm{min}^{-1}$.

O método desenvolvido foi aplicado em diferentes matrizes como saliva e águas de represa. Neste último caso as amostras foram coletadas em diferentes pontos da represa Billings e interessantes correlações entre as quantidades de nitrato e nitrito, data e local das coletas, $\mathrm{pH}$ das amostras e concentração de amônio puderam ser realizadas [214]. No caso das amostras de saliva, conclusões relativas ao papel da atividade bacteriana na transformação de nitrato em nitrito na cavidade bucal foram efetuadas conforme apresenta-se na Figura 43 [213]. Todas a análises realizadas empregando-se o método amperométrico foram corroboradas por técnicas alternativas como espectrofotometria (reação de Griess) ou cromatografia de íons. 


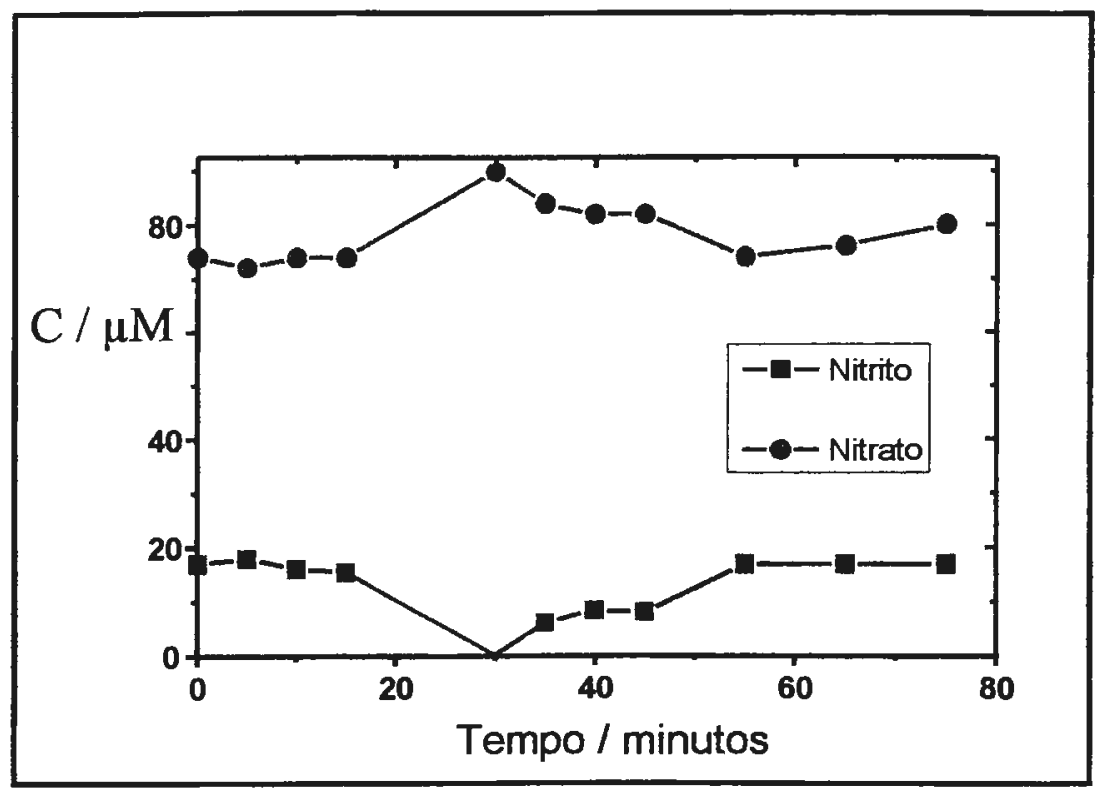

Figura 43: Concentração de nitrato e nitrito na saliva antes e depois da lovagem da boca com uma solução de anti-séptico em tratamento efetuado em $t=20$ minutos.

A formação de triiodeto via oxidação química do iodeto também serviu para o estabelecimento de condições experimentais adequadas para a determinação de hipoclorito em alvejantes [215]. Estudos preliminares demonstraram a viabilidade do procedimento e os resultados obtidos foram concordantes com aqueles oriundos de titulações das amostras por metodologia recomendada (adição de excesso de iodeto e titulação do triiodeto formado com solução padrão de tiossulfato). Todavia, o uso do procedimento em fluxo com deteç̧ão amperométrica é muito mais vantajoso por causa da melhor repetibilidade das determinações e da maior freqüência analítica.

A mesma metodologia foi empregada num estudo envolvendo a determinação da constante de solubilidade termodinâmica do $\mathrm{Ba}\left(\mathrm{IO}_{3}\right)_{2}$ [216]. Para tanto, baseou-se na formação de triiodeto via reação entre iodato e iodeto de acordo com a equação:

$$
8 \mathrm{I}^{-}+\mathrm{IO}_{3}^{-}+6 \mathrm{H}^{+} \rightleftharpoons 3 \mathrm{I}_{3}^{-}+3 \mathrm{H}_{2} \mathrm{O}
$$


No procedimento adotado prepararam-se soluções saturadas de iodato de bário em diferentes valores de força-iônica e estas soluções contendo iodato em equilíbrio com íons bário foram injetadas no sistema FIA. Curvas analíticas apropriadamente preparadas nas várias condições experimentais permitiram a determinação indireta das concentrações de iodato das soluções saturadas, obtendo-se então os valores das constantes de solubilidade condicionais levando-se em conta a estequiometria da substância em estudo. A constante termodinâmica foi determinada graficamente pela extrapolação dos dados à condição de diluição infinita, obtendo-se resultado relativamente próximo àquele descrito na literatura.

Cabe ainda destacar um outro uso deste sistema de determinação indireta, o qual baseouse na catálise da oxidação do iodeto por perborato em meio contendo traços de Mo(VI). O papel catalítico deste metal de transição está associado à formação de um intermediário peroximolibdato, o qual oxida rapidamente iodeto devido à diminuição da barreira energética associada com o processo de transferência eletrônico [217,218]. Em soluções nas quais o catalisador está ausente, a reação de formação do triiodeto também ocorre, mas a cinética é muito mais lenta. Desta forma, a etapa inicial do trabalho consistiu na verificação das condições apropriadas de trabalho onde a formação de triiodeto na ausência de Mo(VI) ocorresse em pequena extensão. $O$ sistema ideal seria aquele para o qual não houvesse formação de triiodeto na ausência de catalisador e para o qual o triiodeto fosse formado proporcionalmente à quantidade de Mo(VT) adicionada ao sistema. Assim sendo, concentrações muito baixas de triiodeto podem ser monitoradas amperometricamente em $+0,20 \mathrm{~V}$ no sistema em fluxo no qual o nível de corrente para o branco (solução contendo iodeto e perborato) seja bastante baixo, possibilitando a diminuição do limite de deteç̧ão para Mo(VI). Estudos até agora realizados demonstram ser possível trabalhar em faixa dinâmica de concentrações de $10^{-7}$ a $10^{-5} \mathrm{M}$ em Mo(VI) e limites de detecção de $10 \mathrm{nM}$ já foram atingidos [219]. 


\subsubsection{Uso de eletrodos modificados como sensores amperométricos}

Um outro procedimento idealizado para o desenvolvimento de métodos amperométricos em fluxo baseou-se na deposição de óxidos de molibdênio em eletrodos de carbono vítreo. Filmes constituídos por estes materiais apresentam excelente condutividade quando polarizados negativamente e observou-se que nas superficies modificadas a redução de substratos como bromato [189] e iodato [196] é significativamente facilitada. O mecanismo proposto em ambos os casos relaciona-se à formação de intermediário em que ocorre a transferência do átomo de oxigênio do substrato para o óxido reduzido em etapa rápida. $\mathrm{O}$ aumento mais significativo da corrente ao se trabalhar com iodato deve-se à maior polarizabilidade do átomo de iodo e desta forma estudos foram efetuados para o desenvolvimento de método analítico para a determinação deste substrato em amostras de sal de cozinha [196]. A Figura 44 apresenta os fiagramas obtidos durante injeções de amostra de sal de cozinha pelo método da adição de padrão e os resultados oriundos de análises de duas amostras distintas são concordantes com aqueles provenientes do uso do método oficial de análise (redução quantitativa do analito na presença de excesso de iodeto e posterior titulação do triiodeto formado com solução padrão de tiossulfato).

Como vantagens do método amperométrico proposto destacam-se o menor consumo de amostra e aumento na freqüência dos ensaios. A repetibilidade para injeções de solução $5 \times 10^{-5} \mathrm{M}$ de $\mathrm{IO}_{3}{ }^{-}$apresentou desvio de $6 \%(\mathrm{n}=22)$ e a linearidade de resposta situou-se entre $1 \times 10^{-5} \mathrm{M} \mathrm{e}$ $1 \times 10^{-2} \mathrm{M}$, não se observando interferência dos oxiânions nitrato, nitrito e perclorato. O bromato interferiu somente quando presente em concentração dez vezes superior à de iodato. Vale destacar que as medições foram efetuadas em potencial de $-0,6 \mathrm{~V}$, razão pela qual houve a necessidade de adaptação de sistema de desoxigenação das soluções para minimização de problemas relativos à redução faradaica do oxigênio dissolvido. 


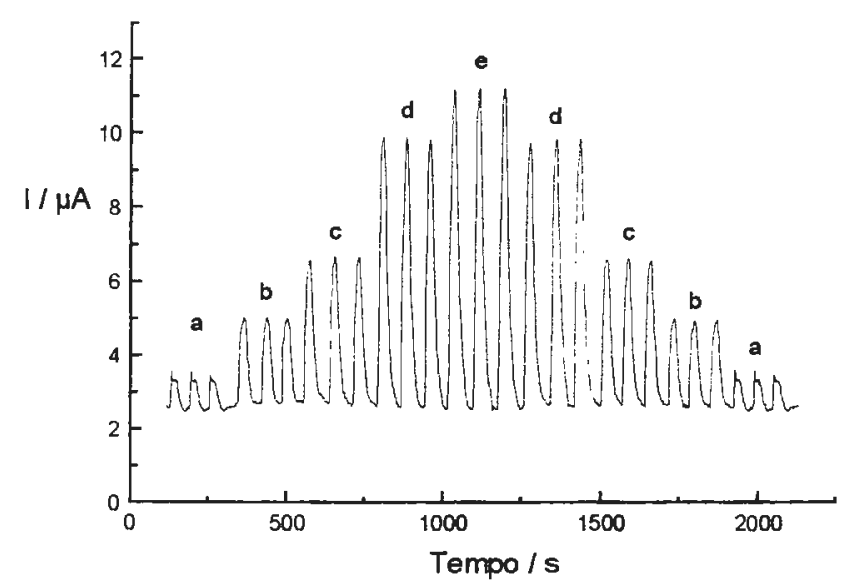

Figura 44. Deteç̧ão amperométrica em eletrodo modificado por óxido de molibdênio polarizado em

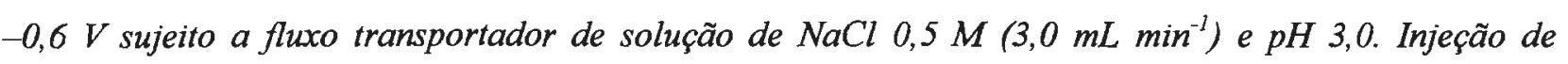
soluções de sal de cozinha $29,3 \mathrm{~g} \mathrm{~L}^{-1}$ em $\mathrm{pH} 2,5$, às quais adicionou-se previamente $\mathrm{KIO}_{3}$ nas seguintes concentrações finais: 0 (a), 0,1 (b), 0,2 (c), 0,4 (d) e 0,5 mM (e).

Ainda no que diz respeito ao uso do eletrodo modificado por óxidos de molibdênio em determinações analíticas, cabe destacar a possibilidade de determinação de nitrito em função da catálise do processo de transferência do átomo de oxigênio de moléculas de $\mathrm{MoO}_{3}$ para o produto da oxidação eletródica do substrato [220]. A Figura 45 mostra fiagramas que permitem a comparação dos sinais obtidos em superficies polidas lisas e modificadas. Dois aspectos são relevantes: a melhoria do sinal analítico em função da catálise e a minimização de envenenamento da superfície do eletrodo, a qual é responsável pela diminuição da corrente no eletrodo polido durante injeções consecutivas de nitrito.

Para aplicação em amostra natural, lingüiça recém-fabricada foi tratada adequadamente a fim de se extrair o nitrito remanescente do processo de preparo. $\mathrm{O}$ extrato diluído foi analisado pelo método amperométrico proposto nesse trabalho, conduzindo a valor similar àquele obtido pelo uso da metodologia padrão (método de Griess). A análise amperométrica pôde ser feita sem a necessidade de uso da técnica de adição de padrão, uma vez que o fator de recuperação calculado para a lingüiça foi de $104 \%$ (relação amostra sintética / amostra natural). Como interferentes, foram testados o ácido ascórbico e o sulfito, presentes geralmente em carnes, mas estes não apresentaram eletroatividade na faixa de potencial trabalhado, em pH 9,1. 


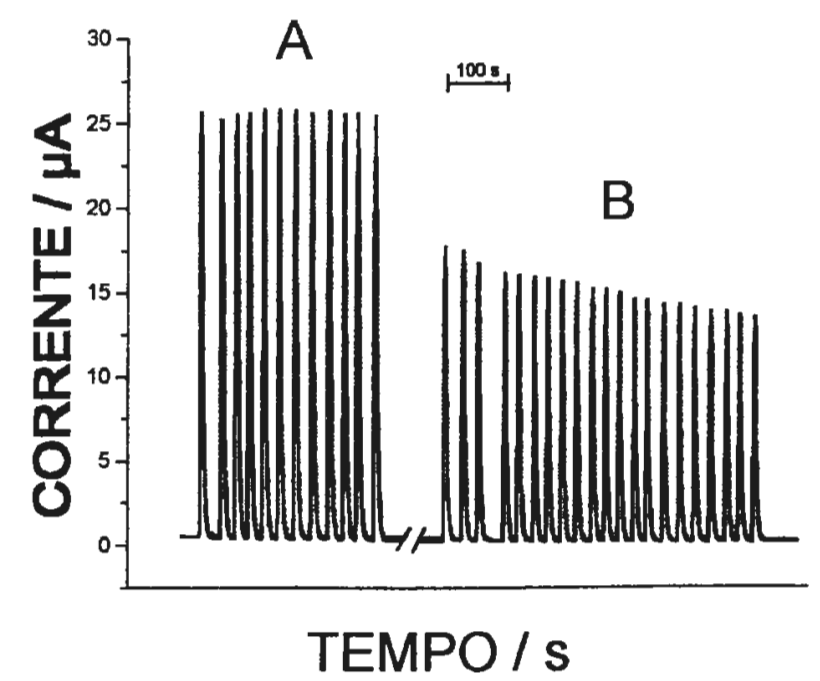

Figura 45. Fiagramas obtidos pela injeção de solução de nitrito $1 \mathrm{mM}$, em fluxo carregador de tampão $p H$ 9,1. $A$ = eletrodo modificado e $B=$ eletrodo polido, $E=1,0 \mathrm{~V}$.

Determinações analíticas em FIA com eletrodo modificado atuando como sensor amperométrico também foram realizadas utilizando as propriedades catalíticas de porfirinas tetrarutenadas de cobalto no que tange à oxidação eletroquímica do nitrito [221]. Neste sentido, os fiagramas apresentados na Figura 46 demonstram claramente a vantagem de se trabalhar com o eletrodo modificado uma vez que se pode trabalhar em potencial menos positivo e com sensibilidade ainda relativamente alta. Com configuração semelhante àquela apresentada na Figura 41, onde apresentou-se sistema para redução de nitrato a nitrito em fluxo, a disposição utilizada demonstrou-se bastante eficiente para a determinação de nitrato e nitrito em níveis de concentração abaixo daqueles prescritos pela legislação referente a águas. Estudos estão sendo agora efetuados com o intuito de empregar o método na análise de águas de rio na região de Ribeirão dos Pires, coletando-se as amostras em pontos estratégicos vizinhos a locais de descarte de rejeitos industriais. $O$ uso do sensor em tais casos não poderá prescindir de revestimento especial à base de membranas restritivas à passagem de interferentes possivelmente existentes nas matrizes. 


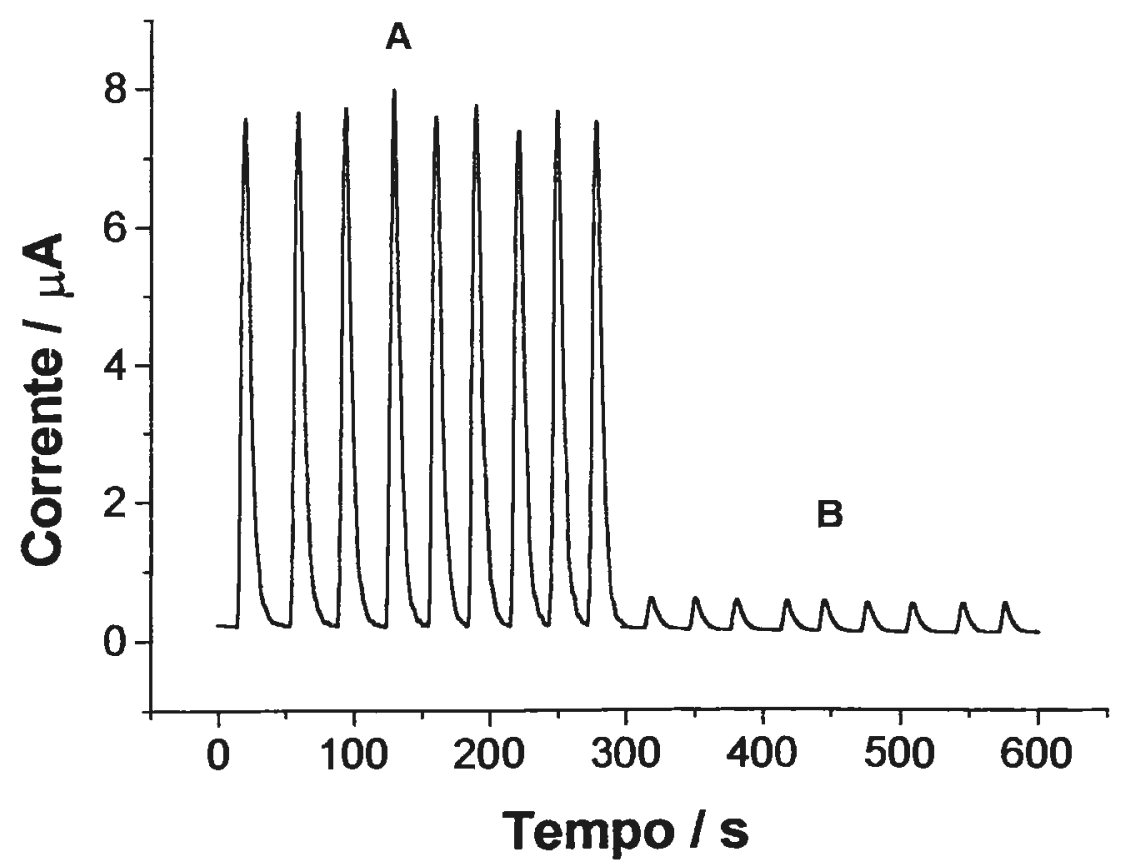

Figura 46. Fiagramas para injeções de solução de nitrito $1 \mathrm{mM}$ em fluxo carregador de tampão acetato $(p H=4,7)$ registrados em $0,75 \mathrm{~V}$ com eletrodo de carbono vitreo modificado com 1 bicamada das porfirinas CoTRBP/ZnTPPS (A) e eletrodo polido (B).

Outro analito de interesse devido à possibilidade de oxidação anódica em eletrodos sólidos é o sulfito. Métodos amperométricos envolvendo a determinação deste analito têm sido apresentados na literatura e geralmente envolvem a deposição de polímeros em eletrodos de platina ou carbono vítreo [208]. Uma alternativa interessante está relacionada a estudos envolvendo a modificação deliberada da superficie de eletrodos de cobre aplicando-se potenciais relativamente positivos trabalhando-se em meio alcalino. Nestas condições tem sido observado que o processo de oxidação anódica do sulfito (relativamente irreversível em superfícies não modificadas) ocorre com menor sobretensão, ocorrendo simultaneamente uma melhoria no sinal de corrente. Tal fato é possivelmente associado à formação de um filme de óxidos de cobre, os quais são aparentemente eficientes na catálise da oxidação eletroquímica do sulfito. Estudos preliminares em sistema FIA têm demonstrado as vantagens deste procedimento e perspectivas futuras estão relacionadas ao desenvolvimento de método para a determinação do analito em amostras de vinho utilizando membranas de difusão as quais permitem a passagem do $\mathrm{SO}_{2}$ 
formado em meio ácido. Minimizam-se, desta maneira, problemas referentes à oxidação de componentes do vinho eletroativos na faixa de potencial empregada.

Embora não diretamente relacionado a processos de eletrodo catalisados por espécies químicas alojadas adequadamente na superficie de eletrodos sólidos, é interessante ressaltar a possibilidade do uso de espécies químicas capazes de catalisar processos de transferência eletrônica estando dissolvidas em solução. São os chamados processos catalíticos EC', nos quais a uma etapa de transferência heterogênea de carga sucede-se reação química com substrato eletroinativo, regenerando-se a forma eletroativa na região próxima à superfície do eletrodo [23]. Do ponto de vista analítico, quanto mais rápida for a etapa química maior será o número de ciclos catalíticos. Como conseqüência, obtém-se uma magnificação sensível da corrente viabilizando o desenvolvimento de métodos analíticos para a quantificação da espécie eletroativa ou do substrato.

Um exemplo deste tipo de estratégia envolveu a determinação cronocoulométrica de U(VI) [222]. Devido ao processo catalítico em que U(IV) (ou U(III)) eletroquimicamente gerado reage com nitrato, correntes significativamente elevadas são obtidas na presença de excesso de substrato trabalhando-se com U(VI) em níveis de traços. O uso da cronocoulometria mostrou-se particularmente favorável pois em razão da possibilidade de discriminação de fenômenos capacitivos medindo-se a carga alguns segundos após o pulso de potencial, limites de detecção da ordem de $10^{-10} \mathrm{M}$ foram atingidos. Demonstrou-se também que adicional redução no limite de detecção pode ser obtido associando-se etapa prévia de pré-concentração do analito e em trabalho posterior adaptou-se o método catalítico a sistema FIA [223]. Esta combinação de estratégias (catálise + pré-concentração) visando à melhoria na sensibilidade das determinações é sem dúvida nenhuma um dos focos de interesse na moderna eletroanalítica. 


\subsubsection{Procedimentos relacionados à geração química de espécies eletroativas}

Demonstrou-se em seção anterior que a adição de sulfito a soluções contendo $\mathrm{Cu}$ (II) complexado a certas glicinas provoca a formação de $\mathrm{Cu}(\mathrm{III})$, o qual pode ser monitorado em potencial de $+0,1 \mathrm{~V}$. A Figura 47 apresenta um gráfico da corrente monitorada com o eletrodo rotativo polarizado no potencial adequado (onde ocorre a redução do cobre trivalente) em função do tempo durante adições de solução de sulfito. Verifica-se a existência de 'degraus' de corrente catódica de intensidade proporcional à quantidade de sulfito adicionado à solução, indicando a potencialidade de emprego do sistema $\mathrm{Cu}$ (II) / $\mathrm{Cu}$ (III) no desenvolvimento de metodologia analítica para determinação deste substrato.

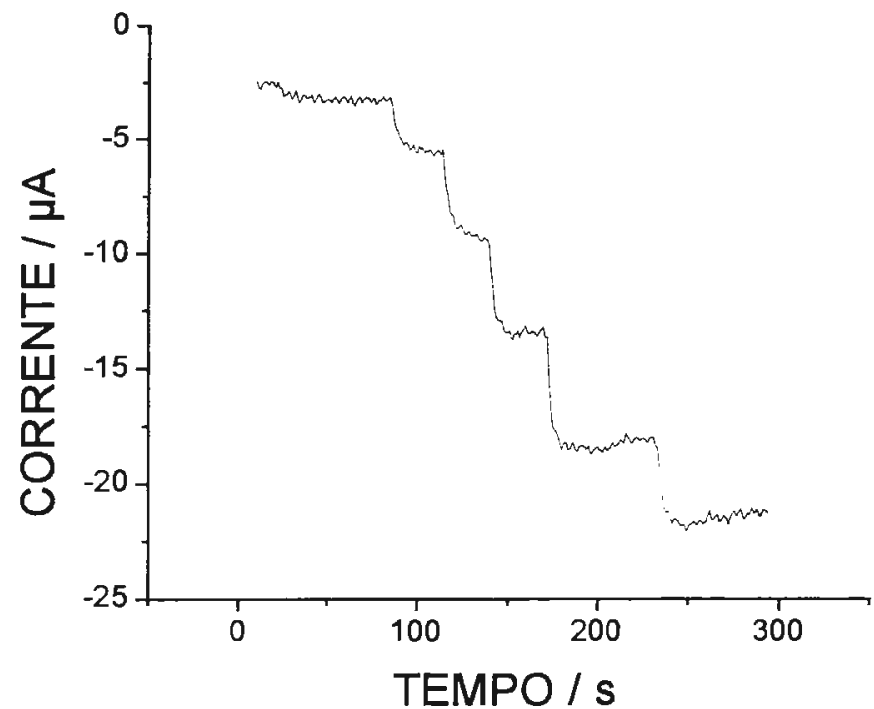

Figura 47. Dependência da corrente medida com eletrodo rotativo (900 rpm) polarizado em $+0,1 \mathrm{~V} \mathrm{em}$ solução tampão pH $10(10,0 \mathrm{ml})$ contendo [CuG4] $1 \mathrm{mM}$, durante adições sucessivas (10 $\mu$ l) de solução de sulfito $2 \mathrm{mM}$.

Com base nos resultados promissores apresentados na Figura 47, estudos preliminares foram efetuados com sistema FIA. Para tanto, montou-se o seguinte sistema: 


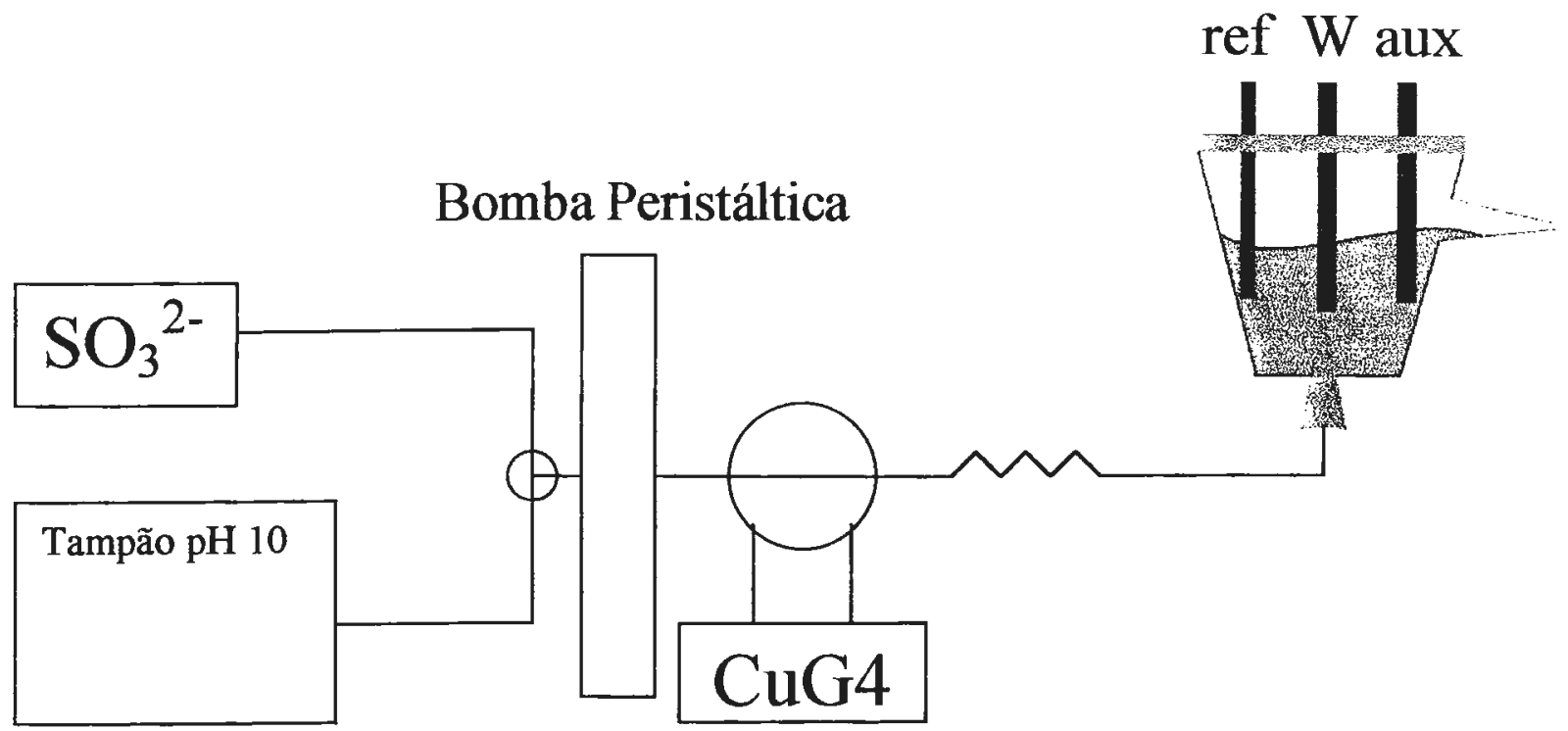

Figura 48. Sistema FIA utilizado no método para determinação de sulfito empregando-se o par Cu (II) / Cu (III) em meio complexante.

A Figura 48 representa o esquema do sistema FIA montado para a realização de testes preliminares relativos à determinação de sulfito utilizando-se o par $\mathrm{Cu}$ (II) / Cu (III). Injeta-se a solução de [CuG4] ao fluxo proveniente de uma confluência entre solução tampão $\mathrm{pH} 10$ e amostra de sulfito pois o ligante é geralmente mais caro do que a amostra que contém sulfito para análise. O material reage em fluxo no interior de uma bobina de 2,0 m (tubo de silicone) e a célula eletroquímica é do tipo "wall-jet". A Figura 49 apresenta o fiagrama obtido em estudos preliminares para a determinação de sulfito em fluxo. Verifica-se a existência de picos de corrente de intensidade proporcionais à concentração de sulfito injetado, indicando a viabilidade do método analítico. 


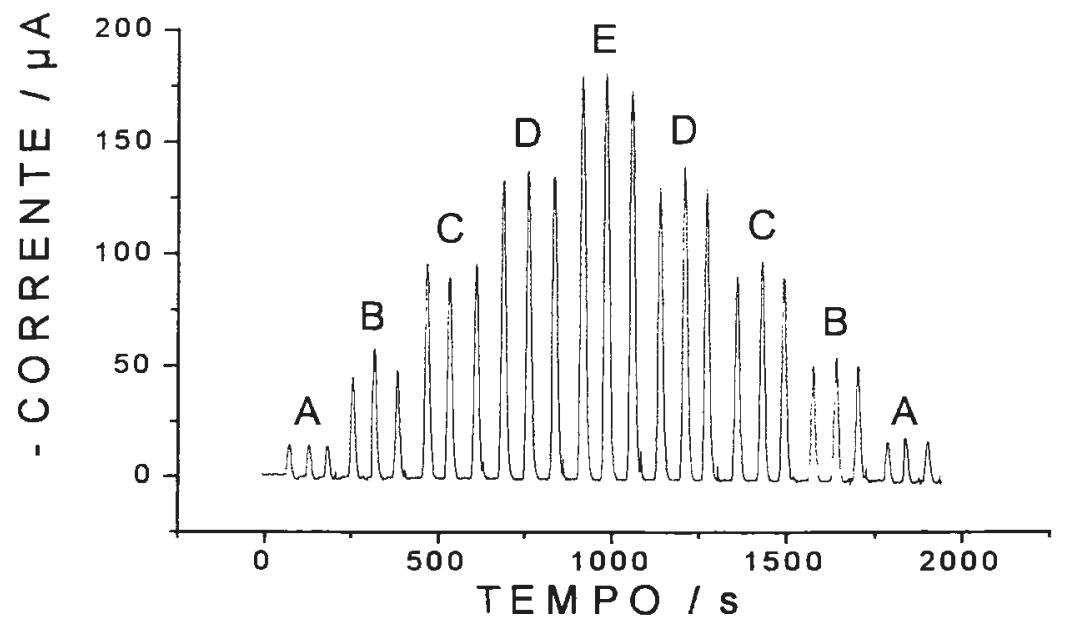

Figura 49. Fiagrama obtido utilizando-se eletrodo de carbono vitreo polarizado em $+0,1 \mathrm{~V}$, pela injeção de [CuG4] $1 \mathrm{mM}$ em fluxo de tampão pH 10 contendo sulfito nas seguintes concentrações: $A=5.10^{-7} \mathrm{M}$; $B=1,5.10^{-6} \mathrm{M} ; \mathrm{C}=2,5.10^{-6} \mathrm{M} ; \mathrm{D}=3,5.10^{-6} \mathrm{M} ; \mathrm{E}=4,5.10^{-6} \mathrm{M}$.

Outro analito de interesse ambiental cuja determinação via métodos eletroquímicos não é muito difundida é o fosfato. A determinação desta substância em águas constitui-se em problema ambiental de contínuo interesse em face à sua atuação como nutriente para diversos microorganismos. Procedimentos espectrofotométricos estão bem estabelecidos na literatura mas envolvem etapa prévia de redução do complexo de $\mathrm{Mo}$ (VI) com fosfato para posterior detecção fotométrica. Além disso, para amostras de águas com elevados valores de turbidez as medidas de absorbância podem conduzir a erros não desprezíveis. Em tais casos, a remoção do material filtrado pode amenizar os problemas associados à deteç̧ão fotométrica; entretanto, adiciona-se uma etapa a mais no procedimento analítico e aumentam-se as possibilidades de arraste de fosfato que pode eventualmente adsorver no material particulado em suspensão [224]. Neste contexto, o desenvolvimento de procedimento eletroanalítico para a determinação de fosfato apresenta-se como alternativa de interesse principalmente devido à simplicidade, baixo custo da instrumentação e possibilidade de atingir-se baixos limites de detecção.

A formação de compostos mistos denominados heteropolimolibdatos na reação química entre fosfato e Mo(VI) em meio ácido é bem conhecida na literatura, havendo inclusive estudos eletroquímicos os quais demonstram a eletroatividade da espécie geralmente conhecida como 12MPA, (12-molybdophosphoric acid), em potenciais relativamente positivos [225,226]. Uma vez 
que o ânion fosfato não é eletroativo nos potenciais normalmente utilizados, métodos analíticos para a quantificação desta espécie têm sido desenvolvidos com base nesta reação de "derivatização"; o sinal de corrente fornecido pela redução do 12-MPA é então diretamente relacionado com a concentração de fosfato [227]. Estudos preliminares neste sistema envolveram a escolha das condições ideais de acidez para a formação do composto 12-MPA registrando-se voltamogramas com microeletrodo de platina $(\mathrm{r}=12,5 \mu \mathrm{m})$. Os resultados indicaram que sinais de corrente mais intensos referentes à redução do composto foram obtidos em solução de $\mathrm{H}_{2} \mathrm{SO}_{4}$ $10 \mathrm{mM}$, observando-se onda voltamétrica bem definida na região de 0,2 a $0,1 \mathrm{~V}$. Uma vez que a estequiometria do complexo é de 1 Mo : $12 \mathrm{P}$ há necessidade de se trabalhar com excesso relativamente grande de $\mathrm{Mo}(\mathrm{VI})$, o qual não é eletroativo nesta faixa de trabalho.

De acordo com a metodologia experimental estabelecida, estudos envolvendo a possibilidade da determinação amperométrica de fosfato foram realizados empregando-se eletrodo rotativo de carbono vítreo polarizado em $+0,1 \mathrm{~V}$ em solução contendo $\mathrm{Mo}(\mathrm{VI}) 10 \mathrm{mM}$ em $\mathrm{H}_{2} \mathrm{SO}_{4} 10 \mathrm{mM}$. Na Figura 50 apresentam-se os resultados de adições consecutivas de solução de fosfato à solução de trabalho, observando-se o aumento imediato da corrente. Este aumento rápido do sinal demonstra que o complexo do fosfato com $\mathrm{Mo}$ (VI) tem cinética rápida de formação. Pela figura pode-se também notar que, pelo menos na faixa de concentração de fosfato utilizada, o sinal de corrente foi proporcional à concentração do analito.

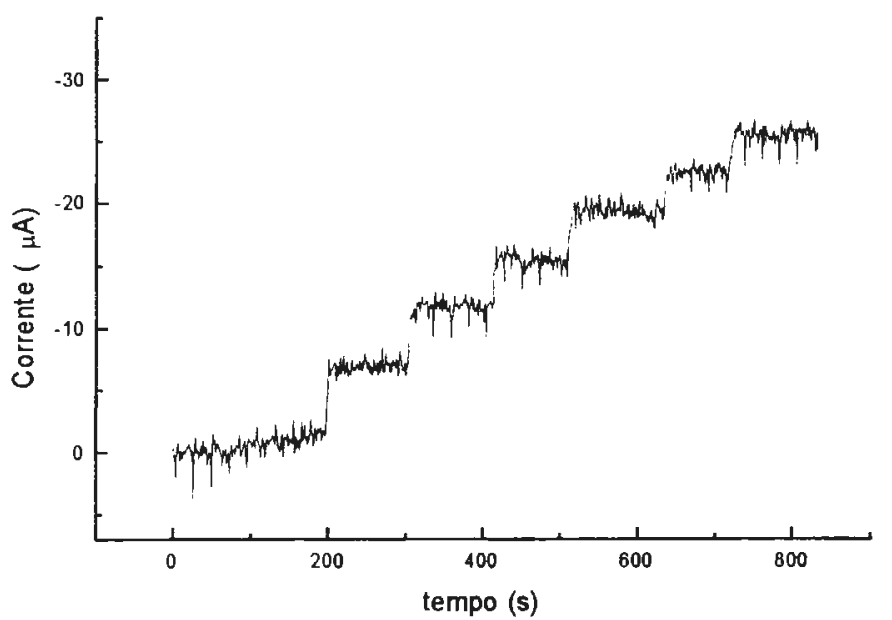

Trabalhos já relatados na literatura demonstram que o composto 12-MPA é mais estável em meios aquosos contendo certa proporção de solventes orgânicos [228,229]. Neste sentido,

Figura 50. Variação da corrente monitorada em eletrodo rotativo de carbono vítreo polarizado em $+0,1 \mathrm{~V}$ durante adições de solução de fosfato (cada degrau de corrente corresponde $\grave{a}$ adição de fosfato $0,05 \mathrm{mM}$, (concentração final em solução)) à solução de trabalho composta de $\mathrm{Mo}(\mathrm{VI}) 10 \mathrm{mM} \mathrm{em} \mathrm{H}_{2} \mathrm{SO}_{4} 10 \mathrm{mM}$. 
estudos foram realizados trabalhando-se com acetona como solvente orgânico e os resultados são apresentados na figura abaixo. Percebe-se claramente a melhoria na sensibilidade em meios aquosos contendo 20 e $40 \%$ de acetona em relação às condições de ausência deste solvente ou em quantidades excessivas. Esta observação é importante uma vez que no desenvolvimento do método analítico para análise de fosfato em águas parece ser possível aumentar consideravelmente a sensibilidade das determinações no sistema FIA adicionando-se às soluções de trabalho quantidades apropriadas de acetona. Nas condições experimentais otimizadas, pretende-se desenvolver procedimento em fluxo para a análise de fosfato com detecção amperométrica. $O$ método analítico será posteriormente utilizado na análise de fosfato em amostras de águas do rio Ribeirão dos Pires.

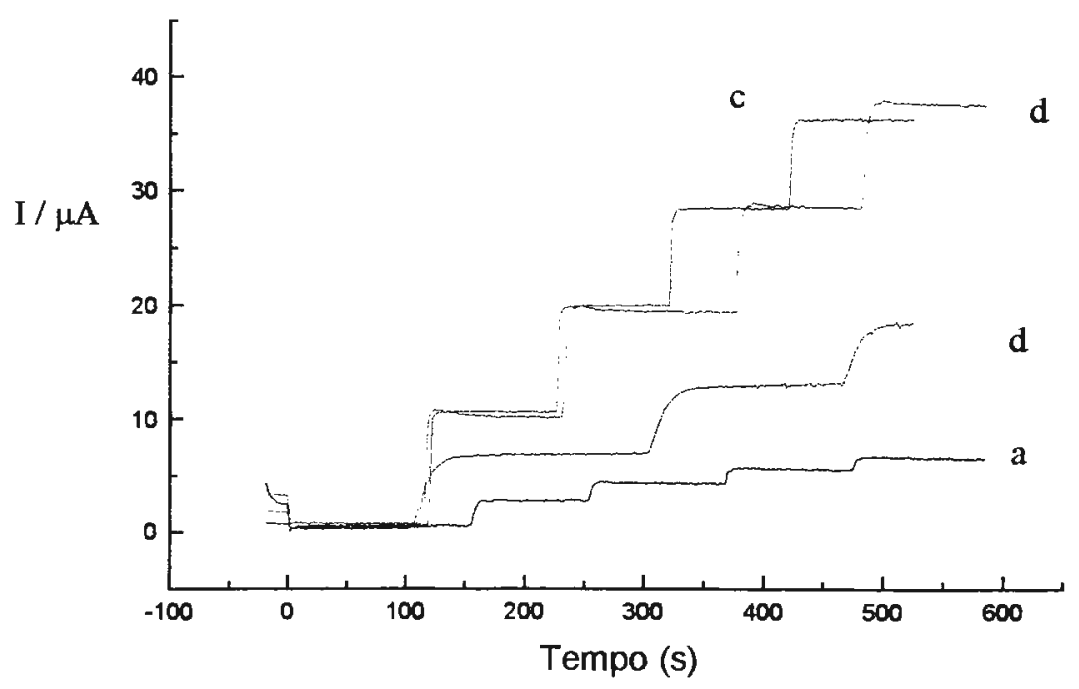

Figura 51. Variação da corrente monitorada em eletrodo rotativo de carbono vitreo polarizado em $+0,1 \mathrm{~V}$ durante adições de solução de fosfato (cada adição corresponde a fosfato 0,05 $\mathrm{mM}$, (concentração final em solução)) às solução de trabalho compostas de $\mathrm{Mo}(\mathrm{VI}) 10 \mathrm{mM}$ em $\mathrm{H}_{2} \mathrm{SO}_{4} 10 \mathrm{mM}$ e diferentes porcentagens de acetona: $a=0, b=20, c=40, d=60 \%(v / v)$. 


\section{CONSIDERAÇÕES FINAIS}

As contribuições arroladas no presente texto demonstram o empenho no esclarecimento do mecanismo de processos eletródicos referentes a alguns sistemas químicos e posterior aplicação no desenvolvimento de métodos analíticos em fluxo. As vantagens inerentes ao emprego de microeletrodos em soluções estacionárias ou em movimento controlado, quer seja do ponto de vista acadêmico ou aplicado, foram discutidas e confirmadas com base em dados extraídos de diferentes sistemas químicos. Assim sendo, os resultados apresentados constituemse em prova inequívoca das amplas possibilidades de atuação e possível penetração da eletroanalítica em áreas como bioquímica, indústria de alimentos e química ambiental, fundamentadas em aspectos favoráveis dos métodos eletroquímicos. Estes incluem a versatilidade, possibilidade de controle das reações eletródicas pela seleção de potenciais apropriados, facilidade de automação pois medem-se sinais elétricos, "compatibilidade ambiental" uma vez que o reagente empregado é o elétron e custo baixo da instrumentação.

Embora haja vantagens indiscutíveis no uso de técnicas eletroquímicas no desenvolvimento de sensores, há aspectos que ainda estão no limiar de plausíveis soluções quando se pensa em termos "realmente práticos". Um exemplo clássico é a operação de sensores para glicose; quando implantados no tecido humano, é de se esperar uma pronta resposta do organismo contra a "invasão", resultando no desenvolvimento de camadas protetoras que tendem a isolar o dispositivo do ambiente celular. Outros ítens a serem considerados relacionam-se à necessidade de recarregamento da bateria do sensor e eventual recalibração periódica. Trata-se, portanto, de aspectos de ordem prática os quais dificultam sobremaneira a disseminação do uso rotineiro destes dispositivos.

Apesar das preocupações acima expostas, há na literatura exemplos de artefatos para medições "in-situ" baseados em informações eletroquímicas [230-233]. Estes geralmente se baseiam na pré-concentração de íons metálicos presentes em ambientes aquáticos e posterior determinação da concentração das espécies acumuladas. A minimização de interferências associadas ao envenenamento da superfície do eletrodo tem sido efetuada com base no uso de polímeros orgânicos como Nafion e acetato de celulose. Recentemente demonstrou-se que o recobrimento do eletrodo com uma membrana de gelatina sólida pode ter vantagens adicionais relacionadas ao menor efeito da convecção nas medições, uma vez que a camada protetora 
possui espessuras relativamente grandes sem diminuir significativamente a velocidade de transporte do analito à superficie do eletrodo [234].

No que tange à possibilidade de redução da exposição do eletrodo a contaminações provenientes de amostras reais, cabe também destacar os seguidos progressos oriundos da introdução de amostras por sistemas FIA ou BIA ("batch injection analysis"). Este último apresenta como vantagem adicional a inexistente dispersão da amostra. Menores tempos de contato da amostra com o eletrodo são também obtidos realizando-se o experimento em escalas reduzidas de tempo, possibilidade relativamente simples ao se trabalhar com a técnica de voltametria de onda quadrada ou com microeletrodos. Nestes casos pode-se adicionalmente conseguir informações qualitativas com base no voltamograma registrado de forma completa $[235,236]$.

Em razão das crescentes facilidades computacionais e de desenvolvimentos na área de quimiometria, há que se destacar iniciativas pioneiras no sentido de elaboração de sistemas de inteligência artificial que possam simular alguns dos sentidos humanos como o olfato e o gosto [237-240]. Com este intuito, "narizes" e "línguas" instrumentais têm sido desenvolvidos com base na deteç̧ão de alguns analitos componentes de amostras complexas como sucos, águas de diferentes procedências, óleos comestíveis, compostos voláteis em misturas gasosas, etc. Nestes casos, vale-se de análise multivariada dos resultados fornecidos por vários sensores que possibilitam a maximização da informação sobre o composto em questão, mesmo que se tenha dados de qualidade precária.

Dos trabalhos apresentados neste texto crítico e levando-se em conta o panorama atual da química eletroanalítica, percebe-se o contínuo crescimento da área de sensores eletroquímicos e dois aspectos principais têm sido destacados como desafios para os próximos anos. Um deles diz respeito à miniaturização dos sensores, de modo a se poder trabalhar em microambientes. Neste sentido, pesquisas na área de microeletrodos e no desenvolvimento de novos materiais têm contribuído favoravelmente para a obtenção de resultados amplamente inusitados. $\mathrm{O}$ outro aspecto de interesse vincula-se à possibilidade de coleta de dados em sistemas reais e com manipulação mínima das amostras; desta forma, os resultados obtidos podem ser analisados e correlacionados com outros parâmetros no contexto em que estão inseridos. Observa-se, portanto, que o termo "sensor" passa a ser usado num contexto mais restrito e ideal, segundo o qual a informação é obtida em tempo real (ou após alguns poucos segundos). Cabe também 
destacar que sensores do tipo "tiras" (por exemplo, para se medir o pH) não se enquadram na classificação a que se está referindo uma vez que nestes casos o sinal não pode ser medido de maneira contínua e reversivel.

O futuro das investigações voltadas para o desenvolvimento de sensores eletroquímicos neste Instituto de Química é bastante promissor pois há massa crítica e condições de infraestrutura nos diferentes campos do conhecimento. A elaboração racional de sistemas macromoleculares ou outros compostos que viabilizem o reconhecimento de analitos de interesse e possibilitem interações eletródicas em potenciais mais amenos certamente constitui-se em etapa relevante do processo. Procedimentos para a caracterização da interação entre substrato e material imobilizado no eletrodo consistem em passo importante para a explicação dos mecanismos responsáveis pela catálise do processo eletródico e neste sentido há especial intenção do uso de técnicas espectroscópicas e de análise de superfície, pouco citadas nos trabalhos aqui discutidos. A colaboração com colegas da área de Engenharia de Materiais pode trazer subsídios para a fabricação de microestruturas às quais serão depositados filmes adequados para os propósitos analíticos. Estabelecidas as condições ideais para a construção e uso dos sensores, a aproximação com pesquisadores vinculados a áreas correlatas (bioquímica, medicina, fisiologia, química ambiental, geoquímica, etc) certamente será de valia para testes dos dispositivos fabricados em condições reais e sugestões a respeito de novos projetos e idéias.

A linha de pesquisa a que se propõe seguir certamente dependerá da formação de equipe competente e com visão abrangente não só em aspectos ligados à área de Analítica mas em Química como um todo. Esta equipe está sendo formada gradualmente e os resultados iniciais estão apresentados neste trabalho. Conforme já frisado, interações eficientes com profissionais de diversos setores são também altamente desejáveis para que se atinja pleno êxito nas proposições estabelecidas. Como não poderia deixar de ser, este é o caminho da moderna Química Analítica, área do conhecimento preocupada com a expansão do conhecimento sobre a matéria e sua composição e com a melhoria da qualidade de vida dos seres humanos. 


\section{REFERÊNCIAS BIBLIOGRÁFICAS}

1. R.F.Lane e A.T. Hubbard, J. Phys. Chem., 77 (1973) $1401,1411$.

2. R.W. Murray, Acc. Chem. Res., 13 (1980) 135.

3. J. Zak and T. Kuwana, J. Electroanal. Chem., 150 (1983) 645.

4. R.W. Murray, Electroanal. Chem. 15 (1989) 267.

5. C.E.D. Chidsey and R.W. Murray, Science, 231 (1986) 25.

6. R.W. Murray, A.G. Ewing and R.A. Durst, Anal. Chem., 59 (1987) 379A.

7. H.D. Abruña, Coord. Chem. Rev., 86 (1988) 135.

8. M.F.B. Souza, Quim. Nova, 20 (1997) 191.

9. Comission on Electroanalytical Chemistry, Pure and Appl. Chem., 69 (1997) 1318.

10. L.R. Faulkner, Electrochim. Acta, 34 (1989) 1699.

11. E. Laviron, J. Electroanal. Chem., 131 (1982) 61.

12. C.P. Andrieux, J.M. D.-Bouchiat and J.M. Savéant, J. Electroanal. Chem., 131 (1982) 1.

13. C.P. Andrieux, J.M. D.-Bouchiat and J.M. Savéant, J. Electroanal. Chem., 169 (1984) 9.

14. W.J. Albery and A.R. Hillman, J. Electroanal. Chem., 170 (1984) 27.

15. F.B. Kaufman and E.M. Engler, J. Am. Chem. Soc., 101 (1979) 549.

16. P. Denisevich, K.W. Willman and R.W. Murray, J. Am. Chem., Soc., 103 (1981) 4727.

17. C.R. Martin and L.S. Van Dyke, "Molecular Design of Electrode Surfaces", John Wiley, New York, 1992.

18. R.D. Rocklin and R.W. Murray, J. Phys. Chem., 85 (1981) 2105.

19. K.-N. Kuo and R.W. Murray, J. Electroanal. Chem., 131 (1982) 37.

20. X. Chen, P. He and L.R. Faulkner, J. Electroanal. Chem., 222 (1987) 223.

21. B. Lindholm, J. Electroanal. Chem., 250 (1988) 341.

22. M.E.G. Lyons, Analyst, 119 (1994) 805.

23. A.J. Bard and L.R. Faulkner, "Electrochemical Methods: Fundamentals and Applications", Wiley, New York, 1980.

24. A..M. Becka and C.J. Miller, J. Phys. Chem., 97 (1993) 6233

25. D. Mandler and I. Turyan, Electroanalysis, 8 (1996) 207. 
26. F. Bonosi, G. Ricciardi and F. Lelj, Thin Solid Films, 243 (1994) 310.

27. S. Pfeiffer, C. Mingotaud, C.G.-Lagrange and P. Delhaes, Langmuir, 11 (1995) 2705.

28. S. Liu, Z. Tang, A. Bo, E. Wang and S. Dong, J. Electroanal. Chem., 458 (1998) 87.

29. M.D. Baker, C. Senaratne and J. Zhang, J. Phys. Chem., 98 (1994) 1668.

30. K. Kalcher, J.M. Kauffmann, J. Wang, I. Svancara, K. Vytras, C. Neuhold and Z. Yang, Electroanalysis, 7 (1995) 5.

31. T.M. Swager, Acc. Chem. Res., 31 (1998) 201.

32. T.E. Mallouk and J. Gavin, Acc. Chem. Res., 31 (1998) 209.

33. R.Greef, R. Peat. L.M. Peter, D. Pletcher, and J. Robinson, "Instrumental Methods in Electrochemistry", Ellis Horwood, New York, 1993.

34. J.Q. Chambers, J. Electroanal. Chem., 130 (1981) 381.

35. C.R. Martin, I. Rubinstein and A.J. Bard, J. Am. Chem. Soc., 104 (1982) 4817.

36. P. Daum, J.R.Lenhard, D. Rolison and R.W. Murray, J. Am. Chem. Soc., 102 (1980) 4650.

37. D.N. Blauch and J.-M. Savéant, J. Am. Chem. Soc., 114 (1992) 3323.

38. K. Marsymiuk and K. Doblofer, Electrochim. Acta, 39 (1994) 217.

39. K. Ashley, F. Weinert and D.L. Feldheim, Electrochim. Acta, 36 (1991) 1863.

40. F. Ni, M. Feng, L. Gorton and T.M. Cotton, Langmuir, 6 (1990) 66.

41. P.A. Christensen and A. Hamnett, "Techniques and Mechanisms in Electrochemistry", Blackie Academic \& Professional, Glasgow, 1994.

42. D.A. Buttry and M.D. Ward, Chem. Rev., 92 (1992) 1355.

43. R.P. Baldwin and K.N. Thomsen, Talanta, 38 (1991) 1.

44. J. Wang, Electroanalysis, 3 (1991) 225.

45. V.B. Nascimento and L. Angnes, Quim. Nova, 21 (1998) 614.

46. C. Henry, Anal. Chem., 70 (1998) 594A.

47. X. Cai, B. Ogorevc, G. Tavcar and K. Kalcher, Electroanalysis, 7 (1995) 639.

48. G.S. Wilson and G. Sittampalam, Anal. Chem., 55 (1983) 1608.

49. G. Navy, G.A. Gerhardt, A.F. Oke, M.E. Rice, R.N. Adams, R.B. Moore, M.N. Szentirmay and C.R. Martin, J. Electroanal. Chem., 188 (1985) 85.

50. M.A.T. Gilmartin and J.P Hart, Analyst, 120 (1998) 1029.

51. G.G. Guilbault and G.L. Lubrano, Anal. Chim. Acta, 64 (1973) 439. 
52. P.W. Davies and F. Brink, Rev. Sci. Instrum., 13 (1942) 524.

53. H.A. Laitinen and I.M. Kolthoff, J. Phys. Chem., 45 (1941) 1062.

54. A.M. Bond, K.B. Oldham and C.G. Zoski, Anal. Chim. Acta, 216 (1989) 177.

55. R.M. Wightman, Anal. Chem., 53 (1981) 1125A.

56. S. Pons and M. Fleischmann, Anal. Chem., 59 (1987) 1391 A.

57. M. Fleischmann, S. Pons, D.R. Rolison and P.P. Schimdt, "Ultramicroelectrodes", Datatech Systems, Morgantown, NC, 1987.

58. M.I. Montenegro, M.I., J. Daschbach and A.M. Queiros, "Microelectrodes - Principles and Applications", NATO ASI Series, Reidel, Dordrecht, 1990.

59. M. Ciszkowska and Z. Stojek, J. Electroanal. Chem., 466 (1999) 129.

60. M. Ciszkowska and Z. Stojek, Anal Chem., 64 (1992) 2372.

61. M. Ciszkowska, Z. Stojek and J.G. Osteryoung, J. Electroanal. Chem., 398 (1995) 49.

62. M. Ciszkowska and Z. Stojek, J. Electroanal. Chem., 213 (1986) 189.

63. R. Brina, S. Pons and M. Fleischmann, J. Electroanal. Chem., 244 (1988) 81.

64. J.O. Howell and R.M. Wightman, Anal. Chem., 56 (1984) 524.

65. P.J. Kulesza and L.R. Faulkner, J. Am. Chem. Soc., 115 (1993) 11878.

66. R. Kashyap amd M. Gratzi, Anal. Chem., 70 (1998) 1468.

67. R.A. Clark and A.G. Ewing, Anal. Chem., 70 (1998) 1119.

68. C. Beriet and D. Pletcher, J. Electroanal. Chem., 375 (1994) 213.

69. K. Winkler, J. Electroanal. Chem., 388 (1995) 151.

70. J.V. Macpherson, M.A. Beeston and P.R. Unwin, J. Chem. Soc., Far. Trans., 91 (1995) 899.

71. J.A. Alden and R.G. Compton, J. Phys. Chem., 101 (1997) 9606.

72. M. Fleischmann, F. Lasserre and J. Robinson, J. Electroanal. Chem., 177 (1984) 115.

73. K. Aoki, M. Ishida and K. Tokuda, J. Electroanal. Chem., 245 (1988) 39.

74. M. Fleischmann, F. Lasserre, J. Robinson and D. Swan, J. Electroanal. Chem., 177 (1984) 97.

75. K.B. Oldham, C.G. Zoski and A..M. Bond, J. Electroanal. Chem., 248 (1988) 467.

76. S. Daniele, P. Ugo, G.A. Mazzocchin and G. Bontempelli, J. Electroanal. Chem., 267 (1989) 129. 
77. G. Denuault, M. Fleischmann, D. Pletcher and O.R. Tutty, J. Electroanal. Chem., 280 (1990) 243.

78. G. Denuault, M. Fleischmann and D. Pletcher, J. Electroanal. Chem., 280 (1990) 255.

79. A. Jaworski, M. Donten, Z. Stojek and J.G. Osteryoung, Anal. Chem., 71 (1999) 167.

80. J.O. Howell, J.M. Gonçalves, C. Amatore, L. Klasinc, R.M. Wightman and J.K. Kochi, J. Am. Chem. Soc., 106 (1984) 3968.

81. G. Che and S. Dong, Electrochim. Acta, 37 (1992) 2695, 2701.

82. J.V. Macpherson, S. Marcar and P.R. Unwin, Anal. Chem., 66 (1994) 2175.

83. R.D. Martin and P.R. Unwin, J. Electroanal. Chem., 397 (1995) 325.

84. J.V. Macpherson and P.R. Unwin, Anal. Chem., 70 (1998) 2914.

85. J.A. Alden and R.G. Compton, Anal. Chem., 72 (2000) 199A.

86. P.R. Unwin and A.J. Bard, J. Phys. Chem., 95 (1991) 7814.

87. F. Zhou, P.R. Unwin and A.J. Bard, J. Phys. Chem., 96 (1992) 4917.

88. R.D. Martin and P.R. Unwin, J. Chem. Soc., Far. Trans., 94 (1998) 753.

89. A.N. Correia, L.H. Mascaro, S.A.S. Machado, L.H. Mazo e L.A. Avaca, Química Nova, 18 (1995) 475 .

90. D.O. Wipf, A.C. Michael and R.M. Wightman, J. Electroanal. Chem., 269 (1989) 15.

91. M.E. Rice and C. Nicholson, Anal. Chem., 61 (1989) 1805.

92. L. Hernández, P. Hernández and F. Patón, Anal. Chim. Acta, 327 (1996) 117.

93. T.J. Cardwell, J. Mocak, J.H. Santos and A.M. Bard, Analyst, 121 (1996) 357.

94. J. Wang, T. Martinez, D.R. Yaniv and L.D. McCormick, J. Electroanal. Chem., 278 (1990) 379.

95. M.L. Bowers and B.A. Yenser, Anal. Chim. Acta, 243 (1991) 43.

96. K.R. Wehmeyer and R.M. Wightman, J. Electroanal. Chem., 196 (1985) 417.

97. G.Zhao, D.M. Giolando and J.R. Kirchhoff, J. Electroanal. Chem., 379 (1994) 505.

98. X. Zhang, B. Ogorevc, G. Tavcar and I.G. Svegl, Analyst, 121 (1996) 1817.

99. X. Zhang and B. Ogorevc, Anal. Chem., 70 (1998) 1646.

100. A. Schulte and R.H. Chow, Anal. Chem., 70 (1998) 985.

101. C.J. Slevin, N.J. Gray, J.V. Macpherson, M.A. Webb and P.R. Unwin, Electrochem. Commun., 1 (1999) 282. 
102. K.R. Wehmeyer, M.R. Deakin and R.M. Wightman, Anal. Chem., 57 (1985) 1913.

103. D.H. Craston, C.P. Jones, D.E. Williams and N.El Murr, Talanta, 38 (1991) 17.

104. Z. Porat, J.C. Crooker, Y. Zhang, Y. Le Mest and R.W. Murray, Anal. Chem., 69 (1997) 5073 .

105. M.P. Nagale and I. Fritsch, Anal. Chem., 70 (1998) 2902.

106. M.J. Nuwer and J. Osteryoung, Anal. Chem., 61 (1989) 1954.

107. W.L. Caudill, O.J. Howell and M.R. Wightman, Anal. Chem., 54 (1982) 2532.

108. H.-P. Nirmaier and G. Henze, Electroanalysis, 9 (1997) 619.

109. J. Wang, A. Brennsteiner, L. Angnes, A. Sylvester, R.R. LaGasse and N. Bitsch, Anal. Chem., 64 (1992) 151.

110. H.P Wu, Anal. Chem., 65 (1993) 1643.

111. V.B. Nascimento, M.A. Augelli, J.J. Pedrotti, I.G.R. Gutz and L. Angnes, Electroanalysis, 9 (1997) 335.

112. J.M. Elliott, P.R. Birkin, P.N. Bartlett and G.S. Attard, Langmuir, 15 (1999) 7411.

113. H.R. Corti, D.L. Goldfarb, M.S. Ortiz and J.F. Magallanes, Electroanalysis, 7 (1995) 569.

114. C.-L. Wang, K.E. Creasy and B.R. Shaw, J. Electroanal. Chem., 300 (1991) 365.

115. G. Zhao, D.M. Giolando and J.R. Kirchhoff, Anal. Chem., 67 (1995) 1491.

116. A.J. Bard, J.A. Crayston, G.P. Kittlesen, T.V. Shea and M.S. Wrighton, Anal. Chem., 58 (1986) 2321

117. J. Lu and P. Lu, J. Electroanal. Chem., 244 (1988) 339.

118. C. Zhang and X. Zhou, J. Electroanal. Chem., 415 (1996) 65.

119. D. Bustin, S. Jursa and P. Tomcik, Analyst, 121 (1996) 1795.

120. P. Tomcik, S. Jursa, S. Mesaros and D. Bustin, J. Electroanal. Chem., 423 (1997) 115.

121. C.G. Phillips and H.A. Stone, J. Electroanal. Chem., 437 (1997) 157.

122. D.T. Miles, A. Knedlik and D.O. Wipf, Anal. Chem., 69 (1997) 1240.

123. C. Demaille, M. Brust, M. Tsionsky and A.J. Bard, Anal. Chem., 69 (1997) 2323.

124. N.F. Shram, L. Netchiporouk, C. Martelet, N. J.- Renaualt, C. Bonnet and R. Cespuglio, Anal. Chem., 70 (1998) 2618.

125. A..M. Farrington, N. Jagota and J.M. Slater, Analyst, 119 (1994) 233.

126. J.W. Bizler and A.M. Bond, Anal. Chem., 58 (1986) 2859. 
127. E.D.- Zlotorzynska, K. Ahmad and A.B.- Toth, Anal. Chim. Acta, 246 (1991) 315.

128. J.E. Baur, E.W. Kristensen and R.M. Wightman, Anal. Chem., 60 (1988) 2334.

129. C. Hua, K.A. Sagar, K. McLaughlin, M. Jorge, M.P. Meaney and M.R. Smyth, Analyst, 116 (1991) 1117.

130. F.-M. Matysik, A. Meister and G. Werner, Anal. Chim. Acta, 305 (1995) 114.

131. W.L. Caudill, A.G.Ewing, S. Jones and R.M. Wightman, Anal. Chem., 55 (1983) 1877.

132. R.J. Tait, A.M. Bond, B.C. Finnin and B.L. Reed, Collect. Czechosl. Chem. Commun., 56 (1991) 192.

133. R.J. Tait, P.C. Bury, B.C. Finnin, B.L. Reed and A.M. Bond, Anal. Chem., 65 (1993) 3252.

134. J.M. Slater and E.J. Watt, Analyst, 119 (1994) 273.

135. K.R. Wehmeyer and R.M. Wightman, Anal. Chem., 57 (1985) 1989.

136. J. Wang, P. Tuzhi and J. Zadeii, Anal. Chem., 59 (1987) 2119.

137. F. Zhou, J.T. Aronson and M.W. Ruegnitz, Anal. Chem., 69 (1997) 728.

138. M.A. Baldo, C. Bragato and S. Daniele, Analyst, 122 (1997) 1.

139. K. Stulik, Electroanalysis, 11 (1999) 1001.

140. C.M.A. Brett, Electroanalysis, 11 (1999) 1013.

141. H. Emons and Peter Ostapczuk, Analyst, 121 (1996) 1917.

142. V.L.- Avila and H.H. Hill, Anal. Chem., 69 (1997) 289R.

143. J. Namiesnik, Critical Reviews in Analytical Chemistry, 30 (2000) 221.

144. R.N. Adams, "Electrochemistry at Solid Electrodes", Marcel Dekker, New York, 1969.

145. K. Stulik and V. Pacakova, "Electroanalytical Measurements in Flowing Liquids", Ellis Horwood, Chichester, UK, 1987.

146. S. Swathirajan and S. Bruckenstein, J. Electroanal. Chem., 112 (1980) 25.

147. R. F. Furchgott and J. V. Zawadzki, Nature, 288 (1980) 373.

148. R. M. J. Palmer, A. G. Ferrige, S. Moncada, Nature, 327 (1987) 524.

149. J. Horgan, Scientific American, 270 (1994) 70.

150. F. Pariente, J.L. Alonso, H.D. Abruña, J. Electroanal. Chem., 379 (1994) 191.

151. F. Lantoine, S. Trévin, F. Bedioui, J. Devynck, J. Electroanal. Chem., 392 (1995) 85.

152. B.W. Allen, C.A. Piantadosi, L.A. Coury, Jr., Nitric Oxide: Biology and Chemistry, 4 (2000) 75 . 
153. M. Pires, M.J. Rossi and D.S. Ross, Int. J. Chem. Kinet., 26 (1994) 1207.

154. A.R. Butler and D.L.H. Willians, Chem. Soc. Rev., (1993) 233.

155. G. Denuault, M.V. Mirkin, and A.J. Bard, J. Electroanal. Chem., 308 (1991) 27.

156. M. Bertotti and D. Pletcher, J. Braz. Chem. Soc., 8 (1997) 391.

157. D. Dutta and D. Landolt, J. Electrochem. Soc., 119 (1972) 1320.

158. W.F. Linke, in "Solubilities: Inorganic and Metal Organic Compounds", ACS, vol. II, Washington, $4^{\text {th }}$ ed., 1965.

159. "CRC Handbook of Chemistry and Physics", ed. L.H. Gevantman, CRC Press, Boca Raton, FL, 76th ed., 1995.

160. J.R. Lancaster, Jr., Nitric Oxide: Biology and Chemistry, 1 (1997) 18.

161. M. Bertotti e D. Pletcher, $19^{a}$ Reunião Amual da $S B Q$, Poços de Caldas, 1996.

162. J.M. Saveant and E. Vianello, Electrochim. Acta 1965, 10, 905.

163. J. C. Nascimento Filho, B. S. Lima Neto and D. W. Franco, Polyhedron, 15 (1996) 1965.

164. V. Mori, M. Bertotti, R.Z. Osti, H.A.S. Silva e D.W. Franco, X Encontro Nacional de Química Analitica, Santa Maria, 1999.

165. W.M. Schwarz and I. Shain, J. Phys. Chem., 69 (1965) 30.

166. B. S. Freiser, R. L. Woodin and J. L. Beauchamp, J Am. Chem. Soc., 12 (1975) 6894.

167. J. L. Kurtz, G. L. Burce and D. W. Margerum, Inorg. Chem., 17 (1978) 2454.

168. E. T. Gray-Jr, R. W. Taylor and D. W. Margerum, Inorg. Chem., 16 (1977) 3047.

169. T. A. Neubecker, S. T. Kirksey-Jr, K. L. Chellappa and D. W. Margerum., Inorg. Chem., 18 (1979) 444.

170. D. Yoshida, H. D. Moya, R. L. Bonifacio and N. Coichev, Spectroscopy Letters 7 (1998) 1495.

171. S. J. Woltman, M. R. Alward and S. G. Weber., Anal. Chem., 3 (1995) 541.

172. I.M. Kolthoff and I. Hodara, J. Electroanal. Chem., 2 (1963) 5.

173. S. Himeno and A. Saito, J. Electroanal. Chem., 130 (1981) 263.

174. M. Bertotti and R. Tokoro, J. Electroanal. Chem., 360 (1993) 39.

175. S.K. Lahr, H.O. Finklea and F.A. Schultz, J. Electroanal. Chem., 163 (1984) 237.

176. P.J. Kulesza and L.R. Faulkner, J. Am. Chem. Soc., 110 (1988) 4905.

177. P.J. Kulesza and L.R. Faulkner, J. Electroanal. Chem., 248 (1988) 305. 
178. P.J. Kulesza and L.R. Faulkner, Colloids and Surfaces, 41 (1989) 122.

179. S.I.C. Torresi, A. Gorenstein, R.M. Torresi and M.V. Vásquez, J. Electroanal. Chem., 318 (1991) 131.

180. T.C. Arnoldussen, J. Electrochem. Soc., 123 (1976) 527.

181. T.H. Fleish and G.J. Mains, J. Chem. Phys., 76 (1982) 785.

182. P. Pichat, M. Mozzanega and C. Hoang-Van, J. Phys. Chem., 92 (1988) 467.

183. O. Zelaya-Angel, C. Menezes, F. Sanchéz-Sinencio and G.F.L. Ferreira, J. Appl. Phys., 51 (1980) 6022

184. S. Badilescu, K. Boufker, P.V. Ashrit, F.E. Girouard and V.-V. Truong, Appl. Spectrosc., 47 (1993) 749.

185. F. Endres and G. Schwitzgebel, J. Electroanal. Chem., 415 (1996) 23.

186. K. -ichi Machida and M. Enyo, J. Electrochem. Soc., 137 (1990) 1169.

187. S. Dong and B. Wang, J. Electroanal. Chem., 370 (1994) 141.

188. W. Baoxing and D. Shaojun, J. Electroanal. Chem., 379 (1994) 207.

189. M. Bertotti and D. Pletcher, Electroanalysis, 8 (1996) 1105.

190. J.J. Birtill and P.G. Dickens, Mat. Res. Bull, 13 (1978) 311.

191. K. Eda and N. Sotani, Bull. Chem. Soc. Jpn., 64 (1991) 2926.

192. M. Zocchi, L.E. Depero and F. Zocchi, J. Solid State Chem., 92 (1991) 18.

193. T.M. Barbara, G. Gammie, J.W. Lyding and J. Jonas, J. Solid State Chem., 75 (1988) 183.

194. F. Endres and G. Schwitzgebel, Electrochimica Acta, 43 (1998) 431.

195. J.N. Yao, B.H. Loo, K. Hashimoto and A. Fujishima, J. Electroanal. Chem., 290 (1990) 263.

196. L. Kosminsky and M. Bertotti, Electroanalysis, 11 (1999) 623.

197. B. Wang, X.-Y. Liu and S. Dong, J. Electroanal. Chem., 435 (1997) 23.

198. S. Liu, Q. Zhang, E. Wang and S. Dong, Electrochem. Commun., 1 (1999) 365.

199. R.K. Jaworski and J.A. Cox, Electrochim. Acta, 37 (1992) 5.

200. G. Laperrière, M.-André Lavoie and D. Bélanger, J. Electrochem. Soc, 143 (1996) 3109.

201. K.T. Kawagoe and D.C. Johnson, J. Electrochem. Soc., 141 (1994) 3404.

202. J. Feng and D.C. Johnson, J. Electrochem. Soc., 137 (1990) 507.

203. J. Ge and D.C. Johnson, J. Electrochem. Soc., 142 (1995) 1525. 
204. N.D. Popovic, J.A. Cox and D.C. Johnson, J. Electroanal. Chem., 455 (1998) 153.

205. J. Wang and T. Golden, Anal. Chim. Acta, 217 (1989) 343.

206. F. Bedioui and J. Devynck, Acc. Chem. Res., 28 (1995) 30.

207. M. Biesaga, K. Pyrzynska and M. Trojanowicz, Talanta, 51 (2000) 209.

208. K. Araki, L. Angnes, C.M.N. Azevedo and H.E. Toma, J. Electroanal. Chem., 397 (1995) 205.

209. C.M.N. Azevedo, K. Araki, L. Angnes and H.E. Toma, Electroanalysis, 10 (1998) 467.

210. M. Bertotti and D. Pletcher, Anal. Chim. Acta, 337 (1997) 49.

211. A.I. Vogel, “A Textbook of Quantitative Inorganic Analysis", Longman, London, 4th edn. 1978, p. 755.

212. V. Mori and M. Bertotti, Talanta, 47 (1998) 651.

213. V. Mori and M. Bertotti, Analytical Letters, 32 (1999) 25.

214. G.F. Oliveira, V. Mori, M. Bertotti e S. Massaro, $22^{a}$ Reunião Anual da SBQ, Poços de Caldas, 1999.

215. A. H. Melo, L. Carolei, V. Mori e M. Bertotti, , $22^{a}$ Reunião Anual da $S B Q$, Poços de Caldas, 1999.

216. B.M. Martins and M. Bertotti, Talanta, 46 (1998) 149.

217. J.C. Andrade, S.P. Eiras and R.E. Bruns, Anal. Chim. Acta, 255 (1991) 149.

218. C. Karunakaran and B. Muthukumaran, Transition Met. Chem., 20 (1995) 460.

219. T.L. Ferreira, V. Mori e M. Bertotti, $23^{a}$ Reunião Amual da $S B Q$, Poços de Caldas, 2000.

220. J.R.C. Rocha, T.R.L.C. Paixão, L. Kosmisnky and M. Bertotti, no prelo em Electroanalysis.

221. J.R.C. Rocha, K. Araki, H.E. Toma and M. Bertotti, submetido para publicação em Electrochem. Commun.

222. M.I.C. Cantagallo, M. Bertotti and I.G.R. Gutz, Electroanalysis, 6 (1994) 1107.

223. M.A.S. Aguiar, K.S.G. Marquez and I.G.R. Gutz, Electroanalysis, 12 (2000) 742.

224. K. Matsunaga, I. Kudo, M. Yanada and K. Hasebe, Anal. Chim. Acta, 185 (1986) 355.

225. N. Tanaka, K. Unoura and E. Itabashi, Inorg. Chem., 21 (1982) 1662.

226. K. Maeda, S. Himeno, T. Osakai, A. Saito and T. Hori, J. Electroanal. Chem., 364 (1994) 149 
Referências bibliográficas

227. S.M. Harden and W.K. Nonidez, Anal. Chem., 56 (1984).

228. R.A. Chalmers and A.G. Sinclair, Anal. Chim. Acta, 33 (1965) 384.

229. E. Itabashi, Bull. Chem. Soc. Jpn., 60 (1987) 1333.

230. G. Williams and C.D'Silva, Analyst, 119 (1994) 2337.

231. J. Wang, N. Foster, S. Armalis. D. Larson, A. Zirino and K. Olsen, Anal. Chim. Acta, 319 (1995) 223.

232. J. Herdan, R. Feeney, S.P. Kounaves, A.F. Flannery, C.W. Storment, G.T.A. Kovacs and R.B. Darling, Environ. Sci. Technol., 32 (1998) 131.

233. J. Wang, B. Tian, J. Wang, J. Lu, C. Olsen, C. Yarnitzky, K. Olsen, D. Hammestrom and W. Bennett, Anal. Chim. Acta, 385 (1999) 429.

234. J.O. Howell, W.G. Kuhr, R.E. Ensman and R.M. Wightman, J. Electroanal. Chem., 209 (1986) 77 .

235. C. Hsueh, R. Bravo, A.J. Jaramillo and A.B.-Toth, Anal. Chim. Acta, 349 (1997) 67.

236. C.B.-Hébert, M.L. Tercier, J. Buffle, G.C. Fiaccabrino, N.F. Rooij and M.K.-Hep, Anal. Chem., 70 (1998) 2949.

237. Y.G. Vlasov, A.V. Legin, A.M. Rudnitskaya, C.N. Natale and A.D'Amico, Russian J. Appl. Chem., 69 (1996) 848.

238. F. Winquist, P. Wide and I. Lundstrom, Anal. Chim. Acta, 357 (1997) 21.

239. D.B. Hibbert, Electroanalysis, 10 (1998) 1077.

240. Y. Vlasov and A. Legin, Fresenius J. Anal. Chem., 361 (1998) 255. 